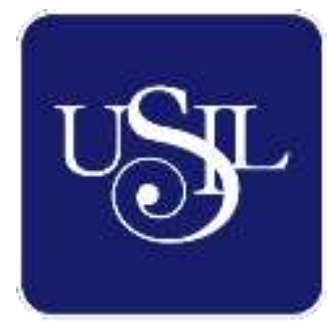

UNIVERSIDAD

SAN IGNACIO

DE LOYOLA

ESCUELA DE POSTGRADO

Maestría en Educación con Mención en Gestión de la Educación

\title{
MODELO EDUCATIVO PARA DESARROLLAR LAS COMPETENCIAS LABORALES EN LOS ESTUDIANTES EN UN INSTITUTO DE EDUCACIÓN SUPERIOR DE LIMA
}

Tesis para optar el grado de Maestro en Educación con Mención en Gestión de la Educación

\section{KATHERINE PAOLA RAMIREZ ARIAS}

\author{
Asesor: \\ Mg. Hernán Gerardo Flores Valdiviezo
}

Lima - Perú

2021 


\title{
Dedicatoria
}

\author{
A Dios, \\ a mis padres y hermanos que siempre me \\ apoyaron a seguir avanzando.
}




\section{Agradecimiento}

A mis padres, que siempre están conmigo con su apoyo incondicional a mis amigos del trabajo por apoyarme y alentarme a esta aventura.

A mis amigos de la maestría que generaban el reto constante de aprender.

y a mí asesor, Mgtr. Hernán Flores Valdiviezo, por su paciencia y dedicación constante. 
Índice de tablas

\section{ÍNDICE}

$\begin{array}{ll}\text { Índice de figuras } & 7\end{array}$

$\begin{array}{lr}\text { Resumen } & 8\end{array}$

$\begin{array}{lr}\text { Abstract } & 9\end{array}$

Introducción 1

Planteamiento del problema de la investigación 1

Formulación del problema. $\quad 5$

Preguntas científicas o preguntas específicas.

$\begin{array}{ll}\text { Objetivos de la investigación } & 6\end{array}$

$\begin{array}{ll}\text { Categorías y subcategorías. } & 6\end{array}$

Población, muestra y unidades de análisis $\quad 8$

Justificación y limitaciones de la investigación $\quad 9$

Metodología de la investigación 11

Enfoque y tipo de investigación.

Diseño de investigación. $\quad 11$

Métodos teóricos 11

Métodos empíricos $\quad 13$

Capítulo I: Marco Teórico 14

Antecedentes internacionales y nacionales de la investigación 15

Definición de competencias.

Definición de competencias laborales.

Definición de las subcategorías de competencias laborales 28

Desarrollo histórico de competencias laborales 32

Enfoques de competencias laborales $\quad 37$

Modelos de competencias laborales 38

Competencias socioemocionales $\quad 39$

Definición de modelos $\quad 40$

Modelo educativo $\quad 42$

Modelo educativo del instituto tecnológico de Lima. $\quad 50$ 
Capítulo II: Diagnóstico o trabajo de campo

Análisis, interpretación y discusión de los resultados $\quad 53$

Análisis de los resultados por técnicas e instrumentos de investigación 53

Entrevista semiestructurada a docentes.

Cuestionario cerrado a estudiantes.

$\begin{array}{ll}\text { Cuestionario cerrado a empresas. } & 61\end{array}$

Presentación de resultados según las categorías emergentes $\quad 64$

Capítulo III: Modelación de la propuesta $\quad 73$

$\begin{array}{ll}\text { Fundamento psicológico } & 75\end{array}$

$\begin{array}{ll}\text { Fundamento pedagógico } & 76\end{array}$

$\begin{array}{ll}\text { Fundamento curricular } & 77\end{array}$

$\begin{array}{ll}\text { Diseño de la propuesta } & 81\end{array}$

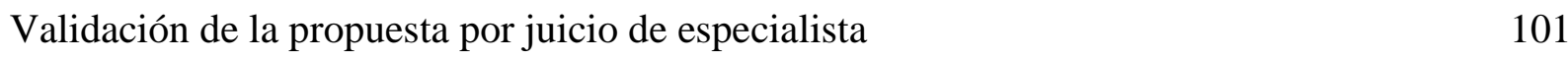

$\begin{array}{ll}\text { Conclusiones } & 104\end{array}$

$\begin{array}{ll}\text { Recomendaciones } & 106\end{array}$

$\begin{array}{ll}\text { Referencias } & 107\end{array}$

$\begin{array}{ll}\text { Anexos } & 114\end{array}$ 


\section{Índice de tablas}

Tabla 1 Categorías y subcategorías apriorísticas. $\quad 6$

Tabla 2. Competencias técnicas de los estudiantes encuestados 56

Tabla 3. Competencias metodológicas de los estudiantes encuestados 57

Tabla 4. Competencias sociales de los estudiantes encuestados. 57

Tabla 5. Competencias participativas de los estudiantes encuestados 58

Tabla 6. Perfil de carreras de los estudiantes encuestados 59

Tabla 7. Proceso de enseñanza de los estudiantes encuestados. $\quad 60$

Tabla 8. Calidad educativa de los estudiantes encuestados 61

Tabla 9. Competencias técnicas de estudiantes realizadas por empresas 62

Tabla 10. Competencias metodológicas de estudiantes realizadas por empresas 62

Tabla 11. Competencias sociales de estudiantes realizadas por empresas 63

Tabla 12. Competencias participativas de estudiantes realizadas por empresas 64

Tabla 13. Cronograma de la propuesta 98

Tabla 14. Expertos seleccionados para validar los instrumentos $\quad 101$

Tabla 15. Tabla de valoración 102

Tabla 16. Resultados de valoración interna y externa por expertos 102

Tabla 17. Tabla de valoración general 103 


\section{Índice de figuras}

Figura 1. Subcategorías de las competencias laborales 32

Figura 2. Tipos de modelos: educativo y pedagógico 43

Figura 3. Modelo educativo del I. E. S. tecnológico de Lima 51

Figura 4. Modelo de competencias del I. E. S. tecnológico de Lima 52

Figura 5. Proceso de calidad del I. E. S. tecnológico de Lima 52

$\begin{array}{ll}\text { Figura 6. Categorías emergentes y apriorísticas } & 65\end{array}$

Figura 7. Categorías alternativas/emergentes y conclusiones aproximativas 66

$\begin{array}{ll}\text { Figura 8. Categoría emergente competencias demandadas por las empresas } & 67\end{array}$

$\begin{array}{lr}\text { Figura 9. Categoría emergente inteligencia emocional } & 68\end{array}$

$\begin{array}{ll}\text { Figura 10. Categoría emergente gestión educativa por procesos } & 69\end{array}$

$\begin{array}{ll}\text { Figura 11. Categoría emergente perfil del ingresante } & 71\end{array}$

$\begin{array}{ll}\text { Figura 12. Diseño analógico de la propuesta de modelo educativo } & 80\end{array}$

$\begin{array}{ll}\text { Figura 13. Dimensiones metodológicas de la propuesta } & 82\end{array}$

Figura 14. Componentes transversales de la propuesta $\quad 83$

Figura 15. Componentes laborales transversales de la propuesta 86

Figura 16. Propuesta del organigrama del área académica 90

Figura 17. El estudiante, como eje primordial del proceso de aprendizaje, contenidos educativos y $\begin{array}{ll}\text { estrategias didácticas } & 94\end{array}$

Figura 18. Propuesta de las áreas involucradas al contacto con las empresas 95 


\section{Resumen}

Esta investigación tiene como objetivo proponer un modelo educativo para desarrollar competencias laborales en estudiantes de un instituto tecnológico de Lima Metropolitana, para lo cual se enmarca en el enfoque cualitativo, con un diseño aplicado educacional dentro del marco del paradigma naturalista e interpretativo. Para la investigación, se trabajó con una muestra de 25 estudiantes del programa de formación regular de las carreras técnicas del instituto tomado en cuenta para la investigación, así como cinco docentes y cinco representantes de las empresas que constantemente solicitan a los estudiantes, a quienes se les aplicó el cuestionario, así como la guía de observación y de entrevista. En el diagnóstico de campo se encontró que las empresas evaluadas consideran que los estudiantes poseen un nivel de competencia laboral óptimo en líneas generales; sin embargo, hay algunas competencias de corte social que necesitan ser reforzadas y mejoradas. Por otro lado, también se obtuvo como resultado que el modelo educativo debe ser actualizado según las necesidades del perfil del estudiante actual, así como las demandas laborales. Los docentes tienen una participación activa en el desarrollo de las competencias de sus estudiantes, lo cual faculta que estos sean sus referentes. La propuesta de un modelo educativo está compuesta por dimensiones metodológicas: dimensión filosófica, dimensión académica y dimensión organización; además de componentes transversales como adaptación contextual, docentes disruptivos, aprendizaje por proyectos y globalización, y todo ello de manera articulada permite que este modelo educativo propuesto tenga mayor solidez en la formación de las competencias laborales de sus estudiantes.

Palabras claves: Competencias laborales, modelo educativo, estudiantes de educación superior tecnológica. 


\begin{abstract}
This research aims to propose an educational model to develop work skills in students of a technological institute in Metropolitan Lima, for which it is framed in the qualitative approach, with an applied educational design within the framework of the naturalistic and interpretive paradigm. For the research, we worked with a sample of 25 students from the regular training program of the technical careers of the institute taken into account for the research, as well as five teachers and five representatives of the companies that constantly request the students, who are He applied the questionnaire to them, as well as the observation and interview guide. In the field diagnosis, it was found that the companies evaluated consider that the students have an optimal level of job competence in general terms; however, there are some social skills that need to be reinforced and improved. On the other hand, it was also obtained as a result that the educational model must be updated according to the needs of the current student profile, as well as job demands. Teachers have an active participation in the development of the competences of their students, which enables them to be their referents. The proposal of an educational model is composed of methodological dimensions: philosophical dimension, academic dimension and organization dimension; in addition to cross-cutting components such as contextual adaptation, disruptive teachers, project-based learning and globalization, and all of this in an articulated manner allows this proposed educational model to have greater solidity in the formation of the labor competencies of its students.
\end{abstract}

Keywords: Labor competencies, educational model, students of higher technological education. 


\section{Introducción}

\section{Planteamiento del problema de la investigación}

La educación es un proceso de socialización en el cual el ser humano tiene la oportunidad de desenvolver mejor sus potencialidades, sus capacidades y sus habilidades; y, con ello, ayuda a la mejora de la calidad de vida de esta. Esta mejora de la calidad de vida no solo se debe al ámbito educativo, sino también al factor económico: mientras más estudios académicos tengas, mejores serán el crecimiento profesional y el salario. El crecimiento económico de Perú en los últimos años se debe a varios factores; sin embargo, esto se debe en poca medida a la capacitación del talento humano de los trabajadores, el conocimiento tecnológico que poseemos y el empleo. Uno de los problemas visibles es la poca comunicación que existe entre las entidades educativas y la oferta laboral actual. Es importante que haya una comunicación fluida entre la academia y la industria, esto permite que ambas partes ejecuten cambios propios de la nueva generación XXI.

En Singapur, el $13 \%$ de su población económicamente activa (PEA) está conformado por trabajadores técnicos; en Perú, solo el $5 \%$. Según estudios realizados por el Instituto Nacional de Estadística e Informática (INEI), actualmente, tenemos un déficit de 200000 profesionales técnicos para la industria actual y cada año egresan solo 100000 jóvenes de las carreras técnicas. Esto supone que debemos poner, en la educación tecnológica superior, mayor énfasis en promocionar carreras técnicas que estén ligadas con lo que está solicitando el mercado laboral actual. Una de las trabas es que el mercado educativo genera mayor oferta a nivel de educación superior universitaria, considerando a la educación técnica como una educación para los excluidos, para aquellos que no pudieron ingresar, pagar o no desean dedicar cinco años de estudios universitarios. Con el poco control de ello, hemos sufrido un aumento del subempleo, pues pasamos de $15 \%$ en 1996 a $45 \%$; en la actualidad, esto es una clara muestra de que nuestros 
egresados universitarios están ingresando a ambientes netamente técnicos. Tomando en cuenta esto, en 1996, el Banco Interamericano de Desarrollo (BID) midió la calidad educativa ofrecida tanto en institutos de educación superior tecnológica (IEST) y en centros de educación técnicoproductiva (Cetpro) en trece departamentos del país, por lo cual encontró que el $20 \%$ de los IEST y el $13 \%$ de los Cetpro operaban en condiciones óptimas.

Es claro mencionar que el mercado laboral actual está solicitando profesionales con un perfil distinto, dándole importancia no solo a las competencias técnicas (saber conocer y saber hacer), sino también a las competencias laborales (saber ser y saber convivir), puesto que debe asegurarle a la empresa u organización que este profesional pueda brindarle mayor aporte a la misma. Estos cambios no surgieron de un momento a otro, sino que se deben a los constantes cambios que vive el mundo desde la tecnología, la sociedad, la salud, la economía, la educación, entre otros; por consiguiente, este cambio impacta en el sector educativo, con lo cual genera que en los centros académicos, tanto básicos como superiores, reestructuren su modelo educativo en función a la transformación mundial que se necesita actualmente.

Uno de los componentes que ha sufrido cambios son esos elementos que cualificaban a un profesional idóneo en un puesto. En un inicio, con el fin de conceptualizar esta necesidad, se determinó como competencias, generando subcategorías, llamadas desde «técnicas», «genéricas», «blandas», «duras» 0 «transversales», hasta ahora denominadas como competencias laborales. Por todo lo expuesto anteriormente, en esta investigación se va a proponer un modelo educativo para desarrollar las competencias genéricas laborales en los estudiantes de un instituto de educación superior en Lima.

El concepto de «competencias laborales» como parte de su formación en estudiantes, tanto de educación básica como de educación superior, ha sido abordado por diversas entidades 
mundiales. Por ejemplo, la Organización Internacional del Trabajo (OIT) en diversas investigaciones ha tocado y profundizado el tema; asimismo, el Banco Mundial, en su documento Competencias para el empleo y la productividad (2010), pone énfasis en ello, dándole un sentido de pertenencia en el mundo laboral. Desde el punto de vista teórico, Spencer y Spencer (1993) son unos de los autores que han investigado este tema desde varias perspectivas, pero desde un punto empresarial, no desde la formación académica.

Por su parte, Alles (2005) (2007) recopila en sus diversos libros una serie de escalas de competencias en la que ayuda al área de recursos humanos a «encasillar» las competencias que se evalúan de la persona en una empresa; «diccionario de competencias» lo denomina la autora. Otro autor importante en la región es Tobón (2005) (2013), quien también investigó el tema, tomando en cuenta que estas son necesarias formarlas y potenciarlas desde su periodo de educación superior.

El Proyecto Educativo Nacional al 2021 (2007), así como en los proyectos educativos regionales, mencionan, a través de sus objetivos y sus políticas, el logro de resultados educacionales o de los programas educativos correlacionado con el adecuado planteamiento de la gestión educativa y el planeamiento estratégico que en sus objetivos integran las instituciones educativas con las empresas del país con el fin de formar profesionales que el mercado laboral solicita.

Es claro mencionar que estas evoluciones sobre las concepciones de competencias o «habilidades blandas» no son ajenas en nuestro país; tanto es así que en la Ley General de Educación (ley n. ${ }^{\circ}$ 28123), artículo 24, se menciona que la participación de la empresa en el desarrollo de los estudiantes es significativa y es relevante la comunicación tanto entre la institución educativa con la industria actual. Por su parte, el Diseño Curricular Nacional de la Educación Superior hace énfasis en que los estudiantes cuenten con una experiencia formativa en 
situación real de trabajo para generar así competencias propias, ya sea de su especialidad o genéricas, para el adecuado desempeño laboral. Todas estas normas establecen criterios para recabar información a través de materiales, según sea el caso, y tomarla en cuenta; así como el fin de articular la participación tanto de las industrias como de las instituciones educativas, y esta cómo intervienen en la obtención de los objetivos de la entidad educativa.

Como se puede inferir de lo dicho anteriormente, esto va a permitir identificar las necesidades de los estudiantes para generar una mejor calidad educativa y potencializar los aprendizajes adquiridos; asimismo, incentivar a que los estudiantes tengan experiencias formativas en situación real de trabajo para que vayan puliendo esos aspectos.

La actual ley n. ${ }^{\circ}$ 30512, Ley de Institutos y Escuelas de Educación Superior y de la Carrera Pública de sus Docentes, regula la creación, el licenciamiento, el régimen académico, la gestión, la supervisión y la fiscalización de los institutos públicos y privados. Bajo los lineamientos de esta ley, se menciona en los componentes curriculares que la institución debe generar dos tipos de competencias en los estudiantes: competencias técnicas o específicas y competencias para la empleabilidad. Esta última es en la cual tomaremos mayor énfasis.

Los desafíos actuales, así como los avances tecnológicos, los cambios generacionales y la globalización, influyen a las instituciones de educación superior a reinventarse, a desarrollar un modelo educativo adecuado a la demanda del hoy y que involucre la formación en el desarrollo de competencias que servirán para hacer frente a los retos que se les presente. Sin embargo, mediante el trabajo de observación, las encuestas, las fichas de evaluación de pasantes y practicantes (del instituto de educación superior de Lima) que se obtuvieron de las empresas de producción, manufactura o minería, se consiguieron resultados no tan favorables, pues se recopiló información acerca de las pocas competencias laborales demostradas en las empresas. 
Dentro de estos resultados, se encontró un inconveniente para comunicarse a todo nivel, gestionar sus recursos y la facilidad de adaptabilidad; no mencionaron las competencias técnicas, ya que consideran que esto se puede aprender con la práctica del trabajo. Con estas evidencias nació mi interrogante: si estamos formando a profesionales técnicos con adecuadas y suficientes competencias laborales, que el mercado laboral está exigiendo a nivel diferente.

Por todo lo expuesto anteriormente, se ve la necesidad de desarrollar un modelo educativo en el cual se fortalezcan competencias laborales y nos asegure lograr el objetivo de la colocación y la inserción laborales de los estudiantes.

\section{Formulación del problema.}

¿Cómo contribuir en la formación de competencias laborales en los estudiantes en un instituto de educación superior de Lima?

\section{Preguntas científicas o preguntas específicas.}

¿En qué estado se encuentra actualmente el desarrollo de las competencias laborales en los estudiantes en un instituto de educación superior de Lima?

¿Cuáles son los fundamentos teóricos del modelo educativo para el desarrollo de competencias laborales?

¿Cómo diseñar la modelación de la propuesta de un modelo educativo para el desarrollo de las competencias laborales en los estudiantes en un instituto de educación superior de Lima?

¿Cómo medir el impacto de la aplicación del modelo educativo para el desarrollo de las competencias laborales en los estudiantes en un instituto de educación superior de Lima? 


\section{Objetivos de la investigación}

\section{Objetivo general.}

La actual investigación tiene como objetivo diseñar un modelo educativo para el desarrollo de competencias laborales en los estudiantes en un instituto de educación superior de Lima.

\section{Objetivos específicos.}

Identificar el estado actual de las competencias laborales en los estudiantes en un instituto de educación superior de Lima.

Explorar la información existente acerca de modelos educativos para el desarrollo de competencias laborales.

Diseñar la modelación de una propuesta de un modelo educativo para el desarrollo de las competencias laborales en los estudiantes en un instituto de educación superior de Lima.

Validar el impacto de la aplicación del modelo educativo para el desarrollo de las competencias laborales en los estudiantes en un instituto de educación superior de Lima.

\section{Categorías y subcategorías}

En la investigación se consideraron dos categorías apriorísticas: la primera es competencias laborales y la segunda es modelo educativo. De estas se desprendieron siete subcategorías.

Tabla 1

Categorías y subcategorías apriorísticas

Categorías apriorísticas Subcategorías apriorísticas Concepto

Conocimientos técnicos, prácticos y

Competencias laborales Competencia técnica procedimentales propios de cada profesión. 
Elementos que utilizará el profesional

Competencia metodológica para aplicar los procedimientos propios del puesto laboral.

Capacidad de colaborar con los otros, e

Competencia social interrelacionarse con sus pares y superiores.

Competencia participativa

Capacidad para organizar, planificar y liderar ciertos procesos en la empresa.

Conjunto de características propias

Perfil de carreras técnicas y personales de cada programa académico.

Procedimiento de transmisión de Modelo educativo Proceso de enseñanza conocimiento sobre alguna materia $o$ tema, mediante una metodología didáctica.

Característica que debe presentar en los

Calidad educativa procedimientos, estrategias y seguimiento a los procesos educativos.

Fuente: Elaboración propia (2019)

\section{Competencias laborales.}

Posesión y desarrollo de conocimientos, destrezas y actitudes que permiten, al individuo que los posee, la capacidad de desarrollar con éxito actividades de trabajo en su área profesional, adaptarse a nuevas situaciones y, en muchos casos, transferir su competencia a áreas profesionales próximas [Centro de Servicios para la Capacitación Laboral y el Desarrollo (Caplab) (2004)].

Se identificaron como subcategorías apriorísticas a otras competencias, tales como competencia técnica, competencia metodológica, competencia social y competencia participativa. 


\section{Modelo educativo.}

Es la conceptualización que orienta a los agentes educativos a la formulación de programas de estudio y a la sistematización de los procesos de enseñanza y aprendizaje, incorporando un sistema que asegure la calidad del proceso con el fin de lograr egresados competentes para la actividad empresarial (Murueta, 2017).

De esta categoría apriorística se desprenden las subcategorías apriorísticas de perfil de carreras, proceso de enseñanza y calidad educativa.

\section{Población, muestra y unidades de análisis}

\section{Población.}

Según Mejía (2005), la población «es la totalidad de sujetos o elementos que tienen características comunes» (p. 95). La población de esta investigación estuvo conformada por 2200 estudiantes de ambos sexos del instituto tecnológico de Lima, de las 13 carreras académicas que brinda esta institución.

\section{Muestra.}

Referente a la muestra, Lanuez, Martínez y Pérez la definen como «un subconjunto de la población o universo[;] es un grupo relativamente pequeño de unidades de población, que poseen las características representativas de toda la población» (2011, p. 105). La muestra está conformada por cinco docentes de las carreras académicas del programa de formación regular, veinticinco estudiantes de estas y cinco representantes de empresas que han contado con los estudiantes y los egresados.

El tipo de muestreo que se utilizó es el no probabilístico por conveniencia, puesto que se puede acceder con facilidad a los individuos empleados en la investigación, siendo consideradas las características de los individuos en común para la investigación, según Mejía (p. 115). La 
muestra elegida para la investigación ha sido seleccionada teniendo en cuenta los criterios exploratorios, ya que se eligió la muestra teniendo en cuenta que, a nivel de este grupo de estudiantes, no se ha hecho mayor estudio acerca del tema y nos interesa conocer las percepciones de este sector; aunado a ello, respecto a la accesibilidad, dada la condición del acceso a la información de este estudio, no ha sido difícil la obtención de información de los sujetos de estudio. Es importante recalcar que esta muestra no representa a todo el colectivo de estudiantes o todas las empresas

\section{Justificación y limitaciones de la investigación}

Justificación.

El constante cambio dentro de las organizaciones y la competitividad que existe en el mundo de las industrias genera que cada una de estas empresas cuente con personal competente tanto en competencias técnicas como en competencias laborales (en algunos casos, denominados blandos). Tomando esta premisa, es importante estudiar las competencias laborales y cómo estas se desarrollan desde la formación académica. Por otro lado, el Ministerio de Educación del Perú (Minedu) ha manifestado en varias ocasiones que en Perú tenemos un déficit de 200000 profesionales técnicos para la industria actual; es decir, hay demanda, pero no hay oferta, y solo 98000 jóvenes culminan sus carreras técnicas; y esto se debe en gran medida a la calidad de institutos que existen en el país.

Las empresas del sector industrial y mineras de Perú, donde están relacionadas las carreras de los estudiantes del instituto en mención, ya no solo evalúan, dentro de sus procesos de selección, aspectos propios de cada carrera académica (competencias técnicas), sino que además evalúan quién se comunica mejor, quién argumenta con solidez sus respuestas, cómo trabaja en equipo, cómo maneja su tolerancia a la frustración y cómo se proyecta dentro de unos años (competencias 
laborales). Esta información se obtuvo de las fichas de evaluaciones de sus pasantías o prácticas en las empresas donde los estudiantes realizaron sus experiencias formativas en situación real de trabajo.

Por lo que se refiere al aspecto teórico, nos va a permitir conocer la teoría y las concepciones acerca de las dos categorías, tanto competencias laborales como el modelo educativo, y cómo estas han ido modificándose a lo largo del tiempo y de cada contexto.

Del mismo modo, el Minedu, con la ley n. 30512, y el Diseño Curricular Básico Nacional de la Educación Superior Tecnológica refuerzan la importancia de desarrollar en los estudiantes las competencias técnicas, las competencias para la empleabilidad y las experiencias formativas en situación real de trabajo. Todas estas competencias refuerzan el postulado de que se deben formar profesionales cada vez más competentes para el mercado laboral actual.

Con esta finalidad, este estudio permitirá la aplicación del método científico en todas sus etapas a fin de llegar a las conclusiones y las recomendaciones o sugerencias, las cuales permitirán mejorar el servicio que ofrece el instituto de educación superior de Lima a sus estudiantes, proponiendo un modelo educativo para desarrollar competencias laborales en dichos estudiantes (Hurtado, 2000).

\section{Limitaciones.}

Dentro de la realización de esta investigación, se encontró que este modelo es para la generación de estudiantes que está por egresar del instituto tecnológico, así como solo es de una de las tres sedes del instituto. Asimismo, otra limitación es la ausencia de investigaciones acerca del tema en instituciones superiores técnicas que puedan servir como fuentes base para el proceso de investigación. La mayoría de las investigaciones y los estudios está enfocada en estudios superiores universitarios, y el perfil estudiantil es variante en muchos aspectos. 


\section{Metodología de la investigación}

\section{Enfoque y tipo de investigación.}

La metodología, el enfoque y el diseño que se emplearon para esta investigación responden al paradigma sociocrítico, dado que, siendo una problemática social, no solo se consideran los estudios teóricos, sino también cómo estas investigaciones contribuyen con la sociedad, generando respuestas a problemáticas sociales, desde una mirada participativa (Arnal, 1992). El tipo de investigación que se utilizó es la investigación aplicada, con el fin de resolver a través de un modelo educativo para desarrollar las competencias laborales de los estudiantes de un instituto de educación superior de Lima. Asimismo, se utilizó la investigación de paradigma naturalista, pues permitió entender cómo se manifiestan las competencias laborales a través de sus conductas o comportamientos, dependiendo de sus funciones y cómo estas impactan en las empresas a través de su desempeño (Cerda, 1991).

\section{Diseño de investigación.}

En esta investigación se utilizó la investigación cualitativa, que ayudó en la descripción y la explicación del problema de las competencias laborales, a partir de los datos que obtuvimos de los sujetos participantes en la investigación. Esta investigación también nos permitirá entender las descripciones detalladas de las situaciones en las cuales se evidencien las competencias laborales de los estudiantes en las empresas, a través de eventos, situaciones y comportamientos observables.

\section{Métodos teóricos}

Los métodos teóricos se conceptualizan como las estructuras teóricas de la investigación y ayudan a la interpretación de los resultados de los métodos empíricos. En esta investigación, para una mejor recopilación de información de datos, se han utilizado los siguientes métodos: 


\section{Método descriptivo.}

El método descriptivo permite describir o detallar las características más relevantes de las categorías a estudiar, con el fin de comprender mejor sus particularidades y saber encaminar la investigación (Bernal, 2010). Para efectos de esta investigación, este método permite entender cómo se manifiestan las competencias laborales de los estudiantes en las diferentes empresas, con el fin de proponer un adecuado modelo educativo para sus estudiantes, así como las características del mercado laboral actual.

\section{Método analítico-sintético.}

Este método permite abordar los fundamentos teóricos de cómo contribuir en la formación de competencias laborales en los estudiantes del instituto tecnológico y así establecer las conclusiones generales del estudio. El método analítico-sintético contribuye a estudiar los hechos de manera separada; es decir, estudiar las categorías de manera aislada, ver cómo entre ellas se relacionan y tener un estudio de manera holística (Hurtado, 2000).

\section{Método inductivo-deductivo.}

Método que contribuyó en el proceso de estructuración de la introducción y la sistematización del marco teórico del modelo educativo para desarrollar competencias genéricas laborales. Del mismo modo, este método nos permite visualizar la problemática de manera holística, partiendo de la general a lo particular (deducción) y de lo particular a lo general (inducción) (Bernal, 2010).

\section{Método sistémico-estructural.}

Permitió la sistematización del modelo educativo para desarrollar competencias laborales. El método facilita establecer las relaciones interactivas entre componentes, relaciones de dependencia, jerarquía, coordinación y subordinación entre etapas, niveles, acciones y componentes que conforman el modelo con las competencias. 


\section{Método histórico-lógico.}

Permite organizar la explicación de la evolución histórica de las competencias y deslindar las concepciones hasta la actualidad y cómo fueron respondiendo a las necesidades sociales de su época. El analizar las categorías, de manera diferenciada, y su evolución en el tiempo ayuda a entender mejor la problemática y la propuesta (Lanuez, Martínez y Pérez, 2008).

\section{Método de modelación.}

Interesa para ensayar y modelar la propuesta teórica de un modelo educativo para desarrollar competencias laborales. Método de modelación que ayuda a tener una mejor perspectiva de las categorías investigadas, con el fin de estudiar y entender las relaciones que tienen entre sí y la amplitud de las mismas. Los esquemas de lo encontrado en el estudio se representan de manera simplificada (Lanuez, Martínez y Pérez, 2008).

\section{Métodos empíricos}

En lo que respecta a los datos o información que los sujetos involucrados nos suministren en la investigación, hemos creído conveniente recoger la información directa y verbalizada de los mismos sujetos. Los métodos empíricos educacionales que se utilizaron son la observación, la encuesta y la entrevista semiestructurada.

\section{La observación.}

La observación que utilizaremos es la observación participante artificial, puesto que se integrará a la sesión de clases a estudiar con el fin de obtener más información del modelo educativo que el docente desarrolla en los estudiantes. Asimismo, se empleó, para una mejor obtención de información, la observación estructurada gracias a la guía de observación. Como mencionan 
Hernández, Fernández y Bautista (2014), este instrumento ayuda a obtener información observando, escuchando las conductas observables del entorno y permitiendo al investigador la información de modo natural y no invasiva.

\section{La encuesta.}

Según Hernández, Fernández y Bautista (2014), este instrumento nos facilitará la obtención de información por parte de los sujetos investigados mediante un conjunto de preguntas respecto de una o más variables a medir, teniendo congruencia con el objetivo del estudio. Además, nos brindará información relevante de su percepción frente a las competencias laborales que presentan los estudiantes del instituto tecnológico. La encuesta se aplicó a los representantes de empresas con varias preguntas que ayudaban a la obtención de información para los objetivos del estudio.

\section{La entrevista semiestructurada.}

Esta técnica permitió reunir información entre un entrevistador y un entrevistado. La entrevista semiestructurada se dio siguiendo la guía de preguntas y el entrevistador tuvo la libertad de agregar preguntas adicionales para recabar más información (Hernández, Fernández y Bautista, 2010). Se aplicó a los docentes del instituto de estudio para interpretar el nivel de competencias laborales que adquieren los estudiantes a lo largo de sus años académicos superiores.

El criterio de especialistas y el criterio de expertos, tanto de empresas como del ámbito educativo. 


\section{Capítulo I}

\section{Marco Teórico}

El tema de competencias laborales ha sido abordado desde varias perspectivas a lo largo del tiempo, por lo cual se llega a la conclusión de que, si estas se desarrollan temprana y adecuadamente, la inserción laboral va a ser óptima y generará nuevas y buenas oportunidades para los estudiantes

\section{Antecedentes internacionales y nacionales de la investigación}

\section{Antecedentes internacionales.}

En lo que se refiere al ámbito internacional, tenemos varios estudios; entre los cuales, algunos sirvieron para el desarrollo de la presenta investigación.

Como referente externo, tenemos a Estrada (2005), quien, en su investigación determinó la concordancia entre las competencias profesionales que las empresas pertenecientes a los sectores de servicios y manufacturas requieren de los ingenieros industriales y, con ello, las competencias que los estudiantes de último año de ingeniería industrial de la Universidad del Bío-Bío (UBB), Chile, y la Universidad Nacional de Misiones (UNAM), Argentina, poseen o perciben que tienen.

Esta investigación surgió al observar la importancia de las competencias «blandas», también denominadas generales o transversales, en el mercado laboral actual, y el hecho de que algunas universidades, por no decir la gran mayoría, no adaptan sus planes, programas o perfiles de egreso a la misma velocidad del cambio; por lo cual existe una brecha entre lo que la universidad produce, en general, y lo que el mercado laboral demanda. Estas competencias «blandas» requeridas por las empresas coinciden parcialmente con aquellas que los estudiantes de la UBB 
consideran tener, pero no sucede lo mismo con los estudiantes de la UNAM. Es por ello que se brindó la sugerencia de que es necesario e imperioso introducir el desarrollo de competencias «blandas» a lo largo de los estudios.

Asimismo, Hernández (2011) en su investigación sobre un modelo para la implantación del Programa Basado en Competencias en la división de administración de la Universidad Tecnológica de Nezahualcóyotl, planteó una propuesta que permitió una adecuada implementación del programa basado en competencias del técnico superior universitario en administración del área de recursos humanos en competencias profesionales. Según la autora, esta propuesta pudo coadyuvar a que los estudiantes alcancen las competencias genéricas y específicas de su perfil.

La autora Herrera (2015) se cuestionó el nivel de las competencias laborales de los colaboradores de ventas de Bimbo Centroamérica y, por ende, lo investigó. Para este trabajo, debió utilizar un estudio descriptivo y aplicar un cuestionario a veinticinco vendedores. Como resultado, se encontró que los vendedores demostraban competencias laborales desarrolladas y ello se vio reflejado en su desempeño, lo cual desencadenó una buena productividad en la empresa.

Godoy (2014) investigó las competencias laborales de los mandos medios y altos de los funcionarios de una industria papelera. Se utilizó el test Compe-TEA, el cual evalúa veinte competencias elementales para los mandos medios y altos, utilizando la investigación descriptiva. Como resultado, se obtuvo que las competencias interpersonales fueron las menos punteadas, ya que la competencia de trabajo en equipo fue la menos trabajada, lo cual afectó la productividad y las demás competencias que implican a la competencia interpersonal, tanto en los mandos medios como altos. En los mandos altos, el puntaje de liderazgo fue el más alto. 


\section{Antecedentes nacionales.}

Sáenz (2010), quien en su investigación encontró, mediante los registros, de que la colocación de los egresados y los estudiantes cayó $1 \%$, aproximadamente, respecto al total de candidatos presentados a empresas.

En esta investigación se obtuvo como resultado que las empresas y las consultoras no encontraron inconvenientes en las competencias técnicas, pero sí en las competencias genéricas, competencias que consideran importantes para la asignación de un puesto de trabajo.

Del mismo modo, Barreda (2009) presentó el estudio sobre la evaluación de competencias genéricas en egresados de medicina veterinaria, en el cual se buscó priorizar las competencias genéricas que debe tener el graduado de la profesión de medicina veterinaria en Lima, desde el punto de vista de los empleadores de médicos veterinarios. El autor encontró que los graduados de esta carrera tenían un alto puntaje en conocimientos de su profesión, así como el sentido ético y la diversidad cultural; sin embargo, los puntos que deben reforzar son el conocimiento de un segundo idioma, la capacidad de autocrítica, la tolerancia a la frustración y el liderazgo. En líneas generales, los resultados encontrados denotaron que el egresado de la carrera de Medicina Veterinaria posee competencias genéricas adecuadas para el nivel que el mercado laboral de su ámbito necesita, sin descuidar el reforzamiento de competencias que obtuvieron bajo puntaje.

Por su parte, Alfaro (2011) presentó la indagación competencias profesionales en el Perú, la cual centró su estudio en el ámbito de las bibliotecas universitarias y pretendió mostrar las tendencias actuales que perfilan las competencias profesionales de los recursos humanos de este tipo de unidad de información. Así, tuvo como objetivos principales, primero, determinar si las competencias que se aplican en el ejercicio profesional difieren significativamente de las competencias que se desarrollaron durante la formación académica universitaria en los 
profesionales de las bibliotecas universitarias de Perú en 2010 y, segundo, discernir si las competencias que se aplican en el ejercicio profesional difieren significativamente de las competencias que se desarrollaron durante la formación académica universitaria, en función al centro de estudios de procedencia de los profesionales antes mencionados.

De igual manera, Granados (2013), en su investigación sobre el desarrollo competencias laborales encontró que casi el 60 \% de los estudiantes investigados demostró buenas competencias laborales y casi el $49 \%$ presentaba adecuados conocimientos respecto a su formación profesional en Turismo. El objetivo de esta investigación fue determinar la relación entre las competencias laborales y la formación profesional de turismo en los estudiantes. Para este estudio se aplicó la investigación descriptiva, el método fue el ex post facto, con diseño correlacional y siendo no probabilística intencionada. La muestra estuvo conformada por 96 estudiantes del décimo semestre de la Escuela Profesional de Administración de Turismo de la UNMSM. Como conclusión, se obtuvo que los resultados son directamente proporcionales entre ambas variables. Esta investigación se tomó como parte de la obtención del grado de doctor en Educación.

\section{Bases teóricas}

La presente sección definirá el concepto de las dos categorías estudiadas en esta investigación. La primera son las competencias laborales y cómo estas influyen en la inserción al mercado laboral de los estudiantes del instituto tecnológico de educación superior de Lima; y la segunda es el modelo educativo y cómo esta herramienta nos puede ayudar a fortalecer las competencias profesionales de los próximos egresados. 


\section{Definición de competencias}

Las competencias han sido ampliamente tratadas en el mundo, más ahora con todos los cambios generacionales, tecnológicos, sociales y económicos que suceden, y son tomadas en cuenta desde la perspectiva de los ámbitos educativo y organizacional, siendo relacionadas al estudio de recursos humanos o gestión del talento humano. Desde el punto de vista educativo, se ha introducido este concepto mediante el diseño curricular, lo cual ha generado una adecuada formación básica que prepara a los estudiantes a un desempeño óptimo en el actual mercado laboral, tomando con fuerza el término de modelo por competencias.

Antes de seguir, es importante mencionar que el término 'competencias' es un término polisémico; es decir, ha sido utilizado en varios contextos. Por ejemplo, Campos y Chinchilla (2009) contextualizan las competencias en un ámbito educativo, en donde definen que las competencias son capacidades integradas y tienen diferentes grados, y que a través de la educación se debe desarrollar en los estudiantes estas capacidades para que puedan desempeñarse como personas independientes, sociables y capaces de buscar soluciones en diferentes ámbitos de su vida.

Para iniciar, tomaremos en cuenta lo que dice la Real Academia Española, que define el término de 'competencia' como «disputa o contienda entre dos o más personas sobre algo». También considera el concepto de «peripecia, aptitud, idoneidad para hacer algo o intervenir en un asunto determinado». Tomando en cuenta la segunda acepción, podemos decir que la competencia es la capacidad que tiene una persona para cumplir bien su objetivo, pero involucrando componentes cognitivos, motivación y cualidades de personalidad.

La Organización de las Naciones Unidas para la Educación, la Ciencia y la Cultura (Unesco) también ha contemplado las competencias de varias aristas; por ejemplo, en su 
indagación Conocimiento complejo y competencias educativas (2009), se plantean diversas posturas respecto a la importancia de las competencias en el ámbito educativo. En este artículo se considera la postura de Tobón (2007), quien menciona que hay diversos enfoques en los cuales se pueden abordar las competencias debido a sus diversas perspectivas, fuentes, contextos y epistemologías, además de que su aplicación puede suceder tanto en el ámbito de las organizaciones como en la educación.

Por otra parte, el documento elaborado por la Oficina Regional de Educación de la Unesco para América Latina y el Caribe, cuyo título es Enseñanza y formación técnico profesional en América Latina y el Caribe: una perspectiva regional hacia el 2030, enfatiza cómo estas entidades educativas deben responder con calidad a las necesidades del mercado actual, considerando la comunicación fluida entre la academia y la empresa, así como las competencias laborales que actualmente se requieren.

En el marco de la premisa anterior, es claro mencionar que Tobón (2010) sostenía que las competencias son el desempeño integral que tiene una persona ante los problemas y que involucra el compromiso ético con el fin de alcanzar metas y objetivos dentro de la sociedad. Esto también se ve reflejado en el informe de Delors (1996), quien llega a la conclusión de que la educación a lo largo de la vida se basa en cuatro pilares: aprender a conocer, aprender a hacer, aprender a vivir juntos y aprender a ser. Aprender a conocer es la adquisición de conocimientos de un tema en el cual se adquiere dominio para darle un valor agregado a su futuro y aprovechar las posibilidades que ofrece la educación a lo largo de la vida. Aprender a hacer para que, junto con el aprendizaje necesario y oportuno, permita a las personas adquirir competencias a fines de seguir procedimientos para el trabajo en equipo, además de toma de decisiones en diversas situaciones. 
Para desarrollar competencias, se deben tener en cuenta las actitudes, las cuales van a permitir que una persona pueda desarrollar de manera exitosa una labor a través de conjunto integrado de funciones y tareas de acuerdo a criterios de desempeño considerados idóneos en el medio laboral, tal como lo menciona Miranda (2003).

Otro autor que está muy ligado a lo dicho anteriormente es Woodruffe (1993), quien manifiesta que las competencias son patrones de conducta observables que aportan los empleados a su puesto de trabajo para realizar las tareas y las funciones con pericia. En conclusión, para Miranda (2003), las competencias son actitudes que se evidencian a través de conductas observables que se aplican en una actividad y facultan el alcance de un buen desempeño.

En el informe de la Secretary's Commission on Achieving Necessary Skills (SCANS) (1992), los investigadores encontraron que los estudiantes, al término de su vida escolar, deben demostrar una serie de competencias y habilidades básicas para insertarse de manera adecuada al mundo laboral. Como resultado de esta investigación, en la cual participaron los Ministerios de Educación y de Trabajo de Estados Unidos, así como estudiantes, empresas y profesores, se desprenden cinco áreas clave para las competencias netamente laborales y tres áreas de habilidades personales que, articuladas, engloban a las dos antes mencionadas. Las definiciones de dichas áreas son necesariamente genéricas, lo que permite su aplicación en cualquier situación de trabajo. Desde esta perspectiva, las áreas de competencia que define la SCANS deben considerarse como un punto de partida para el análisis y las definiciones más específicas que se deben usar para un trabajo en particular. Dichas áreas son las siguientes:

Competencias básicas: estas competencias son consideradas como las habilidades básicas o personales mínimas que debe poseer la persona para un trabajo desde el más básico u operativo. 
Estas son: habilidades básicas, desde la lectura, una adecuada redacción, conocimiento en las matemáticas y capacidad de escucha.

La segunda habilidad que se debe poseer es la comprensión de aptitudes analíticas, tales como buscar soluciones creativas, así como una capacidad analítica para procesar información visual o de percepción de otro sentido y aprender para razonar.

Y, por último, las cualidades personales, que incluyen la responsabilidad, la autoestima, el autoconcepto, la sociabilidad, la gestión personal y ser una persona íntegra y honesta. Estas cualidades, en la actualidad, se toman en cuentan como competencias valiosas al momento de seleccionar a un postulante para un puesto laboral.

Ahora, para que un trabajador logre el éxito o un óptimo desempeño, la persona debe poseer las siguientes competencias:

Gestión de recursos: Esta área se refiere a las conductas relacionadas con la gestión eficiente del tiempo, el dinero, los recursos materiales y de infraestructura así como el potencial humano. El tiempo está relacionado a cómo las personas le dedican tiempo a actividades; prioriza o jerarquiza actividades, del mismo modo define metas, así como programa cada detalle de las actividades y controla la ejecución de programas. En lo que concierne al dinero, este se basa en cómo la persona proyecta, prepara y administra presupuestos, además de mantener registros y datos financieros. En la gestión de materiales, se considera la forma como el individuo posee, recopila, concede y distribuye de manera ordenada. En lo que se refiere al talento humano, cómo muestra sus competencias y sus habilidades en determinadas tareas o funciones; y estos comportamientos se evalúan o miden a través de una evaluación de desempeño gestionado por el área competente según cada empresa. 
Relacionamiento interpersonal: Competencia que tiene que ver con la relación y el manejo que tiene el ser humano para compartir y comunicarse con los demás. Asimismo, incluye la participación que tiene la persona durante algún el trabajo en equipo y el liderazgo que uno puede demostrar en ciertas actividades y situaciones. Del mismo modo, cómo enseña lo aprendido a los otros, la manera de transmitir la información y, finalmente, si trabaja en ambientes diversos, culturales, sociales o de género.

Uso de la información: Área que contempla a conductas relacionadas con el manejo de la información como insumo del proceso de decisiones. Estas conductas son como buscar, adquirir, obtener o recuperar información, además de interpretar y evaluar dicha información. Organizar y mantener actualizada la información, así como comunicar la información de forma adecuada. Finalmente, usa instrumentos tecnológicos para procesar información (por ejemplo, la computadora).

Comprensión de sistemas: Competencia que implica el uso y el manejo de sistemas, así como el comprender los mismos y saber aplicarlos en diferentes situaciones y circunstancias. Algunas teorías mencionan a esta competencia como digital. Del mismo modo, «sistemas» comprende el articular varios procesos de manera sistematizada, evitando o ahorrando tiempo en varias tareas.

\section{Definición de competencias laborales}

Como se ha mencionado anteriormente, tenemos varios autores que han estudiado y conceptualizado esta noción. Es preciso mencionar que la primera acepción de esta expresión fue aplicada y contextualizada para el campo laboral; luego, con los años, se aplicó al ámbito educativo y se agregó al currículo educativo. A medida que evolucionaba la acepción de este concepto en el 
ámbito educativo, se tomó como una competencia propia en la formación de los estudiantes y el resultado de sus egresados.

Para el Centro Interamericano para el Desarrollo del Conocimiento en la Formación Profesional (Cinterfor), organización adjunta a la OIT, las competencias laborales son las capacidades efectivas que presenta una persona para llevar a cabo una actividad laboral exitosamente. La competencia laboral no determina una probabilidad de éxito en la ejecución de un trabajo, sino una capacidad real y demostrada, es así que toda competencia laboral debe ser verificada y evaluada con estándares de calidad propios de la tarea a realizar.

McClellan (1973) mencionaba que desempeñar bien el trabajo dependía más de las características propias de la persona, que de sus conocimientos, su currículum, su experiencia y sus habilidades. Denominando así a las competencias como indicadores de conducta observables que presenta una persona frente al desempeño de un puesto laboral.

Unos de los autores referentes al tema de competencias es Spencer y Spencer (1993), quien considera que la competencia es una característica propia e inherente de una persona y que tiene relación con un excelente desempeño en una situación de trabajo; en conclusión, las competencias, al ser propias, pueden ser potencializadas a lo largo del tiempo, siempre y cuando se genere este desarrollo. Este autor propone el modelo del iceberg, el cual divide en dos partes las competencias: la visible (que comprende destrezas y conocimientos) y la no visible (que implica autoconocimiento, personalidad y motivaciones). Las destrezas lo definen como la capacidad que tiene la persona para ejecutar con habilidad una tarea o función. Los conocimientos son la información o teoría que se tiene sobre un área o contenido. En cuanto al autoconocimiento, se entiende como la capacidad que tiene una persona de reconocerse y aceptarse, así como sus valores; la personalidad engloba las características psíquicas que tiene una persona y la forma de 
reaccionar frente a diversas situaciones; y, por último, las motivaciones son las razones que tiene una persona para realizar o emprender algo, implica además los pensamientos que tiene para dicha acción.

El proyecto Tuning (2000) surgió de la iniciativa de universidades europeas como respuesta a la crisis que se vivía en aquel entonces en la educación superior. En este proyecto, se encontraron diferencias entre resultados académicos (learning outcomes) y las competencias que poseían los estudiantes (competentes). Estos resultados académicos se entendieron como los estándares que se espera que alcance un estudiante respecto al conocimiento propio de su especialidad académica, así como la capacidad que tenga para demostrar en diferentes situaciones; pudiéndose referir a una sola materia o un periodo de estudios concreto; en cambio, las competencias se entienden como la combinación entre conocimientos y habilidades referentes a varios temas. No solo distingue una competencia total, sino competencias específicas y genéricas o transversales, las cuales adquiere en diferentes niveles.

Las competencias específicas han sido definidas como las particularidades que deben adquirir los futuros egresados durante la estancia en el centro de estudios correspondiente y deben ser definidas por la experiencia de la propia institución. Por otro lado, las competencias genéricas son entendidas como las propiedades que debe poseer un egresado. Entre estas características, se reconocen aspectos como los conocimientos, las habilidades, las destrezas y las capacidades que deben tener los estudiantes antes de incorporarse al mercado laboral.

Dentro de las competencias genéricas se desprenden tres subdivisiones:

Instrumentales: capacidad que tiene la persona para comprender conceptos abstractos y propios (ideas), así como saber organizar, tomar decisiones, resolver problemas y sin dejar de lado el saber usa la tecnología y la lingüística. 
Interpersonales: habilidad que se refiere al contacto social y la cooperación de egresados y estudiantes con sus ámbitos laboral y social (networking), sin obviar la capacidad de poder expresar sus ideas, sus pensamientos y sus emociones de manera asertiva.

Sistémicas: competencia que implica el entendimiento de los sistemas o procesos como un todo. Cada área o tarea implica pasos y de ellos se desprenden procesos. Estos procesos, unidos a los de otras áreas, generan sistemas.

Alles (2002) considera en sus diversos libros que las competencias laborales hacen referencia a las características de personalidad de cada individuo, devenidas en comportamientos observables; y, por ende, generan desempeño exitoso en un puesto de trabajo. Cada puesto de trabajo puede tener diferentes características en empresas o mercados diferentes; es decir, no todas las personas calzan en todos los perfiles a cubrir y es ahí donde el área de recursos humanos, con su área de selección y reclutamiento, debe buscar al candidato más idóneo según sea la necesidad para cubrir.

En general, son varios los investigadores que coinciden en opinar que las competencias laborales constituyen una nueva alternativa para incrementar el rendimiento laboral o desempeño y la motivación, entre otros, de cualquier empresa.

Por otro lado, Chávez (2004) indica que el propósito de cualquier organización es identificar y satisfacer tanto las necesidades como las expectativas de sus clientes, a fines de alcanzar ventajas competitivas; lo cual realiza de una manera eficaz y eficiente con el fin de obtener, mejorar y mantener el desempeño global de la organización y sus capacidades.

Del mismo modo, Spencer y Spencer (1993) define con mayor precisión la competencia como una cualidad subyacente en el individuo que está causalmente relacionada con un estándar de desempeño o un desempeño superior en un determinado trabajo o situación. En este sentido, el 
desempeño debe entenderse como el comportamiento humano realizado dentro de un marco determinado de normas, instrumentos y procesos propios de una organización.

Para el Servicio Nacional de Aprendizaje (Sena), en el informe del proyecto educativo institucional (2013), define a las competencias laborales como la capacidad que tiene una persona para realizar tareas productivas en diferentes contextos, tomando en cuenta estándares de calidad dependiente del puesto y rubro a realizar.

Según Byham (2003), las competencias laborales representan las combinaciones de acciones que realiza una persona y que conllevan al éxito de su desempeño de sus tareas laborales. Este mismo autor, demostró que en el proceso de selección se puede identificar las competencias que presenta el individuo dependiendo de las tareas y puesto a realizar, utilizando como herramienta el assessment center.

En la mayoría de las instituciones educativas superiores sólo se preocupan por desarrollar competencias técnicas propias de la carrera, enfocándose en sus proceso de aprendizaje procedimental, y muy pocas ayudan a desarrollar las competencias socioemocionales, capacidades que contribuyen a la resolución de conflictos, comunicación asertiva, inteligencia emocional, motivación. Todas estas capacidades son parte de las competencias laborales. (García, 2013).

Para Mertens (2000), definir la competencia laboral implica conceptualizarla en dos enfoques: el estructural y el dinámico. El enfoque estructural implica generar fases en el desarrollo de las competencias laborales desde lo más elemental a lo más complejo que es la aplicación, e ir acompañando en todo este proceso. En enfoque dinámico va más al tema de cómo el profesional se debe ir adaptando a los cambios económicos, industriales y tecnológicos a nivel nacional e internacional. 


\section{Definición de las subcategorías de competencias laborales \\ Competencia técnica.}

Las competencias técnicas son los conocimientos técnicos, prácticos y procedimentales propios de cada profesión. Se entienden, además, como las habilidades que posee y que debe adquirir un profesional frente a un puesto específico; por ejemplo, un maquinista de maquinaria industrial debe conocer el procedimiento de manejo de la máquina.

De Ansorena (1996), en su libro 15 pasos para la selección de personal con éxito: método e instrumentos, estipula que hay dos tipos de competencias: la competencia técnica y las competencias generales. La primera se describe como la habilidad que posee una persona para ejecutar ciertas tareas y el conocimiento de los procedimientos para dichas funciones que conllevan el óptimo desempeño del puesto. Y las competencias generales son aquellas habilidades o conocimientos que se deben poseer de manera general, tales como el conocimiento del uso de la tecnología de la información o el dominio de algún otro idioma.

En el caso puntual de esta investigación, las competencias técnicas son esenciales, puesto que determina el dominio técnico de la materia, pues saber de qué está compuesto una máquina industrial o un motor permitirá realizar un adecuado mantenimiento preventivo o correctivo y, por ende, va a dar como resultado un excelente trabajo.

\section{Competencia metodológica.}

Las competencias metodológicas son aquellos elementos que utilizará el profesional para aplicar los procedimientos, los pasos y los procesos en cada tarea en cada ambiente laboral.

Bunk (1994), en su modelo de competencias profesionales, proponía que las competencias metodológicas son las capacidades que se tienen al aplicar procedimientos adecuados ante una 
tarea y cómo estas se pueden adaptar variando las circunstancias. Estas competencias se desprenden de cualificaciones profesionales que, a mediados de 1970 en Alemania, se establecieron como parte de la formación pedagógica en los estudiantes. Él las describe como competencias de acción.

Un profesional que posea esta competencia podrá reaccionar de manera óptima utilizando el procedimiento adecuado, según sea el caso, incluso si estas tareas son diferentes o se den en un contexto variado, y es ahí donde la persona podrá utilizarla, según sea el caso, y hacer uso de su capacidad de flexibilidad, su adaptabilidad y su capacidad de resolución de problemas.

Un indicador de esta competencia es la capacidad de resolución de problemas; la cual, según varios autores, es la capacidad que tiene la persona de resolver un problema o dificultad de manera eficiente y eficaz, utilizando sus conocimientos previos ante alguna situación nueva.

Así mismo, dentro de la competencia metodológica, encontramos a la capacidad de adaptación, la cual se entiende como la capacidad de amoldarse a los cambios. Para algunos autores, esta capacidad está enlazada con la versatilidad del profesional. Esta capacidad no solo se relaciona con el adaptarse a alguna situación nueva, sino también a nuevos mercados, contextos, entornos e, incluso, climas. Implica, en muchos casos, una visión más holística de los procesos en diferentes ambientes.

Otra competencia comprendida en este grupo es la flexibilidad, que se comprende como la capacidad de adaptarse fácilmente y trabajar en distintos entornos, situaciones y personas, con diferentes posturas y hasta con diferentes culturas, con el fin de brindar el mejor resultado.

\section{Competencia social.}

Comprendida como la capacidad de colaborar con los otros, así como el de poseer una adecuada comunicación y mostrar un pensamiento orientado al logro de manera conjunta. Para una adecuada 
interrelación con los demás, es importante que la persona sepa primero identificar sus propias fortalezas y debilidades; es decir, un adecuado conocimiento interpersonal (Bunk, 1991).

Para Alles (2005), las relaciones interpersonales son habilidades que, actualmente, el profesional del siglo XXI debe poseer para ser catalogado como un buen profesional; en sus diversos libros, las presenta como competencias transversales.

El trabajo en equipo se entiende como las capacidades de cooperación y colaboración con los otros, así como pertenecer a un grupo y apoyar a fines de alcanzar un buen resultado social. Para otros autores, esta competencia es la habilidad que tiene una persona de participar de manera activa para lograr un objetivo en común. Un buen manejo de relaciones interpersonales ayuda a que los integrantes del equipo logren sus metas.

La comunicación y un estilo de comunicación asertiva también son parte de la competencia social. Para Chiavenato (2007), esta competencia es la capacidad más importante que tiene el ser humano de relacionarse entre sí; aunado a ello, contribuye a la sociedad y las organizaciones. La comunicación es el intercambio de información entre personas, implica escuchar, exponer ideas, hacer preguntas y expresar sentimientos. En toda comunicación se necesita de un código para enviar el mensaje (ondas sonoras, textos, señas y símbolos), un canal, un medio donde se transmita el mensaje y un receptor que decodifique el mensaje.

Las relaciones interpersonales son la interacción social entre dos o más personas, en la cual la comunicación juega un papel importante. Hay estudios que han establecido tipos y estilos de comunicación. El estilo más recomendado para mantener una adecuada relación interpersonal es la comunicación asertiva, habilidad que permite que el emisor del mensaje transmita con claridad y de manera adecuada su mensaje. Hay otros dos estilos de mensajes: el pasivo y el agresivo. 
El estilo pasivo se caracteriza por la transmisión del mensaje de forma sumisa, dejando de lado los propios intereses, deseos o sentimientos. Por el contrario, el estilo agresivo se caracteriza por no respetar las opiniones y los deseos de los demás, imponiéndose de manera agresiva y, en algunos casos, humillante. Otros componentes de una buena relación interpersonal son la empatía, el autoconocimiento, la amabilidad, los valores, el autocontrol y la colaboración. Muchos autores consideran a esta competencia como pilar para el resultado óptimo de buenos resultados en un equipo.

\section{Competencia participativa.}

Competencia en la que se sabe aplicar la participación dentro de una organización y en su entorno. La persona será capaz de planificar y organizar, así como decidir y asumir las responsabilidades que ello implique. Es importante que el profesional se involucre tanto con sus funciones o tareas así como con la organización y su equipo de trabajo.

La capacidad de organización es la habilidad de establecer prioridades, metas y tareas según sea el orden que se convenga, con el fin de lograr la meta propuesta, también implica el mejor uso de materiales o recursos requeridos, como el seguimiento de dicha información (Alles, 2005).

El liderazgo también se contempla en estas competencias, pues es considerada como habilidad básica para llevar al éxito muchas metas profesionales. Se entiende como aquella capacidad de llevar a la acción a los grupos mediante varias estrategias, tomando las decisiones adecuadas y considerando las características del grupo, las funciones y el contexto. Actualmente, esta habilidad está tomando mucho énfasis gracias a la velocidad de los cambios generacionales, por lo cual más profesionales toman mayor liderazgo en sus tareas. 


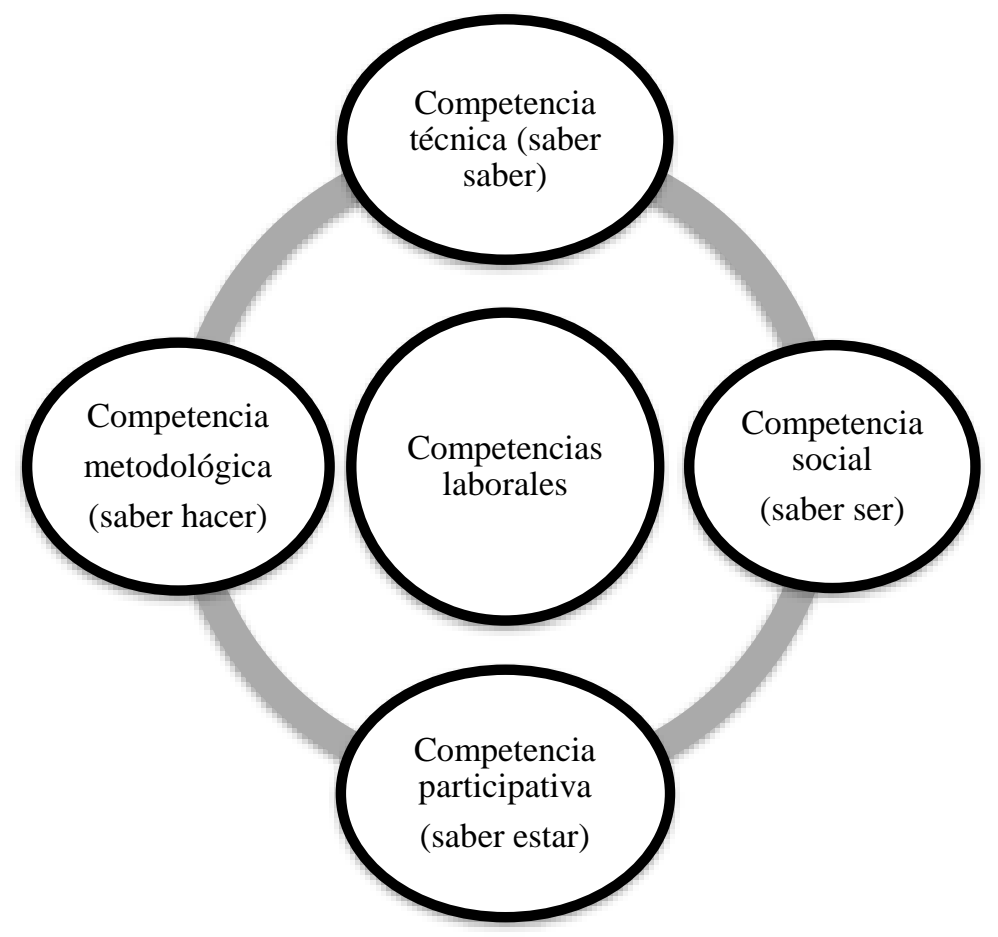

Figura 1. Subcategorías de las competencias laborales

Fuente: Elaboración propia (2019)

\section{Desarrollo histórico de competencias laborales}

El enfoque basado en competencias es relativamente nuevo en el ámbito educativo, pero se viene usando en el ámbito organizacional, por lo menos, desde 1940. El constante cambio a nivel de tecnología, economía, innovación y conocimiento ha desencadenado que la demandas cambien, generando a partir del siglo XXI cambios en la educación superior. Cambio que genera que se refleje una educación que agregue competencias y no solo conocimientos.

Para entender el enfoque de competencias, es necesario conocer los orígenes de sus términos y todo lo que ha involucrado a lo largo del tiempo. Según Corominas (1987), la raíz etimológica de 'competencia' proviene del latín competere, que en español tiene dos acepciones: ‘competer' y 'competir'. Según Mulder, Weigel y Collins (2008), el vocablo ‘competencia' se 
remonta al término ikanótis, de la Grecia antigua, el cual se puede traducir como «persona capaz», es decir, que tiene la capacidad de conseguir algo.

En 1949, el sociólogo T. Parsons, mediante un estudio, determinó que era más preciso valorar a una persona por el logro obtenido y los resultados de este, que por su conjunto de cualidades atribuidas. Posterior a esto, en la década de los sesenta, Noam Chomsky destacó la aparición de la competencia linguiística, definiéndola como la habilidad que tienen los seres humanos para adquirir el lenguaje y los medios para comunicarse. En 1984, Hymes, tomando en cuenta lo dicho por Chomsky, amplía el concepto y, de ese modo, se da cuenta de la capacidad que tienen las personas para determinar cuándo hablar y cuándo no, sobre qué, con quién y de qué forma.

El psicólogo David McClelland, mediante su investigación de motivación, se dio cuenta de que había una relación entre las necesidades personales y el éxito profesional de las personas. Es por esto que, en 1973, previo a estudios e investigaciones, demostró que una persona con calificaciones aprobatorias, buenas referencias laborales o con buenos resultados en los test de inteligencias no determinaban el desenvolvimiento y la adaptación de tal individuo en el trabajo. Por ello, optó por cambiar los indicadores de éxito profesional, a los cuales denominó competencias. Con esta investigación, se revolucionó de alguna manera el proceso de reclutamiento de selección de personal, en el cual solo se determinaba por la experiencia, la hoja de vida profesional y los resultados de los test de inteligencias.

En 1980, en Reino Unido se creó el programa National Vocational Qualifications (NVQs), en el cual participaron países como Canadá, Estados Unidos, Reino Unido, España, Francia, entre otros. Este programa ofrece una certificación que se obtiene a través de una evaluación y una capacitación. Cada participante del programa debe demostrar las competencias que tiene para 
llevar a cabo un trabajo. Estos trabajos están relacionados a contabilidad, hotelería, administración de empresas, entre otros.

A partir de la última década del siglo XX, debido a los cambios en todo ámbito mundial, se toma más en cuenta la importancia de las competencias. Es por esto que, en el ámbito pedagógico, se comienza a incluir en sus programas el enfoque por competencias. Uno de los primeros países es Estados Unidos, donde el ministro de Trabajo, en 1990, designó un comité cuyo principal objetivo fue estudiar con qué grado salen los estudiantes y si estos conocimientos son suficientes para las demandas laborales. La conclusión de este comité fue que los jóvenes terminan las escuelas sin tener el nivel que las empresas requieren. Aquí hubo un quiebre en el ámbito educativo, pues se determinó qué es lo que quieren y necesitan las empresas y las exigencias del mercado laboral y qué es lo que estamos brindando como capital humano.

La Declaración Mundial sobre Educación para Todos y el Marco de Acción para Satisfacer las Necesidades Básicas de Aprendizaje, aprobados por la Conferencia Mundial sobre Educación para Todos en Jomtien, Tailandia (1990), trataron temas como el aumento en la adquisición de conocimientos, habilidades y valores de cada individuo, con el fin de satisfacer las necesidades básicas de aprendizaje y obtener un aprendizaje permanente y no estático.

En 1997, la Organización para la Cooperación y el Desarrollo Económico (OCDE) creó el proyecto de Definición y Selección de Competencias Claves (DeSeCo) con el fin de identificar las competencias necesarias para fortalecer los objetivos en la educación y los sistemas de aprendizajes permanentes. Este proyecto llegó a la conclusión de que son tres los criterios que van a ayudar a fortalecer la identificación y las competencias clave:

i. Que contribuya a lograr resultados de gran valor personal y social.

ii. Que sean aplicables a un gran número de situaciones y ámbitos relevantes. 
iii. Que permitan superar con éxito las exigencias complejas; en otras palabras, que sean beneficiosas para la sociedad.

Tomando en cuenta este proyecto, se creó el Programa Internacional de Evaluación de Estudiantes, conocido como PISA, con el fin de identificar y evaluar los conocimientos y las habilidades adquiridos por los estudiantes, a lo largo de su vida escolar, para la participación en su sociedad. Este programa evalúa tres áreas: comunicación, matemáticas y ciencia.

Es bueno precisar que PISA evalúa a los estudiantes de la educación regular básica, mientras que el proyecto Tuning, tanto para Latinoamérica y Europa, evalúa el nivel superior.

En el ámbito laboral, Martens (2000, citado por Tobón, 2004), en su obra Formación basada en competencias, menciona que el enfoque por competencias en las empresas surge cuando las mismas requirieron y consideraron un aprendizaje organizacional y un desempeño óptimo, según sus funciones, que iban cambiando acorde a los cambios de las necesidades del mercado laboral, así como la movilidad laboral.

En Perú, desde el primer gobierno de Alberto Fujimori (1990), se plasmaron los cimientos de una educación enlazada con la economía, haciendo que se genere un paradigma en el cual se forme a las personas para una adecuada inserción laboral; de este modo, se formó la expresión «técnico productivo» y se aplicó en los diseños curriculares en la educación básica regular. También se tomó en cuenta formar a personas con buenos valores éticos y con conciencia ciudadana.

La Constitución Política de 1993, en el artículo 14, estipula la educación para la vida y el trabajo. La educación deberá promover el conocimiento, el aprendizaje, la práctica y la tecnología. Esto nos brinda los lineamientos de un modelo curricular y pedagógico hasta la actualidad. 
La Ley General de Educación (2003) marca el hito desde los marcos legales para el enfoque de competencias en Perú. En el artículo 24, se incluye la participación de las empresas en la educación con el diseño de políticas educativas, lo cual contribuye con las demandas del mercado laboral y el desarrollo económico productivo del país, además de promover alianzas para la investigación, el desarrollo tecnológico y las capacitaciones profesional y técnica de los trabajadores y los estudiantes del sistema educativo; todo aquello fomentará una mejora en el empleo y la calidad de vida. Asimismo, el artículo 29, inciso B, explica que en la educación superior uno de los objetivos es el logro de competencias profesionales de alto nivel, de acuerdo con la demanda y la necesidad del desarrollo sostenible del país.

El Proyecto Educativo Nacional al 2021 (PEN) plantea en su objetivo cinco que, si tenemos una educación superior de calidad, ello será en factor favorable para el desarrollo y la competitividad nacional, mediante centros universitarios y técnicos que formen profesionales éticos, competentes y productivos.

En el Diseño Curricular Básico Nacional de la Educación Superior Tecnológica (2015), dentro de los componentes curriculares, se contemplan competencias específicas (técnicas) que implican conocimientos y aptitudes relacionados a cada carrera; competencias para la empleabilidad relacionadas al conocimiento; actitudes vinculadas con características personales y sociales de la persona, tales como comunicación, trabajo en equipo, resolución de problemas, toma de decisiones, tolerancia a la frustración; y experiencias formativas en situación real de trabajo. Todos estos componentes formarán a personas en la formación técnica para un adecuado desempeño laboral.

El proyecto educativo institucional del Servicio Nacional de Aprendizaje (Sena) (2013) define las competencias laborales como la capacidad real que tiene la persona para desempeñarse 
en diversos contextos, considerando la calidad del mismo. En este mismo proyecto, se estipula la taxonomía de las competencias: Competencias específicas, transversales y básicas.

\section{Enfoques de competencias laborales}

Como hemos visto, el término 'competencia' ha tenido varias definiciones y enfoques. Mulder,

Weigel y Collins (2008), en su obra de competencia en el desarrollo de la educación y la formación profesional en algunos Estados miembro de la Unión Europea, establecen tres enfoques:

\section{Enfoque conductista.}

Enfoque que está muy relacionado con la evaluación de la conducta. Aquí se toma en cuenta el rendimiento y el desempeño de una persona frente a su puesto laboral, ya sea alguien que no sea exitoso o alguien que sí. Las herramientas que se utilizan para medir el desempeño son la observación y la evaluación del comportamiento en su lugar de trabajo referente a sus funciones. Esta postura también la sostiene tanto Spencer y Spencer como McClelland.

\section{Enfoque genérico.}

A diferencia del enfoque conductista que evalúa las conductas de las personas en su ámbito laboral, este enfoque intenta identificar las posibles habilidades que explican la diferencia entre el desempeño-éxito de una persona y otro de alguien que no es tan exitoso. Es decir, se selecciona al personal exitoso y se establecen competencias genéricas o estándares.

\section{Enfoque cognitivo.}

Este enfoque define competencias como el conjunto de procesos mentales que las personas utilizan para realizar sus funciones o tareas y como consecuencia adquirir conocimiento. Este enfoque está relacionado a la postura de Piaget, quien consideraba la inteligencia y el desarrollo cognitivo. 


\section{Modelos de competencias laborales}

En el informe de modelos internacionales de competencias profesionales, generado por Guerrero y De los Ríos (2013), se menciona la propuesta de Tobón (2008), quien, junto con Gonczi y Athanasou (1996), propone cinco tipos de modelos de competencias profesionales.

El primer tipo es el modelo de competencias basadas en el lugar de trabajo, cuyo origen está en Reino Unido, donde se pone como pilar principal el diseño del trabajo y del puesto; y, luego, se busca a la persona para que se pueda adaptar al puesto previamente definido. Los estándares de desempeño estarán establecidos por la empresa y no por las competencias de las personas.

La segunda propuesta es el modelo de competencias basadas en la teoría del comportamiento. En este enfoque priman las conductas de las personas en su desempeño laboral o en la respuesta observable de su función laboral. Asimismo, está más orientada a resultados que a la competencia en sí. Se originó en Estados Unidos.

El tercer tipo es el modelo de competencias basadas en la estrategia empresarial, en el cual se explica que las competencias son basadas y enfocadas a la mejora de la productividad de la empresa. Los autores proponen el enfoque de Core Competences, poniendo como centro el término ‘competencias', oponiéndose a la propuesta anterior. Este modelo se desarrolló inicialmente entre Japón y EE. UU.

La cuarta propuesta es el modelo de competencias basado en un enfoque cognitivo y de motivación; como su propio nombre lo dice, considera la importancia de aspectos como la motivación interna, la motivación externa, el cómo el puesto de trabajo contribuye a la persona, así como su contexto, su cultura, sus valores y su desarrollo. Este modelo también trata de un modelo aplicado al aprendizaje constante, ya sea de manera interna como de manera social. 
El quinto tipo es el modelo de competencias basado en un enfoque holístico, en el cual la competencia era el resultado de aspectos personales del trabajador, ya sea como la comunicación, la creatividad, el autoconocimiento, la resolución de problemas, el trabajo en equipo, entre otros, las cuales se denominan metacompetencias, necesarias para el desarrollo de las competencias cognitivas, que juntas generaban un valor mayor en el desarrollo de sus competencias.

\section{Competencias socioemocionales}

La definición de inteligencia emocional (IE) fue dada por primera vez por Mayer y Salovey (1990), desde entonces se han hecho investigaciones y aplicaciones en los ámbitos educativos, organizacionales y de salud. Muchos autores han ido modificando con el tiempo sus postulados, incluso han llegado a incorporar componentes cognitivos sobre el manejo de sus emociones; asimismo, se han generado y validado instrumentos que ayuden a identificar el control emocional de las personas.

Según Mayer y Salovey:

[L]a inteligencia emocional incluye la habilidad para percibir con precisión, valorar y expresar emoción; la habilidad de acceder y/o [sic _ - o- ] generar sentimientos cuando facilitan pensamientos; la habilidad de comprender la emoción y el conocimiento emocional; y la habilidad para regular las emociones para promover crecimiento emocional e intelectual. (1997, p. 10)

En pocas palabras, es la habilidad que tiene una persona para manejar sus sentimientos y sus emociones, discriminándolos y utilizándolos dependiendo sea la situación. Este modelo implica cuatro estructuras: 


\section{Percepción emocional.}

La habilidad que tienen las personas para percibir sus emociones, identificarlas y expresarlas a través de lenguajes verbal y no verbal (conducta). También implica el entender y percibir las emociones de los otros (empatía).

\section{Facilitación emocional del pensamiento.}

Las emociones tienen influencia en el proceso cognitivo, el cual identifica la emoción percibida, prioriza el pensamiento de este y la atención en la información. Aquí se puede encontrar el cambio fisiológico producido por las emociones percibidas y hasta cambios en el humor. Es importante mencionar que el entorno y las emociones de la persona ayudan a afrontar diversas situaciones.

\section{Comprensión emocional.}

Significa comprender las propias emociones, así como la de los otros. En este entendimiento y comprensión es necesario que las personas tengan contacto con las otras; es decir, saludables relaciones interpersonales.

\section{Regulación emocional.}

Para un adecuado control emocional, es importante regular las emociones. Hay teorías que indican que esto se va a dar con el pasar de los años, pero también a medida que la persona sepa discriminar, reconocer y manifestar sus emociones en diferentes contextos. Si la persona no tiene este contacto con los otros, le va a ser complicado regular sus propias emociones. Habilidad para controlar emociones negativas y potenciar las emociones positivas, sin represión o exageración.

\section{Definición de modelos}

Para entender mejor el concepto de modelos educativos, es indispensable separar ambos conceptos para su mejor entendimiento. El término 'modelo' en las ciencias formales o fácticas es muy amplio, por eso es indispensable entender el uso de esta palabra y no de 'mapa', 'método' o 
'representación'. El concepto de la palabra ‘modelo’ nació en la crisis de 1929 en Estados Unidos con el crash financiero, en el cual los economistas, tratando de integrar los enfoques matemáticos y todo lo que implique esta crisis financiera, dieron como respuesta a todo esto como «modelo». Tinbergen es el primero en utilizar la palabra ‘modelo' en el campo de la política económica, con el fin de representar la simulación de conflictos en la economía actual. Este concepto interesó a economistas, partidos políticos, sindicatos y agencias gubernamentales. Para tal efecto, el modelo viene a ser una construcción teórica-científica para describir la realidad sistematizada, jerarquizada, funcional y operacional; no es estática, sino es moldeable y adaptativa según la realidad en ese momento.

En el ámbito educativo, la concepción de 'modelo' sufre una alteración y se llega a considerar, según Escudero (1981), como:

[La] construcción que representa de forma simplificada una realidad o fenómeno con la finalidad de delimitar alguna de sus dimensiones que permite una visión aproximativa, a veces intuitiva, que oriente estrategias de investigación para la verificación de relaciones entre variables, y que aporta datos a la progresiva elaboración de las teorías. (1981, p. 11)

Otro autor que revisó el concepto de modelo en el ámbito educativo fue Castillo y Cabrerizo, quienes indicaron que, entre lo dicho anteriormente por Escudero, también puede ser considerado lo siguiente: una representación, el ideal de lo que se quiere conseguir y también como una muestra.

Un modelo educativo es una guía o pauta que orienta a los especialistas y los educadores en la elaboración y el análisis de los programas educativos, en el método de enseñanza y en el aprendizaje de la información. 


\section{Modelo educativo}

Los modelos educativos han variado según la historia $\mathrm{y}$, con estos, la complejidad y las articulaciones que involucran de este. Es claro que en todos los modelos se consideran a los educadores, el educando, el contenido y la estrategia para transmitir.

Algunos modelos ponen como eje fundamental al docente, quien es, según algunos autores, el encargado de impartir la información directa a los estudiantes. Otros autores mencionan que nos deberíamos enfocar en los estudiantes, puesto que ellos son quienes recibirán el conocimiento. Otros modelos se enfocan en la forma como se trasmite, la metodología y la estrategia pedagógica; ello con el sustento de que el mundo está cambiando y, con ello, la misma forma de aprender la información.

Fornaca (1991), en el texto Componentes epistemológicos en la reconstrucción histórica de los modelos educativos y pedagógicos, expresa que los modelos educativos pueden plantearse como un conjunto correlacionado en específicas situaciones históricas y sociales, de fenómenos, de datos, de acontecimientos, de hechos, de fuerzas, de situaciones, de instituciones, de mentalidad, tendencias a utilizar, a promover, a controlar conocimientos, informaciones, mitos, valores, capacidades, comportamientos, modalidades de enseñanza y de aprendizaje individual y colectivo a la vez.

La Universidad de Guadalajara, según el Modelo Educativo Siglo XXI, manifiesta que para ellos el modelo educativo «es una pretensión propositiva para generar los hábitos y las normas institucionales, que conformen una cultura que, edificada por los diferentes actores universitarios, explicite los valores, [las] preferencias, [las] aspiraciones y [los] compromisos de la institución» (2007, p. 18). El modelo educativo para la universidad es la fuerza orientadora de su ser y su quehacer universitario; además, encuentra su fin último en la sociedad. 


\section{Diferencia entre modelo educativo y modelo pedagógico.}

Para la diferencia de estas expresiones, nos valimos de los tesauros de educación superior; en esta oportunidad, tomamos en cuenta a dos: Tesauro de la Unesco (Comisión de las Comunidades Europeas, 2007) y Tesauro Europeo de la Educación (2007a). En el Tesauro de la Unesco hemos podido encontrar la expresión «modelo educacional», en vez de «modelo educativo», la cual se considera como la representación de un concepto o un sistema educativo por medio de un diagrama de dos o tres dimensiones, una fórmula matemática u otro procedimiento parecido. En el Tesauro Europeo de la Educación se obtuvieron las acepciones de modelo didáctico y método educativo, los cuales son usados como método de enseñanza, didáctico, pedagógico y metodología de la enseñanza.

El modelo pedagógico es un instrumento de las instituciones educativas que debe dejar claro para qué se enseña y para qué se estudia, el sustento pedagógico y el perfil del egresado, según Zubiría (1994).

\begin{tabular}{|l|}
\hline \multicolumn{2}{|c|}{ Modelo educativo } \\
\hline - Factores sociales que permiten \\
realizar la educación como \\
proceso de enseñanza. \\
- Aspectos tecnológico, teórico, \\
metodológico e instrumental. \\
\hline
\end{tabular}

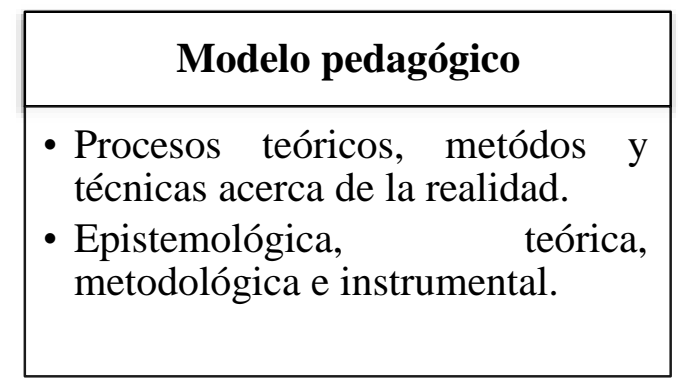

Figura 2. Tipos de modelos: educativo y pedagógico Fuente: Elaboración propia (2019)

\section{Tipos de modelos educativos.}

Para Kaufman y Herman (1997), el modelo educativo debe contemplar la misión, el entorno y su influencia, así como la visión de la institución educativa, las estrategias, las acciones y el seguimiento del programa. 


\section{Modelo tradicional.}

Este modelo se refiere, principalmente, a elaborar un programa de estudios o un diseño curricular estándar. Este modelo no tiene mayores elementos, puesto que no contempla una evaluación constante ni características propias de los estudiantes según su cultura. Los elementos que intervienen son: el profesor, persona que tiene el papel activo en este modelo, quien utiliza mayormente el pizarrón para exponer sus ideas y sus conocimientos; el método, utilizado cotidianamente e, incluso, en algunos puntos llega a parecer memorización, así como la resolución de problemas mediante los libros; el alumno, quien tiene un rol pasivo, lo cual a veces no le brinda oportunidad innovadora; y la información.

\section{Modelo de Ralph Tyler.}

Este modelo pone énfasis en los objetivos educacionales. Cada diseño curricular tiene un programa establecido, pero lo más importante son los objetivos, a dónde se quiere llegar. Esto hace que el profesor deba realizar sus actividades en función a los objetivos del programa.

Aquí utilizan diversos métodos y técnicas que se aplicarán en los programas y que el profesor selecciona según sea el caso. El alumno, a diferencia del modelo tradicional, trabaja en equipo, conoce los objetivos y busca ir más allá.

Otras ventajas que proporciona este modelo son la evaluación, la participación de especialistas y la comunidad.

\section{Modelo de Popham-Baker.}

Modelo que enfatiza la sistematización de la enseñanza; es decir, plasmar sistemas, procesos para que sirvan de guía a los profesores. Aquí se plantean objetivos e hipótesis de experimentación con el fin de evaluar los resultados obtenidos. 
Los resultados de la evaluación previa se analizan y comparan con la evaluación final, teniendo en cuenta si se llegó al objetivo planteado, o si se logró el aprendizaje propuesto para el alumno.

En su libro de modelos educativos y académicos, Tünnermann (2008) recopiló los modelos educativos de varias universidades de México y Latinoamérica, con el fin de conocer los paradigmas educativos propios de cada institución educativa. En el Instituto Politécnico Nacional de México, encontramos un modelo educativo en el cual involucran valores, misión y visión, con el fin de que el egresado represente la filosofía del instituto; esta representación debe garantizar que está acorde a las necesidades del mercado actual. Este mismo ideal se ve similar en la Universidad Autónoma de Yucatán, pues no solo se debe incluir el objetivo del proyecto educativo, sino que esta educación debe ser integral y humanista.

La Universidad Veracruzana involucró en su modelo educativo lo propuesto por la Unesco en la Declaración Mundial sobre la Educación para el Siglo XXI (1998). Dicha declaración pone en manifiesto las cualidades que los egresados deben poseer para el nuevo mercado actual; tales como el aprendizaje permanente, el desarrollo autónomo, el trabajo en equipo, la comunicación con diversas audiencias, la creatividad y la innovación en la producción de conocimiento y en el desarrollo de tecnología, la destreza en la solución de problemas, el desarrollo de un espíritu emprendedor, la sensibilidad social y la comprensión de diversas culturas.

Como podemos entender, un modelo educativo debe contemplar un sistema holístico del centro de estudios; tales como la docencia, la investigación, la extensión, la vinculación y los servicios.

Este modelo también debe contemplar el proceso de enseñanza-aprendizaje; aunado a ello, tenemos también varios autores que ponen como factor primordial al contexto social, el contexto 
significativo o el lenguaje que tiene el estudiante. Por ejemplo, Bruner afirma que lo que estipula el desarrollo intelectual en un niño es el grado en que haya calado una educación adecuada conjuntamente con las vivencias que se hayan tenido. Por consiguiente, si uno le explica con adecuadas metodologías a un niño, esto permitirá que genere un mejor concepto de lo aprendido. Su teoría destaca el papel del adulto en la educación. A diferencia de Piaget, quien proponía que el aprendizaje es continuo, Bruner propone que el ser humano aprende por etapas y procesos cognitivos, en el cual la metodología del aprendizaje, así como su entorno y sus experiencias vividas, contribuirán con el desarrollo cognitivo del niño.

Por ende, Bruner, al tener como postulado el proceso cognitivo en etapas, considera al lenguaje como medio importante para entender e interpretar a su entorno, como un proceso cognitivo superior, en el cual interviene el pensamiento, la percepción y la interpretación.

Otro autor importante en este proceso de la escuela conductista es Vygotsky, quien hace hincapié en la importancia del entorno social del niño. Vygotsky presupone que el lenguaje es una herramienta psicológica importante para el desarrollo cognitivo del niño; por tal razón, a medida que el niño va creciendo, el lenguaje se torna más complejo. Este lenguaje se puede quedar en básico si es que no tiene estimulantes sociales para aprehenderlo.

Muchos autores consideran que el lenguaje ha sido el proceso cognitivo superior clave en el desarrollo humano, ya que implica varios procesos internos y externos, desde la percepción hasta la transmisión de información del medio.

Así es que, para Vygotsky, el aprendizaje es por procesos y va a depender de los estímulos y los aprendizajes que pueda recibir en cada etapa de su vida, siendo el lenguaje una herramienta fundamental para el desarrollo cognitivo. Mientras que, para Piaget, es un proceso continuo en el cual la experiencia que tenga el niño con su entorno será factor para su inteligencia, produciéndose 
pensamientos lógicos por edades: sensomotora, preoperacional, operaciones concretas y operaciones formales.

\section{Definiciones de las subcategorías del modelo educativo \\ Perfil de la carrera.}

Para definir claramente el perfil de la carrera y del egresado que el instituto desea, primero se debe tener en cuenta la misión (expresión de las necesidades que socialmente la institución desea satisfacer), la visión (proyección a futuro de manera realista) y los valores institucionales (filosofía institucional). Es importante definir cuál es el rumbo o filosofía de la institución educativa, ya que en función de ello se van a moldear sus planes y sus mallas curriculares.

Los objetivos educacionales por carrera así como institucionales son un segundo punto a considerar, sin dejar de lado la necesidad profesional del mercado laboral actual, los resultados finales de cada competencia y las capacidades que debe tener el perfil del profesional a formar; luego, diseñar el plan curricular y, al final, el plan de temas.

Para la plataforma Universia (2018), el perfil de una carrera es la suma de habilidades, capacidades y competencias que debe poseer un profesional según sea la carrera académica, es como una capacitación que posee un profesional para su profesión.

Según Diaz (1990), antes de elaborar el perfil profesional es primordial establecer los fundamentos del plan curricular, así como la metodología a implementar. Aunado a ello, se deben tener también los fundamentos de aplicación a corto, mediano o largo plazo, así como las necesidades del mercado laboral actual. El siguiente paso es establecer la disciplina que más se acerca a esta necesidad profesional y, con el fin de no duplicar esfuerzos, revisar qué otras instituciones educativas ya la ofrecen, para así marcar la diferenciación que el perfil del egresado 
desea tener. Para construir un perfil profesional, Diaz establece que se debe realizar una investigación sobre los conocimientos, las técnicas y los procedimientos actuales de cada disciplina académica; luego, se determina el campo de acción donde trabajará el egresado, así como las especializaciones a las cuales podría aplicar.

\section{Proceso de enseñanza.}

Que involucra la elaboración del material didáctico, así como la selección del docente, identificar y delimitar el capital humano, tecnológico y material que debe usar. En este proceso es sumamente importante el perfil que tienen sus postulantes, así como los estudiantes que ingresan a estudiar.

El proceso de enseñanza consiste en la transmisión de conocimientos específicos o generales de alguna materia o tema, utilizando alguna metodología didáctica. Este procedimiento implica varios factores (ambiente, herramientas tecnológicas y didácticas y personalidad del estudiante y docente) y personajes (Docente y estudiante).

Para Doménech, la definición de 'aprendizaje' se entiende desde el conductismo, el cual consiste en adquirir conocimientos, y la definición de enseñanza es el proceso de transmitir y construir información de manera tanto informativa como formativa.

Desde el punto de vista del conductismo, Pavlov es uno de los autores que propuso el condicionamiento clásico, en el cual el aprendizaje se da mediante reflejos condicionados. Skinner y Thorndike propusieron que el aprendizaje debe darse de manera voluntaria, además de que ese aprendizaje sería llamado condicionamiento operante.

Por otro lado, en la corriente constructivista tenemos varios ponentes reconocidos, uno es Piaget, quien propone que el aprendizaje se construye mediante el desarrollo del individuo; es decir, el conocimiento se construye con cada experiencia que tenemos y evoluciona con nuestro propio crecimiento cognitivo. Ausubel, por su lado, atribuye la expresión «aprendizaje 
significativo», en la cual los saberes o conocimientos previos son fundamentales para la adquisición de conocimientos; él aporto la técnica del mapa conceptual y reforzó la capacidad de aprender a aprender. Y, por último, Vygotski aportó la influencia sociocultural que cada individuo posee y que contribuye con el desarrollo psicológico de cada uno. En esta corriente, el docente juega un papel importante, pues es el modelador de información y del desarrollo del conocimiento.

\section{Calidad de la calidad.}

Se entiende como el acompañamiento del estudiante durante su formación profesional, tomando en cuenta los resultados de las encuestas tanto realizadas a los empleadores como a los docentes. Actualizar los planes de temas, así como la malla curricular, de ser el caso. Esta actualización se genera a través de las reuniones de comités consultivos por departamento o áreas académicas, en donde, periódicamente, se deberían reunir con representantes de empresas para recabar información de la necesidad laboral actual; esto articula mejor la comunicación entre la academia y la industria. Por otro lado, las alianzas y los convenios con entidades nacionales e internacionales.

La calidad educativa es una característica y una cualidad de la educación; se logra cuando se alcanza el objetivo de la educación: formar de manera integral a las personas.

Cuando uno menciona calidad educativa, inmediatamente, se nos viene a la mente calificación, estrategias de mejora, evaluaciones constantes y supervisión o seguimiento de los procesos y la metodología. Sin embargo, se deben considerar no solo los procesos internos de cada entidad educativa, sino los procesos externos; tales como las normativas, las regulaciones y los lineamientos que emite el Ministerio de Educación, el perfil del estudiante, las influencias sociales, culturales y hasta generacionales; todo lo cual se debe considerar dentro de los procesos de calidad educativa. 
Un autor que ha investigado esta área de la educación es Soria (1996), quien define como calidad educativa a la calidad de recursos (tanto materiales como humanos) y las características que posee cada institución educativa (procesos y ambientes); las cuales, llevadas de la mejor manera, ayudarán a la adquisición de conocimientos, capacidades y competencias de sus estudiantes.

La Unesco considera que la calidad se da como resultado de la educación básica y debe proporcionar condiciones y conocimientos básicos para una adecuada convivencia en sociedad y en democracia, así como el desarrollo de algunas competencias laborales, como la capacidad de resolver problemas y el entendimiento de nuestras capacidades y habilidades.

Hussen (1986) propone tres aspectos para evaluar la calidad educativa: primero, los insumos que posee cada institución educativa; segundo, el proceso de enseñanza; y, tercero, los resultados o logros académicos.

\section{Modelo educativo del instituto tecnológico de Lima}

Para el instituto tecnológico en mención, un modelo educativo es una conceptualización que orienta a los agentes educativos a la formulación de programas de estudio y a la sistematización de los procesos de enseñanza y aprendizaje, incorporando un sistema que asegure la calidad del proceso con el fin de lograr egresados competentes para la actividad empresarial (Área de Calidad Educativa del I. E. S. tecnológico de Lima, 2018).

El siguiente cuadro representa gráficamente el modelo que predica el instituto: 


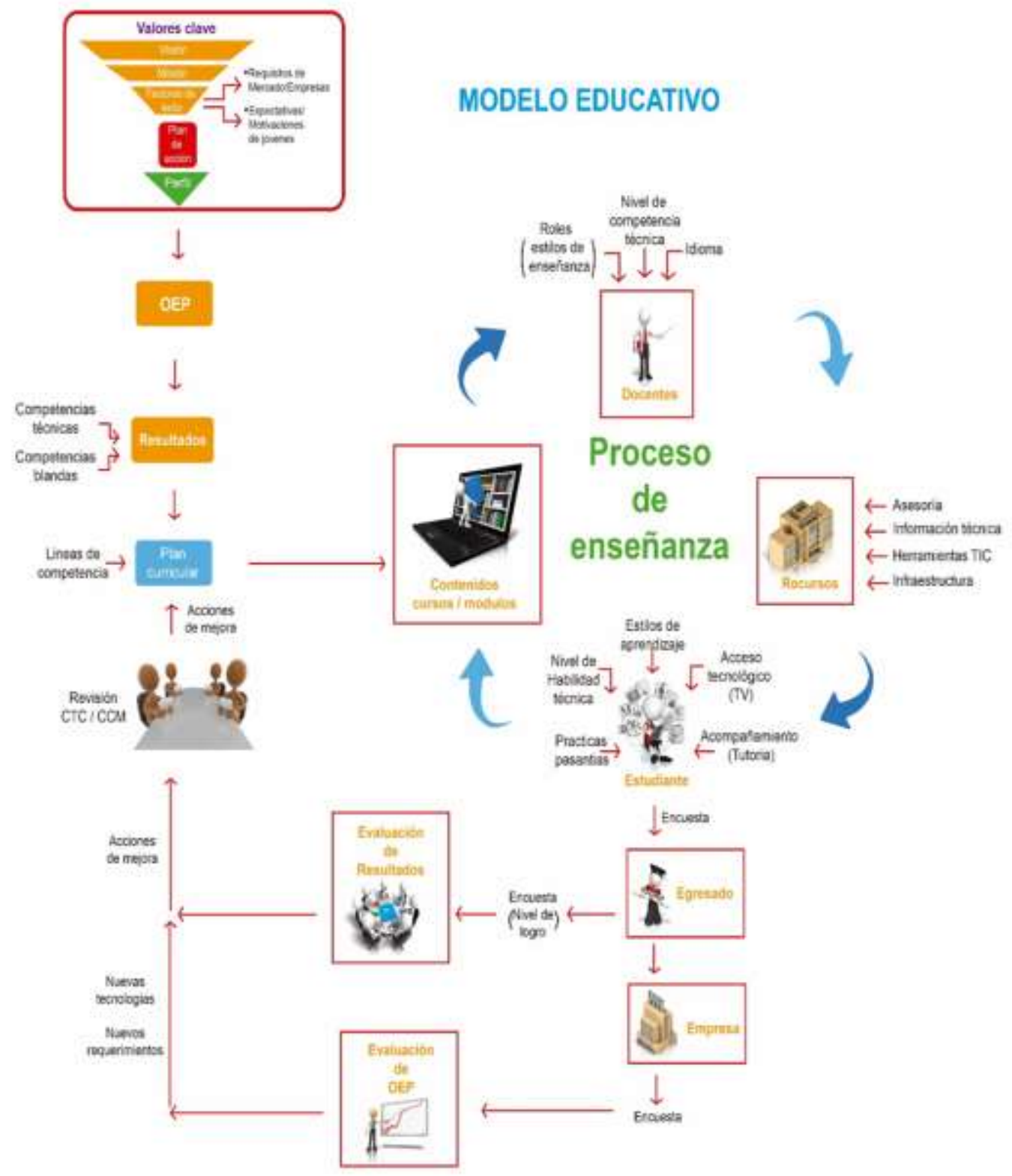

Figura 3. Modelo educativo del I. E. S. tecnológico de Lima

Fuente: Área de Calidad Educativa del instituto de educación superior de Lima (2018)

Referente a la gestión de competencias de la curricular del instituto educativo superior, esta se basa en lo siguiente: 


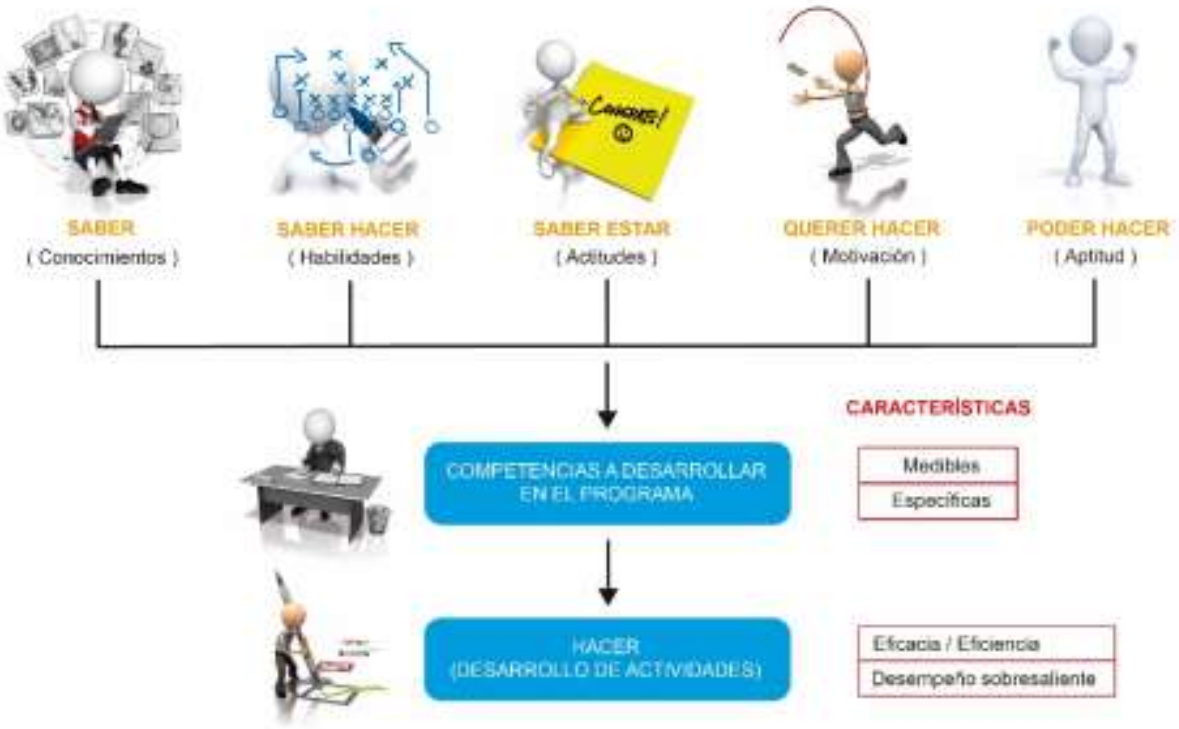

Figura 4. Modelo de competencias del I. E. S. tecnológico de Lima Fuente: Área de Calidad Educativa del instituto de educación superior de Lima (2018)

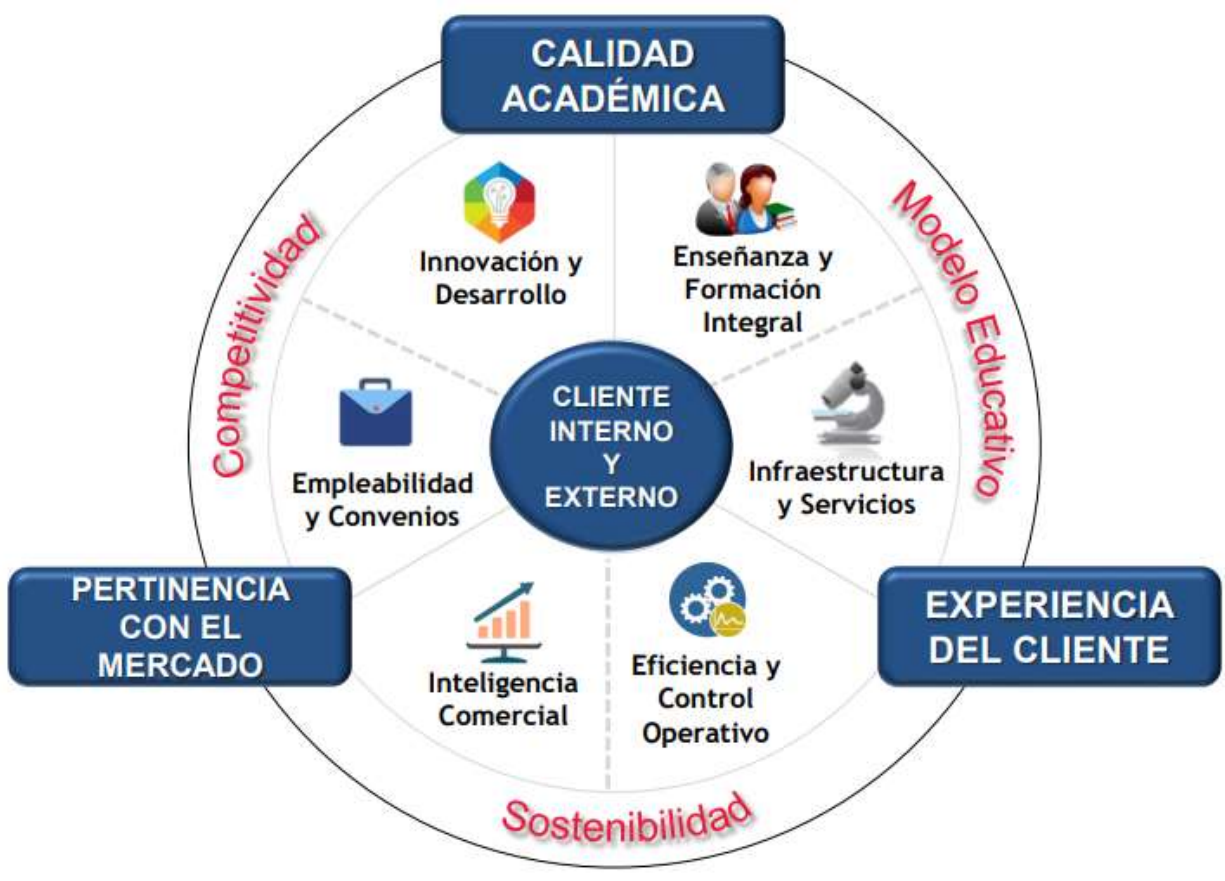

Figura 5. Proceso de calidad del I. E. S. tecnológico de Lima

Fuente: Área de Calidad Educativa del instituto de educación superior de Lima (2018) 


\section{Capítulo II}

\section{Diagnóstico o trabajo de campo}

\section{Análisis, interpretación y discusión de los resultados}

En este capítulo se presentarán los resultados encontrados al aplicar las diferentes técnicas de recopilación de datos, los instrumentos como las entrevistas semiestructuradas a cinco docentes de diferentes áreas académicas, los cuestionarios cerrados a veinticinco estudiantes elegidos por el criterio del muestreo no probabilístico que pertenecen al último año de estudios del instituto y cinco representantes de empresas que cuentan con alumnos y egresados del instituto tecnológico de Lima. Dichos instrumentos fueron debidamente revisados y validados por expertos relacionados al tema a investigar.

\section{Análisis de los resultados por técnicas e instrumentos de investigación Entrevista semiestructurada a docentes.}

Se diseñó una guía de entrevista de veintidós preguntas, la cual se aplicó a cinco docentes de diversas carreras académicas del programa de formación regular del instituto. Todos los docentes evaluados se mostraron interesados en el tema de la investigación, puesto que lo consideran un área muy álgida en estos momentos, momento en el cual estamos notando un cambio rápido en las necesidades del mercado laboral, así como en el perfil o el capital humano que tenemos: la actual generación con habilidades de necesidades variantes.

En lo que se refiere al perfil de carrera, los docentes manifestaron que conocen la visión y la misión del instituto; sin embargo, alguno de ellos manifestó imprecisiones con los objetivos educacionales, pues los confundió con los planes de temas o competencias terminales de las unidades didácticas. Los objetivos educacionales implican una planificación curricular detallada y el proceso educativo del modelo educativo. 
Respecto a la planeación didáctica, los docentes mostraron conocimiento en su tema, previa preparación dependiendo del curso o grupo a dictar. Del mismo modo, los docentes expusieron que los temas son explicados sin contratiempos, ya que el perfil del estudiante contribuye a ello, aplicando casos reales o situacionales, metodologías ágiles o aula invertida. Ahora, lo que sí mencionan los docentes es que se debe poner énfasis en reforzar la competencia de comunicación, puesto que les cuesta expresar sus ideas con fluidez, o con una adecuada gramática, tanto en la forma verbal como escrita. Esta falencia ya la traen desde la educación básica y les es dificultoso modificar esto en solo su curso, por lo cual proponen que sea un trabajo transversal.

En lo que se refiere a calidad educativa, los docentes cuestionaron que no haya lineamientos definidos para la generación de proyectos que cultiven el trabajo en equipo, la creatividad y la innovación. Si bien es cierto el alumno realiza ejemplares proyectos; sin embargo, muchos de ellos no tienen el impacto que se desearía, empero, se pueden generar proyectos que articulen con otras carreras. Por otro lado, consideran que nuestros egresados están bien posicionados gracias a la calidad de los mismos y al prestigio que tiene la institución; no obstante, mencionan que en los últimos años esto ha ido decayendo por la competencia laboral. Referente a los convenios con empresas o instituciones, consideran que se puede hacer aún más por ello, ya que solo se tienen convenios con algunas empresas, además de que la demanda de alumnos ha superado cierto límite y ya no se puede abarcar a todos; no obstante, con otras entidades educativas se pueden generar nuevas oportunidades de desarrollo profesional.

En cuanto a las competencias técnicas, consideran que los estudiantes adquieren las competencias técnicas de cada carrera según el nivel estipulado y que están más que capacitados en ellos, lo cual les genera mayor facilidad para insertarse al mundo laboral. Sin embargo, el perfil del ingresante no es claro, por lo cual los ingresantes no tienen las competencias cognitivas básicas 
para adaptarse al modelo del instituto y, finalmente, al egresar, no cumplen los estándares de calidad del instituto.

Para los docentes entrevistados, sus estudiantes tienen la capacidad de resolver problemas, ya sean situacionales del día a día o problemas de la industria; lo cual permite que se adapten con facilidad, ya sea por el horario, el régimen de trabajo o la cultura de la empresa donde practican o trabajan. También mencionan que esto sea por el tipo de carreras que estudian o por el origen demográfico de sus estudiantes.

Los docentes mencionaron que sus estudiantes se relacionan adecuadamente con sus pares; sin embargo, cuando la comunicación implica a sus superiores, les cuesta hacerla, ya sea por las palabras que usa o por la falta de seguridad de ellos. Trabajan adecuadamente en equipo, generan resultados favorables y esto ha ido mejorando en función al avance de sus ciclos.

Sin embargo, los mismos docentes mencionan que entre ellos, si bien trabajan en equipo, no todos son líderes o les cuesta ejercer esta competencia; por lo cual ellos proponen actividades que prueban ello. Esta competencia se va mejorando en función a los años de egreso y al tiempo en el mercado laboral, con lo cual se logra alcanzar, en muchos casos, cargos de jefatura o gerencia.

\section{Cuestionario cerrado a estudiantes.}

Se aplicó un cuestionario de veintidós preguntas a veinticinco estudiantes de diversas carreras académicas del instituto superior de Lima. El objetivo consistió en identificar la percepción del nivel de competencias que tienen los estudiantes en las empresas cuando realizan sus experiencias formativas en situación real de trabajo.

Dicho cuestionario cerrado se elaboró y validó por juicio de expertos, con escala Likert, provenientes de siete subcategorías y veinte indicadores, usando el criterio de muestreo no probabilístico. 
Los resultados del cuestionario evidenciaron que el $48 \%$ de los estudiantes evaluados consideran que casi siempre ellos poseen adecuadas competencias técnicas, lo cual les permite demostrar dominio, conocimiento y destreza técnica acerca de su carrera académica; y el $38 \%$ de los estudiantes mencionan que siempre muestran un alto grado de conocimientos teóricos y prácticos al momento de realizar una tarea laboral, con lo que obtienen muy buenos resultados en los mismos.

\section{Tabla 2.}

Competencias técnicas de los estudiantes encuestados

\begin{tabular}{cccccc}
\hline & Frecuencia & Porcentaje & $\begin{array}{c}\text { Porcentaje } \\
\text { válido }\end{array}$ & $\begin{array}{c}\text { Porcentaje } \\
\text { acumulado }\end{array}$ \\
\hline \multirow{2}{*}{ Válido } & A veces & 7 & $14 \%$ & $14 \%$ & $14 \%$ \\
\cline { 2 - 6 } & $\begin{array}{c}\text { Casi } \\
\text { siempre }\end{array}$ & 24 & $48 \%$ & $48 \%$ & $62 \%$ \\
\cline { 2 - 6 } & Siempre & 19 & $38 \%$ & $38 \%$ & $100 \%$ \\
\cline { 2 - 6 } & Total & 50 & $100 \%$ & $100 \%$ & \\
\hline
\end{tabular}

Fuente: Elaboración propia (2019)

Asimismo, el $56 \%$ (14) de los estudiantes consideraron que casi siempre evidencia adecuada capacidad para resolver problemas, así como una adecuada capacidad de adaptación y flexibilidad, englobando todo ello como competencias metodológicas. Por otro lado, 7 de los estudiantes (es decir, el 22,28\%) consideran que siempre muestran estas competencias en la industria, aplicando procedimientos adecuados al momento de resolver algún problema y buscando soluciones que se puedan adaptar al momento. 
Tabla 3.

Competencias metodológicas de los estudiantes encuestados

\begin{tabular}{cccccc}
\hline & Frecuencia & Porcentaje & $\begin{array}{c}\text { Porcentaje } \\
\text { válido }\end{array}$ & $\begin{array}{c}\text { Porcentaje } \\
\text { acumulado }\end{array}$ \\
\hline \multirow{2}{*}{ Válido } & Nunca & 1 & $4 \%$ & $4 \%$ & $4 \%$ \\
\cline { 2 - 6 } & A veces & 3 & $12 \%$ & $12 \%$ & $16 \%$ \\
\cline { 2 - 6 } & $\begin{array}{c}\text { Casi } \\
\text { siempre }\end{array}$ & 14 & $56 \%$ & $56 \%$ & $72 \%$ \\
\cline { 2 - 6 } & Siempre & 7 & $28 \%$ & $28 \%$ & $100 \%$ \\
\cline { 2 - 6 } & Total & 25 & $100 \%$ & $100 \%$ & \\
\hline
\end{tabular}

Fuente: Elaboración propia (2019).

En cuanto a las competencias sociales, el $47 \%$ de los estudiantes responden que casi siempre evidencia una adecuada relación interpersonal, un buen trabajo en equipo y asertividad al momento de comunicarse. Por otro lado, el $35 \%$ de los estudiantes indicaron que siempre trabajan de manera colaborativa con otras personas, comunicándose de manera óptima, con lo cual obtuvieron así un excelente resultado. En esta área, se trabajó con cuatro preguntas, a fines de cubrir el contenido de la subcategoría.

Tabla 4.

Competencias sociales de los estudiantes encuestados.

\begin{tabular}{cccccc}
\hline & & Frecuencia & Porcentaje & $\begin{array}{c}\text { Porcentaje } \\
\text { válido }\end{array}$ & $\begin{array}{c}\text { Porcentaje } \\
\text { acumulado }\end{array}$ \\
\hline \multirow{2}{*}{ Casi nunca } & 3 & $3 \%$ & $3 \%$ & $4 \%$ \\
\cline { 2 - 6 } & A veces & 15 & $15 \%$ & $15 \%$ & $19 \%$ \\
\cline { 2 - 6 } & Casi siempre & 47 & $47 \%$ & $47 \%$ & $66 \%$ \\
\cline { 2 - 6 } & Siempre & 35 & $35 \%$ & $35 \%$ & $100 \%$ \\
\cline { 2 - 6 } & Total & 100 & $100 \%$ & $100 \%$ & \\
\hline
\end{tabular}

Fuente: Elaboración propia (2019) 
En relación con sus competencias participativas, competencia que implica la capacidad de organización y de decisión en sus funciones y sus tareas laborales, así también como la capacidad de liderar alguna responsabilidad encomendada en grupos o solos, el $44 \%$ de los evaluados mostraron que casi siempre evidencian estas competencias en las empresas, y el $39 \%$ mencionó que siempre. Esto se pudo obtener con cuatro preguntas.

Tabla 5 .

Competencias participativas de los estudiantes encuestados

\begin{tabular}{cccccc}
\hline & Frecuencia & Porcentaje & $\begin{array}{c}\text { Porcentaje } \\
\text { válido }\end{array}$ & $\begin{array}{c}\text { Porcentaje } \\
\text { acumulado }\end{array}$ \\
\hline \multirow{2}{*}{ Válido } & Casi nunca & 5 & $5 \%$ & $5 \%$ & $4 \%$ \\
\cline { 2 - 6 } & A veces & 12 & $12 \%$ & $12 \%$ & $16 \%$ \\
\cline { 2 - 6 } & $\begin{array}{c}\text { Casi } \\
\text { siempre }\end{array}$ & 44 & $44 \%$ & $44 \%$ & $60 \%$ \\
\cline { 2 - 6 } & Siempre & 39 & $39 \%$ & $39 \%$ & $100 \%$ \\
\hline
\end{tabular}

Fuente: Elaboración propia (2019)

En lo que se refiere a la subcategoría de perfil de carreras, el $45 \%$ de los estudiantes consideraron que casi siempre sus docentes son especialistas en su materia y han contribuido en el desarrollo de su ética profesional; asimismo, estos conocimientos aprendidos ayudaron en su desempeño durante la aplicación de su proyecto de innovación en empresa o en sus prácticas preprofesionales. Del mismo modo, el $36 \%$ manifestó que siempre evidenció ello; y el $16 \%$, a veces. Es importante resaltar que ningún estudiante considera que la institución educativa nunca ha contribuido en su vida profesional.

En esta competencia, se agruparon tres preguntas que implicaban la misión de la I. E., así como la estructura y la organización del instituto. También considera el conocimiento del docente 
en su materia o especialización, tanto en la parte teórica como en la práctica, aplicándolo in situ en la industria a través de sus experiencias en situación real de trabajo, sin omitir la contribución de la ética profesional.

Tabla 6.

Perfil de carreras de los estudiantes encuestados

\begin{tabular}{cccccc}
\hline & Frecuencia & Porcentaje & $\begin{array}{c}\text { Porcentaje } \\
\text { válido }\end{array}$ & $\begin{array}{c}\text { Porcentaje } \\
\text { acumulado }\end{array}$ \\
\hline \multirow{2}{*}{ Válido } & Casi nunca & 1 & $1 \%$ & $1,3 \%$ & $4 \%$ \\
\cline { 2 - 6 } & A veces & 9 & $12 \%$ & $12 \%$ & $16 \%$ \\
\cline { 2 - 6 } & Casi siempre & 34 & $45 \%$ & $45,3 \%$ & $61,3 \%$ \\
\cline { 2 - 6 } & Siempre & 31 & $41 \%$ & $41,3 \%$ & $100 \%$ \\
\hline
\end{tabular}

Fuente: Elaboración propia (2019)

En la subcategoría sobre proceso de enseñanza, el $44 \%$ de los estudiantes perciben que las metodologías que utilizan sus docentes son adecuadas en su aprendizaje, las mismas que son corroboradas a través de actividades prácticas o casos reales en la industria, buscando la óptima solución de problemas en la industria, de manera creativa y factible. El $37 \%$ de estos refirieron que siempre y ningún estudiante mencionó que nunca le fue útil este proceso de enseñanzaaprendizaje. Esta competencia comprendía tres preguntas. 
Tabla 7.

Proceso de enseñanza de los estudiantes encuestados.

\begin{tabular}{cccccc}
\hline & & Frecuencia & Porcentaje & $\begin{array}{c}\text { Porcentaje } \\
\text { válido }\end{array}$ & $\begin{array}{c}\text { Porcentaje } \\
\text { acumulado }\end{array}$ \\
\hline \multirow{2}{*}{ Cálido } & Casi nunca & 1 & $1 \%$ & $1,3 \%$ & $4 \%$ \\
\cline { 2 - 5 } & A veces & 13 & $17 \%$ & $17,3 \%$ & $16 \%$ \\
\cline { 2 - 5 } & Casi siempre & 33 & $44 \%$ & $44 \%$ & $61,3 \%$ \\
\cline { 2 - 5 } & Siempre & 28 & $37 \%$ & $37,3 \%$ & $100 \%$ \\
\cline { 2 - 5 } & Total & 75 & $100 \%$ & $100 \%$ & \\
\hline
\end{tabular}

Fuente: Elaboración propia (2019)

En lo que concierne a los indicadores de calidad educativa, el $48 \%$ de los estudiantes encuestados mostraron que casi siempre el instituto promueve proyectos académicos que implican la innovación y la creatividad según la carrera académica, así como la calidad de sus clases y la puntualidad de las mismas. De igual manera, el $32 \%$ de los evaluados perciben que siempre hay un adecuado seguimiento del estudiante, que están constantemente en evaluación de sus resultados académicos y se preocupan por la empleabilidad de los egresados a través de contactos con empresas o convenios. Solo el $4 \%$ percibe que nunca; $1 \%$, casi nunca; y el $15 \%$, a veces. 
Tabla 8 .

Calidad educativa de los estudiantes encuestados

\begin{tabular}{cccccc}
\hline & & Frecuencia & Porcentaje & $\begin{array}{c}\text { Porcentaje } \\
\text { válido }\end{array}$ & $\begin{array}{c}\text { Porcentaje } \\
\text { acumulado }\end{array}$ \\
\hline \multirow{2}{*}{ Válido } & Nunca & 3 & $4 \%$ & $4 \%$ & $4 \%$ \\
\cline { 2 - 6 } & A veces & 11 & $15 \%$ & $14,7 \%$ & $20 \%$ \\
\cline { 2 - 5 } & Casi siempre & 36 & $48 \%$ & $48 \%$ & $68 \%$ \\
\cline { 2 - 5 } & Siempre & 24 & $32 \%$ & $32 \%$ & \\
\hline
\end{tabular}

Fuente: Elaboración propia (2019)

\section{Cuestionario cerrado a empresas.}

Se aplicó un cuestionario cerrado de veintiún preguntas a cinco representantes de empresas que generalmente solicitan estudiantes o egresados del instituto en mención. El objetivo consistió en recopilar información respecto al conocimiento sobre las competencias laborales que observan en los estudiantes o egresados.

Esta encuesta se elaboró y validó por juicio de expertos; además, se empleó un cuestionario cerrado con escala Likert, proveniente de cuatro subcategorías y diez indicadores, usando el criterio de muestreo no probabilístico.

Los resultados que se encontraron evidencian que, en relación con las competencias técnicas, el $52 \%$ de los representantes de las empresas percibieron que los estudiantes siempre cumplen sus funciones con eficiencia y eficacia, aplicando sus conocimientos técnicos en sus funciones diarias y que los mismos están acorde a la necesidad de la industria, también muestran crecimiento profesional y personal, y son capaces de reconocer sus capacidades y sus limitaciones. Dentro de esta subcategoría se contemplan cinco preguntas. 
Tabla 9.

Competencias técnicas de estudiantes realizadas por empresas

\begin{tabular}{cccccc}
\hline & & Frecuencia & Porcentaje & $\begin{array}{c}\text { Porcentaje } \\
\text { válido }\end{array}$ & $\begin{array}{c}\text { Porcentaje } \\
\text { acumulado }\end{array}$ \\
\hline \multirow{3}{*}{ Válido } & A veces & 4 & $16 \%$ & $16 \%$ & $20 \%$ \\
\cline { 2 - 6 } & Casi siempre & 8 & $32 \%$ & $32 \%$ & $52 \%$ \\
\cline { 2 - 6 } & Siempre & 13 & $52 \%$ & $52 \%$ & $100 \%$ \\
\cline { 2 - 6 } & Total & 25 & $100 \%$ & $100 \%$ & \\
\hline
\end{tabular}

Fuente: Elaboración propia (2019)

En cuanto a las competencias metodológicas, el $43 \%$ de los representantes mencionaron que los estudiantes siempre siguen órdenes de sus superiores sin complicaciones, así como la facilidad para definir un objetivo y empezar a trabajar en él, también buscan alternativas para solucionar problema y se adaptan con facilidad en diferentes escenarios físicos y en diferentes horarios que les proponga la empresa.

Tabla 10.

Competencias metodológicas de estudiantes realizadas por empresas

\begin{tabular}{cccccc}
\hline & Frecuencia & Porcentaje & $\begin{array}{c}\text { Porcentaje } \\
\text { válido }\end{array}$ & $\begin{array}{c}\text { Porcentaje } \\
\text { acumulado }\end{array}$ \\
\hline \multirow{2}{*}{ Válido } & A veces & 4 & $13 \%$ & $13,3 \%$ & $20 \%$ \\
\cline { 2 - 6 } & Casi siempre & 13 & $43 \%$ & $43,3 \%$ & $63,3 \%$ \\
\cline { 2 - 5 } & Siempre & 13 & $43 \%$ & $43,3 \%$ & $100 \%$ \\
\cline { 2 - 5 } & Total & 30 & $100 \%$ & $100 \%$ & \\
\hline
\end{tabular}

Fuente: Elaboración propia (2019)

En la categoría de competencias sociales, se pudo encontrar que el $68 \%$ de los encuestados indicaron que casi siempre los estudiantes y los egresados trabajan fácilmente con personas de otras áreas o puntos de vista, así como construyen adecuadamente relaciones asertivas, 
permitiendo la efectividad en el trabajo en equipo o encomendado, trasmitiendo de manera adecuada sus pensamientos o ideas tanto de forma oral como escrita. El $32 \%$ de ellos percibieron que siempre evidencian estos indicadores. En esta competencia se consideraron los indicadores de trabajo en equipo, estilo de comunicación y relaciones interpersonales.

Tabla 11.

Competencias sociales de estudiantes realizadas por empresas

\begin{tabular}{cccccc}
\hline & & Frecuencia & Porcentaje & $\begin{array}{c}\text { Porcentaje } \\
\text { válido }\end{array}$ & $\begin{array}{c}\text { Porcentaje } \\
\text { acumulado }\end{array}$ \\
\hline \multirow{2}{*}{ Válido } & Casi siempre & 17 & $68 \%$ & $68 \%$ & $68 \%$ \\
\cline { 2 - 6 } & Siempre & 8 & $32 \%$ & $32 \%$ & $100 \%$ \\
\cline { 2 - 5 } & Total & 25 & $100 \%$ & $100 \%$ & $100 \%$ \\
\hline
\end{tabular}

Fuente: Elaboración propia (2019)

Para las competencias participativas, los representantes de las empresas indicaron que el $48 \%$ de los estudiantes casi siempre son capaces de cumplir con responsabilidad las tareas encomendadas, de tomar decisiones de forma adecuada, buscar soluciones creativas ante los problemas, colaborar con otras áreas con entusiasmo y saber organizarse para cumplir dentro del tiempo establecido sus tareas. El $36 \%$ percibió que siempre muestran estas actitudes. Los indicadores que se contemplaron dentro de esta subcategoría son la capacidad de organización, la capacidad de decisiones y el liderazgo. Con estos resultados, podemos inferir que los estudiantes muestran estas competencias con óptimos resultados en la empresa. 
Tabla 12.

Competencias participativas de estudiantes realizadas por empresas

\begin{tabular}{cccccc}
\hline & Frecuencia & Porcentaje & $\begin{array}{c}\text { Porcentaje } \\
\text { válido }\end{array}$ & $\begin{array}{c}\text { Porcentaje } \\
\text { acumulado }\end{array}$ \\
\hline \multirow{2}{*}{ Válido } & A veces & 4 & $16 \%$ & $16 \%$ & \\
\cline { 2 - 6 } & Casi siempre & 12 & $48 \%$ & $49 \%$ & $49 \%$ \\
\cline { 2 - 6 } & Siempre & 9 & $36 \%$ & $35 \%$ & $84 \%$ \\
\cline { 2 - 6 } & Total & 25 & $100 \%$ & $100 \%$ & $100 \%$
\end{tabular}

Fuente: Elaboración propia (2019)

\section{Presentación de resultados según las categorías emergentes}

Luego de analizar la información y realizar el proceso de categorización y codificación, se agruparon y determinaron las estrategias apriorísticas y categorías emergentes que surgieron durante este proceso.

Las entrevistas permitieron identificar que los docentes consideran importante, que en su proceso formativo en el instituto, se desarrolle las competencias laborales en los estudiantes; del mismo modo, en la triangulación de datos de las entrevistas a docentes y de las encuestas a los estudiantes y a los representantes de las empresas, se encontró cuatro categorías emergentes: actuales competencias demandadas por las empresas, baja inteligencia emocional en los estudiantes, ausencia de gestión educativa por procesos y perfil del ingresante. 


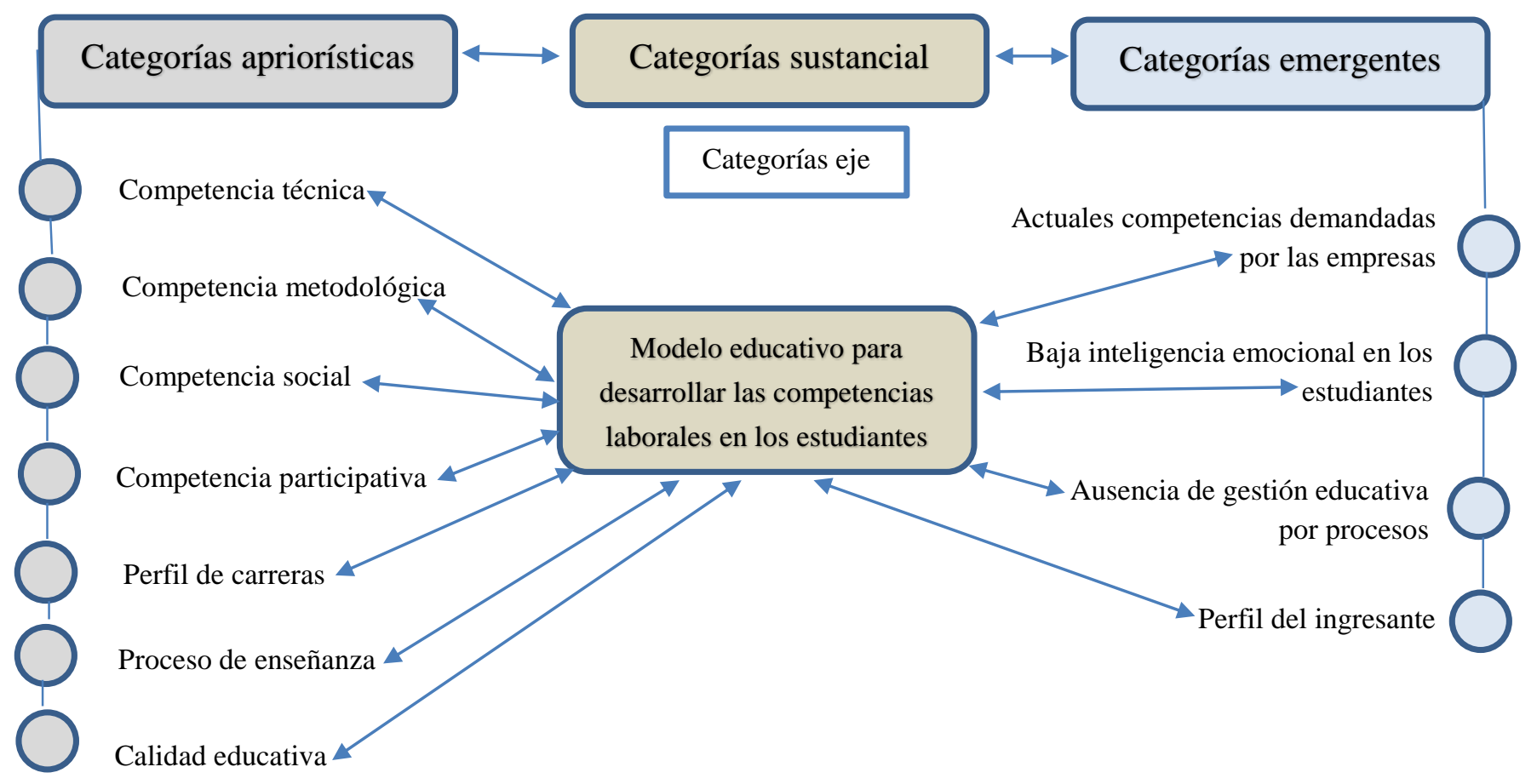

Figura 6. Categorías emergentes y apriorísticas

Fuente: Elaboración propia (2019) 


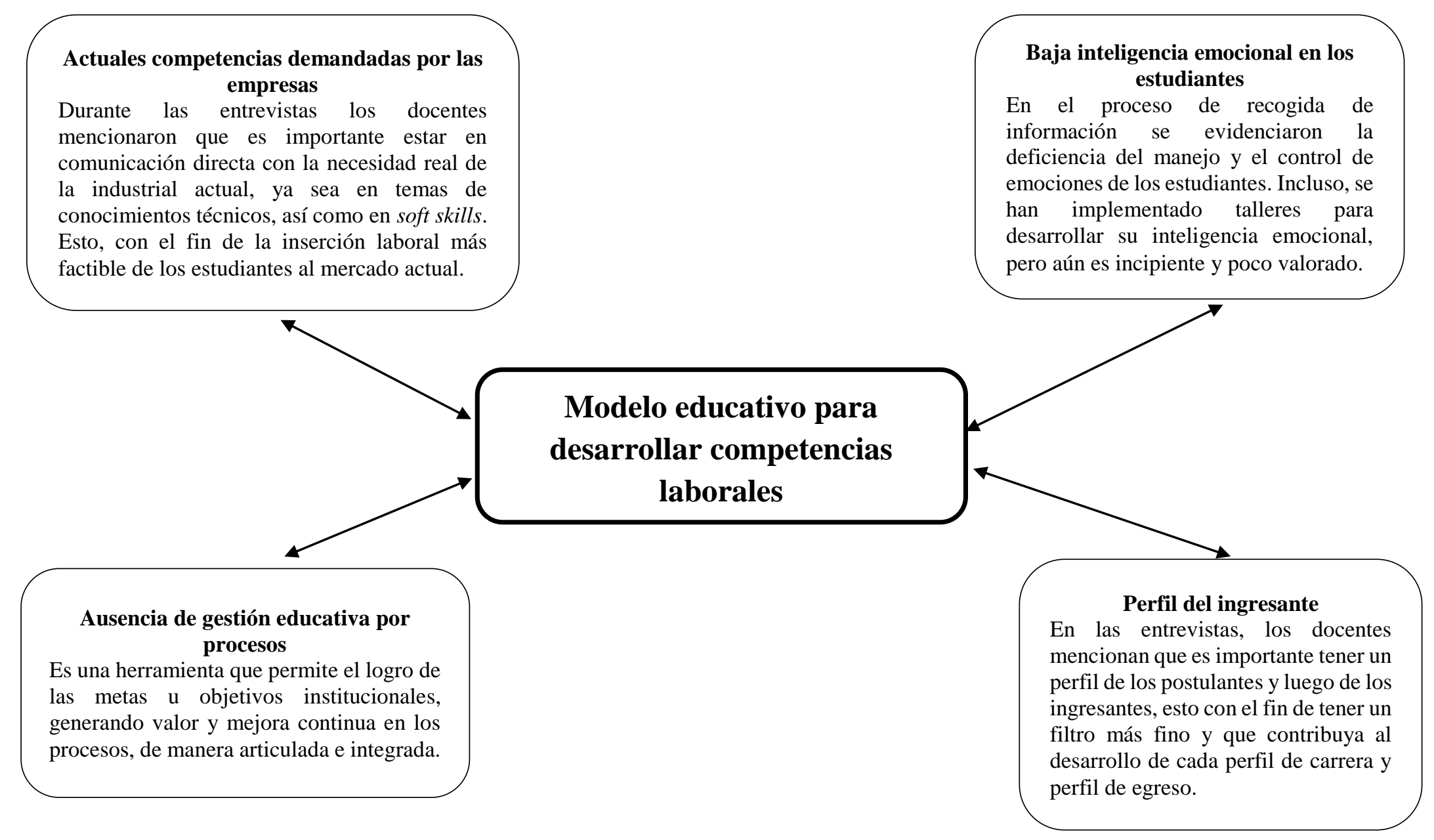

Figura 7. Categorías alternativas/emergentes y conclusiones aproximativas Fuente: Elaboración propia (2019) 


\section{Actuales competencias demandadas por las empresas.}

El Proyecto Educativo Nacional al 2021, objetivo estratégico n. ${ }^{\circ}$ 5, explica que, a fines de que la educación superior sea de calidad y útil, es necesario que las universidades o institutos superiores conversen directamente con las industrias según su sector, esto con el fin de que los próximos egresados sean de calidad en función a lo que el mercado laboral necesite actualmente.

Del mismo modo, el Banco Mundial, en su estudio Skills Toward Employability and Productivity (STEP) (2010), hizo hincapié en desarrollar las competencias laborales propias de cada trabajo desde una entidad educativa. Que no solo la entidad educativa se dedique a brindar información teórica, sino que esta sea aplicable a la productividad, necesidad del país, con lo cual se genera empleo y se mejora la calidad de vida de las personas. De igual manera, el informe Estrategias de competencias de la OCDE reporte diagnóstico: Perú 2016 muestra ya, en el pilar 1, la necesidad de desarrollar competencias relevantes con el fin de mejorar el acceso a una educación superior de calidad y la transición al empleo.

Si bien es cierto que el instituto tiene comunicación directa con la industria actual, es importante generar procesos establecidos con el fin de tener no solo la necesidad de la industria, sino también de la proyección laboral y económica del país.

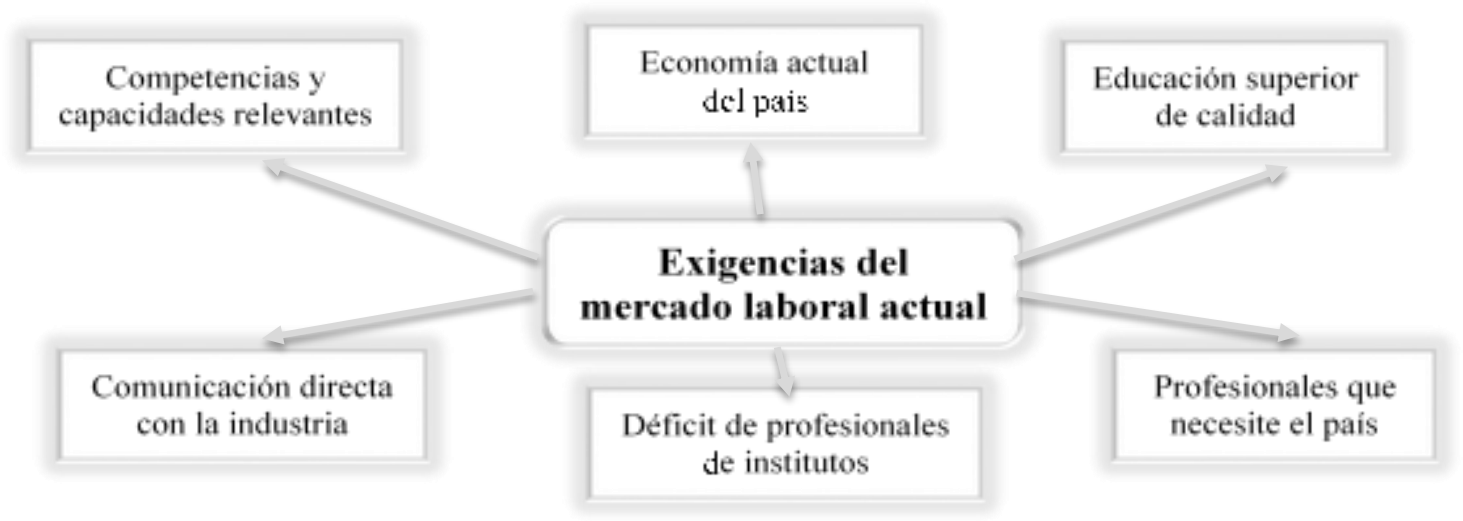

Figura 8. Categoría emergente competencias demandadas por las empresas Fuente: Elaboración propia (2019) 


\section{Baja inteligencia emocional en los estudiantes.}

La inteligencia emocional ha cobrado valor en el ámbito laboral de un tiempo a esta parte, inclusive ya es parte de las evaluaciones del proceso de selección y de desempeño.

Golleman (1995) define a esta inteligencia como conocer nuestras propias emociones, manejarlas, motivarse a sí mismo, reconocer las emociones de los demás y establecer relaciones con los demás.

Por otro lado, Alles (2002), en sus diversos libros, hace mención de que, para una adecuada evaluación de competencias, es necesario considerar la capacidad que tiene una persona para manejar sus emociones y la relación que tiene con los demás, de ahí se desprenden las demás competencias. Ella también menciona a McClelland, quien es también autor de varios libros acerca del tema.

Es importante mencionar que, en las entrevistas y las encuestas, docentes, estudiantes y representantes de las empresas informaron que consideran a la inteligencia emocional como parte de la formación y el desarrollo de los estudiantes; en tal sentido, es importante considerar esta categoría como parte de un proceso educativo y de empleabilidad.

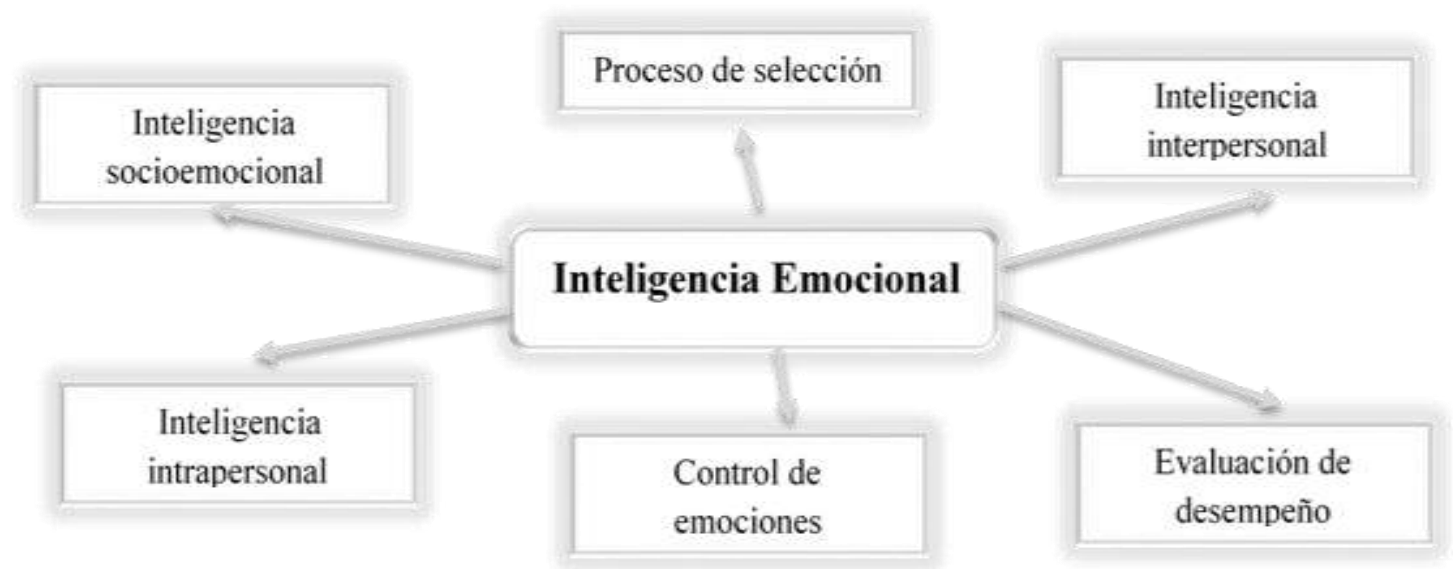

Figura 9. Categoría emergente inteligencia emocional Fuente: Elaboración propia (2019) 


\section{Ausencia de gestión educativa por procesos.}

En toda organización, para el logro de objetivos, son importantes los procesos detallados y reales. Es importante mencionar que, para un efectivo modelo educativo, se deben contemplar procesos detallados y que impliquen a toda la comunidad educativa; es decir, procesos administrativos, académicos, de calidad, de mejora, entre otros.

Gómez (2009) conceptualiza la gestión por procesos como la forma en la que se administra una organización, dándole valor al objeto diferenciador para el cliente y los entes involucrados. Asimismo, Bergholz (2011) considera, por su parte, que esta gestión ayuda a enfocar la metodología del trabajo y, con ello, atribuye a la cultura organizacional y apoya los procesos de mejora de la organización.

En las entrevistas, los docentes nos indicaron que no evidenciaron procesos establecidos y que cada departamento académico genera procesos o los adaptan según su perfil o criterio, lo cual genera desorden y entregables de poca calidad.

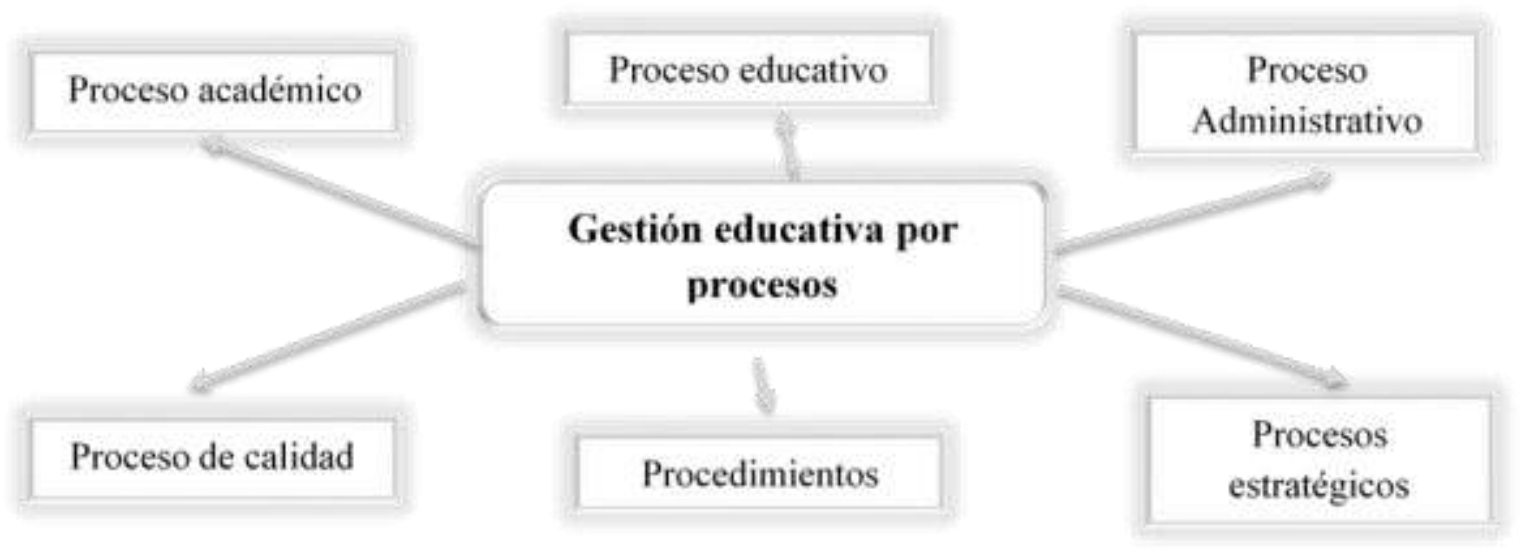

Figura 10. Categoría emergente gestión educativa por procesos Fuente: Elaboración propia (2019) 


\section{Perfil del ingresante.}

En las entrevistas se pudo obtener que, para los docentes, era importante y necesario saber cómo estaban llegando los ingresantes; esta información los ayudaba a canalizar sus clases y sus metodologías de enseñanza y aprendizaje. Tres docentes mencionaron que el perfil de muchos estudiantes hacía que el desarrollo de habilidades blandas se complicara, ya que el origen socioeconómico dificultaba ello, así como la autoestima y el autoconocimiento de cada uno de ellos. Es importante saber el nivel académico de física, matemática y comunicación, así como el perfil de personalidad, los estilos de aprendizaje y el nivel sociocultural.

Con los cambios respecto a las generaciones de personas, muchas universidades e institutos superiores han reformulado su perfil de ingresantes, haciendo que hasta la forma de captación, admisión y desarrollo académico sea modificada. Actualmente, muchos de estos centros de conocimiento tienen estudiantes de la generación Z, o millennials, donde son, como dicen varios autores, nativos digitales, aprenden de manera más rápida e inmediata, tienen facilidad para los procesos digitales, con capacidad de hacer varias tareas al mismo tiempo; asimismo, su principal medio de comunicación son las redes sociales, y es esto último en donde el centro educativo debe poner énfasis y estrategias para captar la atención de su actual público objetivo.

Por su lado, Tobón (2006), en su libro Competencias, calidad y educación superior, mencionó la importancia de las universidades e institutos de saber qué público está entrando a su comunidad estudiantil, esto con el fin de poder generar actividades para formarlos en el perfil de egreso según su misión. 


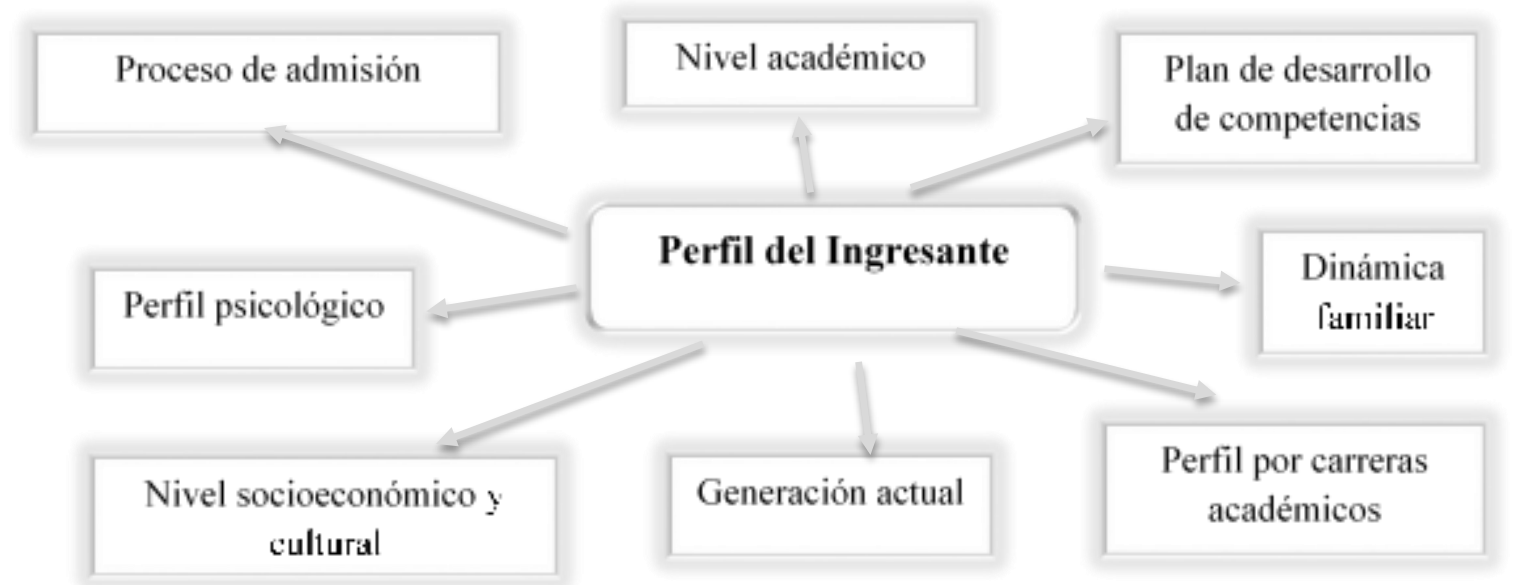

Figura 11. Categoría emergente perfil del ingresante Fuente: Elaboración propia (2019) 


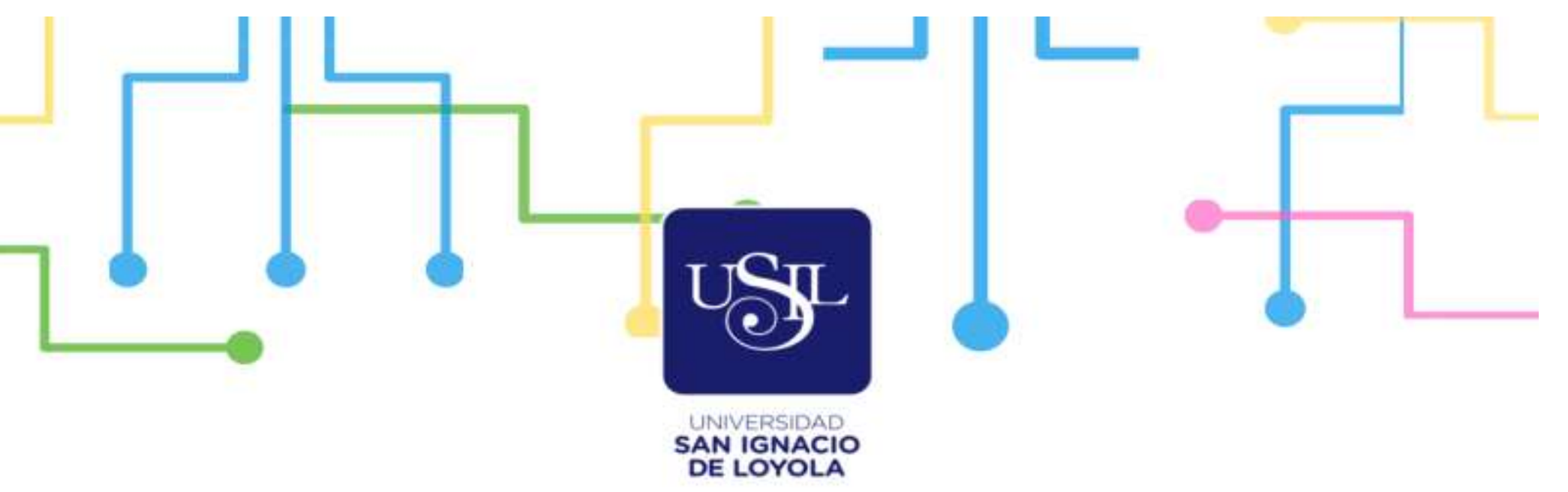

\section{ESCUELA DE POSTGRADO}

Maestría en Educación con mención en Gestión Educativa

MODELO EDUCATIVO PARA DESARROLLAR COMPETENCIAS LABORALES EN ESTUDIANTES DE UN INSTITUTO DE EDUCACIÓN SUPERIOR DE LIMA

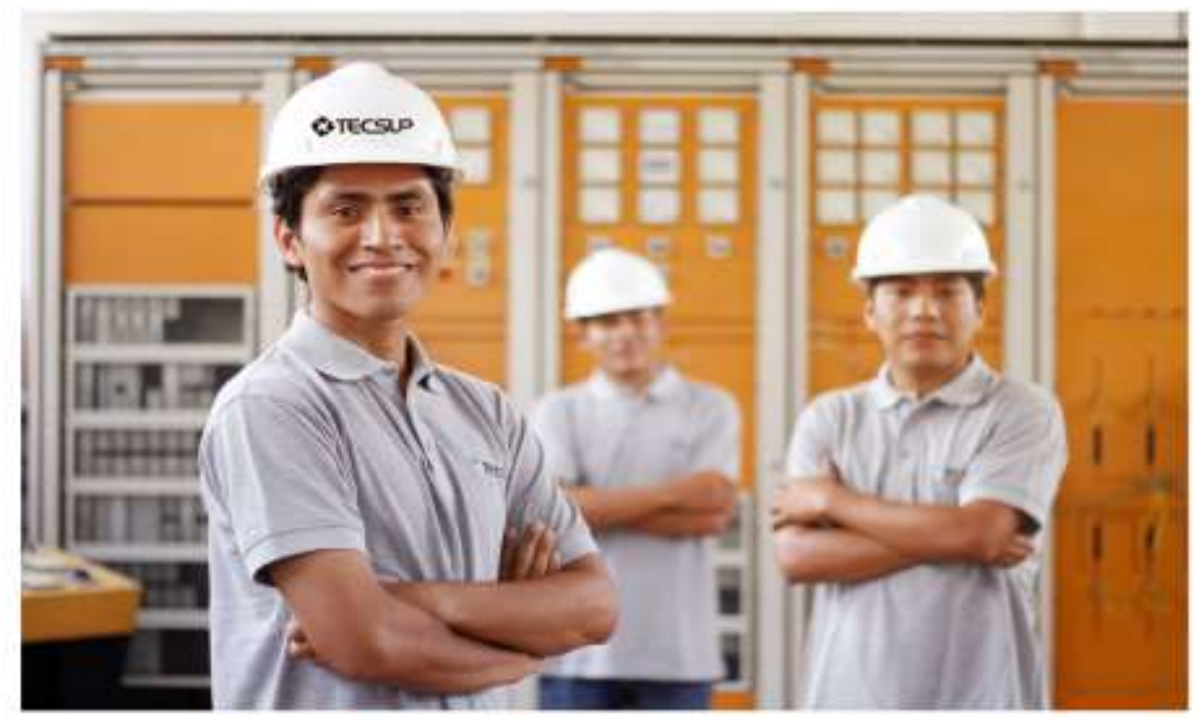

Autor:

KATHERINE PAOLA RAMIREZ ARIAS

Líma - Perú 2019 


\section{Capítulo III}

\section{Modelación de la propuesta}

\section{Introducción}

Un modelo es una construcción teórica para describir una realidad frente a una ciencia, que implica procesos y ayuda a anticiparnos a los futuros comportamientos.

Un modelo educativo, en sí, busca representar la realidad de los principales actores, así como los diversos contextos. En la educación superior, el modelo educativo debe ser la guía que comprenda la realidad de los sistemas y los subsistemas del I. E. S. T., para que luego se conviertan en indicadores de calidad educativa. El instituto educativo no va a tener rumbo definido si no tiene un modelo educativo ya establecido, el cual debe ir cubriendo las necesidades de las demandas actuales, tanto académicas como laborales.

De acuerdo con los resultados encontrados de la investigación acerca de los modelos educativos y las competencias laborales, actualmente, se propone un modelo educativo para desarrollar competencias laborales en los estudiantes del instituto educación superior de Lima, con el objetivo de contribuir con la empleabilidad de calidad de los estudiantes, así como en proponer un modelo educativo según los cambios.

La estratégica metodológica está dirigida a toda la comunidad educativa, docentes, estudiantes y administrativos.

\section{Propósito de la propuesta}

Brindar a la comunidad educativa del instituto de educación superior de Lima un modelo educativo actualizado que contribuya a desarrollar las competencias laborales de los estudiantes, así como integrar y gestionar procesos establecidos con el fin de diseñar actividades académicas y administrativas para interiorizar el modelo educativo de la institución. 


\section{Justificación de la propuesta}

Luego de una detallada observación, investigación y análisis de los resultados de los instrumentos, se propone presentar la propuesta de un modelo educativo que contribuya a desarrollar las competencias laborales de los estudiantes del instituto bajo estudio.

Es necesario mencionar que durante la investigación se encontró que el instituto educativo no cuenta con un modelo educativo actualizado; esto a que cada departamento académico, así como las áreas administrativas, tiene sus propios procesos, pero no convergen en muchos casos entre sí, guiándose solo de los objetivos educacionales del área de calidad educativa. Esta deficiencia ha generado que no se tenga un orden ni sistemas integrados, además de que haya constantes cambios, para mejora de la calidad, pero no bajo un modelo educativo que guíe y prime en todo proceso de cambio y mejora.

Los estudiantes, como parte del contacto con las empresas, tienen el programa de las experiencias formativas en situación real de trabajo (contacto con la industria). Esto se da recién a partir del segundo año de estudios de manera básica mediante proyectos tecnológicos en la industria en un periodo de un mes, y en el último año mediante sus prácticas preprofesionales o profesionales.

La inserción al mundo laboral está acompañada de docentes que solo evalúan las competencias y los conocimientos técnicos, mas no las habilidades socioemocionales. A fines de minimizar esta brecha de habilidades blandas de los estudiantes, el área de servicios educativos del instituto educativo superior, ha generado actividades extracurriculares como talleres, charlas o activaciones para desarrollar y potenciar dichas habilidades.

Por otro lado, el instituto tiene comunicación directa con las empresas del medio, pero no hay un sistema en el cual se pueda tener un reservorio digital o físico de esta información y generar 
oportunidad de mejora en las áreas de la formación de los estudiantes. Esta comunicación con las empresas es una ventaja que se puede potenciar.

Por todo lo expuesto anteriormente, se propone un modelo educativo que ayudará a desarrollar las competencias laborales de los estudiantes del instituto superior de Lima.

\section{Fundamento psicológico}

Los estudiantes que son parte de esta investigación, se encuentran en el último año de estudios y oscilan entre edades de 18 a 20 años; sus características, así como sus rasgos de personalidad y sus procesos afectivos, están aún en proceso de madurez.

Asimismo, en este periodo, está aún en proceso su autoconcepto en un contexto diferente, así como la relación de su proceso cognitivo y social. Por tal motivo es importante entender ello, para que los docentes y la comunidad educativa puedan entenderlos, orientarlos y guiarlos en una adecuada formación.

Otro punto para tomar en cuenta es el perfil del estudiante, muchos de ellos provienen de familiares disfuncionales (Padres separados), el $90 \%$ de los estudiantes son de sexo masculino, el nivel socioeconómico de sus hogares se encuentra entre D y E, provienen de colegios estatales y de varios departamentos de Perú, con creencias particulares, entre otros. Estas características hacen así, un proceso más complejo en la formación en sus competencias laborales.

Bandura (1987) postula que una persona, para conseguir un rendimiento o desempeño adecuado en una actividad específica, no solo tiene involucrados sus conocimientos y sus habilidades propias para la tarea a realizar, sino además la característica del contexto, cómo ello puede motivar a un buen desempeño; en otras palabras, el ambiente influye en el comportamiento y viceversa, lo cual deja generando aún el constructo de personalidad del estudiante. La teoría que postula Bandura (1984) indica que la persona aprende por modelado; es decir, tiene un modelo 
que imitar y que involucra un proceso que empieza con la atención, sigue la retención, luego la reproducción y, por último, la motivación, ya sea con refuerzos o castigos.

Esta teoría nos ayuda mucho a entender cómo aprenden loes estudiantes ya sea en las aulas o en las empresas, con el fin de completar las competencias requeridas para cada carrera.

Del mismo modo, tenemos otros autores, tales como Vielma y Salas (2000) y Busot (1997), quienes citan a Bandura, Piaget, Bruner, Ausubel y Vygotsky, entre otros investigadores.

\section{Fundamento pedagógico}

El propósito de la institución educativa es la formación de personas de bien, con el objetivo de contribuir con su sociedad. Es por ello que se adopta el aprendizaje constructivista (Piaget, 1979), en el cual los estudiantes aprenderán con el contacto del medio, en el cual ellos consolidarán sus conocimientos y sus aprendizajes a través del contacto directo con las empresas.

El aprendizaje constructivista aporta no solo en la forma del aprendizaje, sino a los procesos que el ser humano aprende y con los cuales transforma su realidad. El estudiante va a lograr los objetivos en función de la interpretación que denomine. Por otra parte, Vygotsky (1978) considera que esta interacción es parte del contacto con el medio social, con el contexto. El ser humano va a ir en constante aprendizaje, ya sea como parte de él o de lo que el entorno le dé como insumo.

Dentro del marco legal de Perú, los actuales Lineamientos Académicos Generales para los Institutos de Educación Superior y Escuelas de Educación Superior Tecnológica generales incluyen, en el punto 10, el enfoque pedagógico, recalcando la formación de alternancia, formación

que se puede desarrollar en dos o más contextos de aprendizaje, ya sea en el I. E. S. T., empresa o comunidad, con el fin de lograr las competencias vinculadas al programa de estudio. 


\section{Fundamento curricular}

La propuesta del modelo educativo para desarrollar las competencias laborales tiene como base los Lineamientos Académicos Generales para los Institutos de Educación Superior y Escuelas de Educación Superior Tecnológica, bajo la ley n. 30512, Ley de Institutos y Escuelas de Educación Superior y de la Carrera Pública de sus Docentes.

La ley n. ${ }^{\circ} 30512$ estipula brindar calidad en los estudios técnicos, con una normativa que regule los procesos de la adecuada formación profesional de los estudiantes, los mismos que en los lineamientos académicos desmenuza para su mejor entendimiento; de ese modo, en el punto de organización curricular, hace la diferencia entre las competencias que el estudiante debe tener para insertarse al mundo laboral, respecto a la parte de organización curricular.

La primera es la competencia técnica, competencia que implica conocimientos, destrezas y actitudes que debe poseer el estudiante sobre su materia académica y que le permita un óptimo desempeño laboral.

La segunda son las competencias para la empleabilidad, aquí sí detalla específicamente competencias inherentes de la persona, tales como sus características personales como sociales. Estas competencias pueden ser la adecuada forma de expresarse, ya sea de manera verbal, escrita u en otro idioma, su capacidad para resolver problemas, su adaptabilidad y su flexibilidad ante los problemas o situaciones que se le presente, su orientación al logro, su capacidad de liderazgo, su gestión de tiempo, su emprendimiento, así como el manejo de las tecnologías de información, entre otras.

La tercera competencia es más cómo el estudiante se va a interconectar con el mundo laboral actual, es así que lo denomina experiencia formativa en situación real de trabajo. Esta experiencia busca consolidar ambas competencias antes mencionadas, así como desarrollar nuevas 
competencias que su perfil profesional determine. Asimismo, incentiva a que cada carrera académica tenga la pertinencia básica en el proceso formativo para el incremento y las oportunidades de empleabilidad con mejores condiciones laborales y de calidad de vida.

\section{Fundamento socioeconómico}

La OCDE, en su informe Estrategias de competencias de la OCDE reporte diagnóstico: Perú (2016), menciona que, para incrementar la productividad y la competitividad del país, es necesario brindar educación superior de calidad, sustentada por la demanda del mercado laboral, para que la oferta sea variada y real.

Del mismo modo, la ley n. ${ }^{\circ} 30612$ asevera que se fundamenta por las demandas del sector productivo del país, ofreciendo oportunidades laborales calificadas. Con ello se busca la mejora de mano calificada y que los estudiantes técnicos tengan la posibilidad de desempeñarse eficientemente en diversos puestos de trabajo; a mayor oportunidad laboral, mayor será el incremento económico del país.

El Informe Anual del Empleo 2018, del Ministerio de Trabajo y Promoción del Empleo, manifestó que la economía creció un 4 \%, mientras que el empleo nacional registró un aumento de 1,6\%. Asimismo, la población económicamente activa (PEA) se emplea en tres grandes sectores: agricultura (38\%), servicios $(26 \%)$ y hotelería, comercio y restaurantes $(22 \%)$.

Examinando la PEA solo del sector servicios, se tienen los siguientes datos: con secundaria completa, $27 \%$; con educación superior universitaria completa, $19 \%$; con educación superior no universitaria completa, $16 \%$; y con secundaria incompleta, $14 \%$.

Por otro lado, como menciona Vygotsky (1978), el ser humano tiene influencia en su aprendizaje social y va construyendo constructos sobre la base de lo que la sociedad y su entorno le brinde. Al ver el estudiante que su entorno mejora, va a tener una mejor perspectiva y calidad 
de vida. De todo lo expuesto anteriormente, se propone el siguiente esquema gráfico funcional, el cual engloba las etapas, el estado en que se encontró la problemática y el estado ideal. 
Esquema gráfico teórico-funcional de la modelación de la propuesta

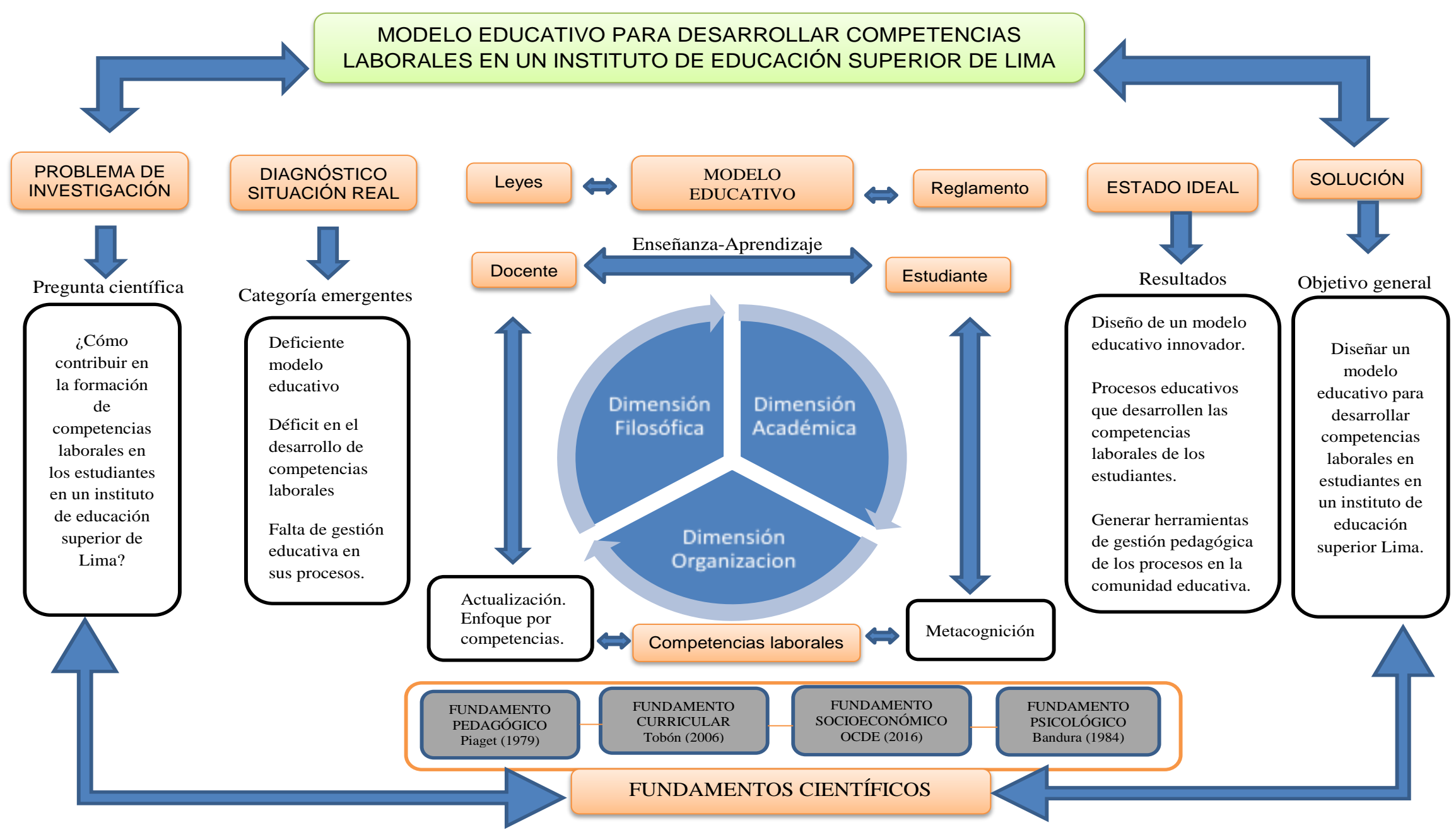

Figura 12. Diseño analógico de la propuesta de modelo educativo

Fuente: Elaboración propia (2019) 


\section{Diseño de la propuesta}

El modelo educativo está compuesto por tres dimensiones metodológicas que, a su vez, contienen componentes transversales con el fin de lograr el objetivo de esta investigación. En la propuesta se contempla a toda la comunidad educativa, y serán informados mediante capacitación, talleres (Docentes y administrativos) y, comunicados oportunos (Estudiantes) a través de las plataformas comunicacionales que se utiliza en el instituto tecnológico de Lima.

La primera dimensión es la filosófica, dimensión que implica el horizonte y esencia del instituto. Hay personal administrativo y docentes que conocen parte de la historia de la institución, pero no su misión visión y valores con claridad. Es importante revalorizar esta información, y ello será mediante actividades de una comunicación corporativa, y se contará con el apoyo del área de gestión de talento a través del worplace (Red social que usa el instituto para sus colaboradores), webinars, y comunicados oficiales.

La segunda dimensión es la académica, dimensión donde se centra el proceso de enseñanza-aprendizaje, contenidos curriculares, así como las modalidades de enseñanza (Presencial, virtual y semipresencial). En esta dimensión el rol del docente tendrá un peso importante ya que será uno de los principales actores en la eficacia de esta propuesta, y es por ello que será capacitado periódicamente en temas de habilidades o herramientas tecnológicas, así como la información del conocimiento, y se tendrá que definir claramente el perfil del docente que se necesita para cada tipo de estudiante que se tiene (Jóvenes y adultos).

La última dimensión es la de la organización. En esta dimensión se revisará y reestructurarán los procesos y protocolos de todas las áreas, para que tengan una mejor productividad y así contribuir en el desarrollo de las competencias laborales. 
Se generará reuniones con las áreas de gestión del talento, administración, tecnología de la información, comercial y académica, para que, a través de capacitaciones y una campaña de comunicación, se llegue a todos los colaboradores involucrados. En esta área, la dirección general del instituto tendrá un papel importante, ya que hasta se tendrá que obtener sistemas informáticos para los procesos.
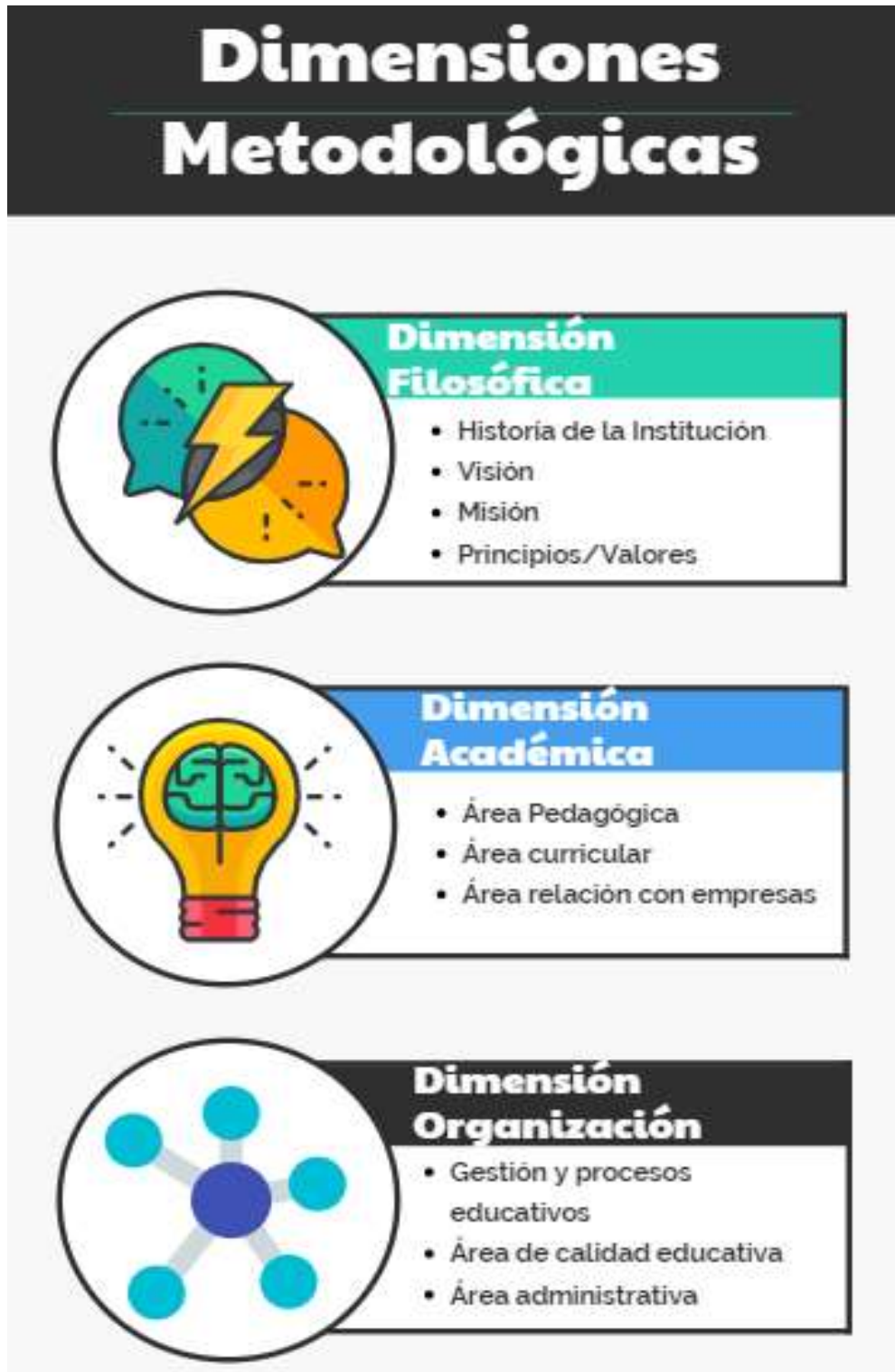

Figura 13. Dimensiones metodológicas de la propuesta Fuente: Elaboración propia (2019) 
Para que esta propuesta tenga mejor entendimiento y llegada a los involucrados, se articuló componentes transversales; estos componentes van a estar a introducidos en los itinerarios formativos, así como en los objetivos educacionales y en los resultados de medición de mejora continua. Cada componente va a estar articulado, y trabajado en cada área, tanto académica, como administrativa y comercial.

\section{Componentes transversales}

Los componentes trasversales estarán dentro de los procesos y la metodología de todas las áreas administrativas y académicas; además, será indispensable un trabajo en conjunto para el logro del objetivo de un adecuado e innovador modelo educativo que se ajuste a las necesidades del mercado, así como a los cambios generacionales de los estudiantes y la problemática social.

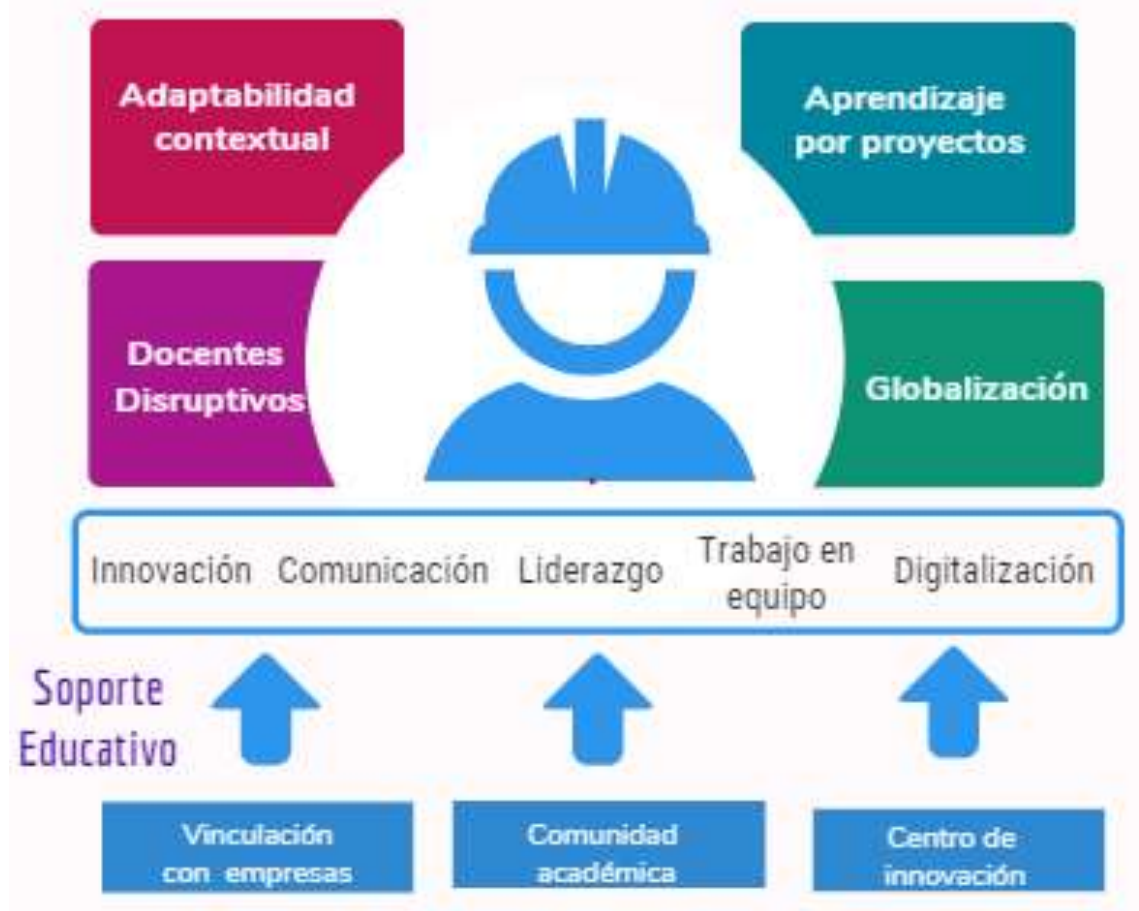

Figura 14. Componentes transversales de la propuesta Fuente: Elaboración propia (2019) 


\section{Adaptabilidad contextual.}

Los procesos y las metodologías que se utilizarán deben estar en constante cambio y adaptación, según sea la coyuntura del momento, se debe considerar el qué, el cómo, el dónde y el cuándo el estudiante desea aprender; del mismo modo, el docente debe moldearse a estas nuevas formas de aprendizaje para adaptar su forma de enseñanza. La enseñanza ya no será del todo presencial y tendrá un factor virtual o a distancia ya sea síncronas o asíncronas.

La revisión constante de las mallas curriculares, los planes de temas, así como la estrategia y la metodología de enseñanza, va a ser considerada cada cierto tiempo, siempre y cuando no afecte la información presentada de licenciamiento ante el Minedu.

\section{Aprendizaje por proyectos.}

El instituto tecnológico de Lima tiene dentro de sus estrategias de aprendizaje proyectos integradores; en cada semestre académico, cada estudiante, en grupo, presenta un proyecto que tenga impacto en la sociedad y la industria. Estos proyectos involucran conocimientos de, mínimo, tres materias que llevan en ese periodo académico.

El desarrollo del proyecto se da a lo largo del semestre, con asesorías constantes de uno o dos docentes asignados para cada grupo. Al momento de sustentar sus proyectos no solo se considerará evaluar las competencias técnicas, sino también su competencia social, participativa y metodológica.

Del mismo modo, las casuísticas así como los ejemplos que se dan en cada materia serán de corte industrial y social, con el fin de desarrollar en los estudiantes competencias laborales.

\section{Docentes disruptivos.}

Para tener estudiantes motivados, se debe tener docentes que inspiren no solo a trabajar para ganar dinero, sino a estudiar una profesión para cambiar su vida y la vida de su entorno; en otras palabras, 
mejorar su calidad de vida. Es por ello que es indispensable contar con un perfil de docentes caracterizados por ser innovadores, actualizados, vinculados a la industria y las necesidades del mundo actual y con facilidad al uso de las nuevas tecnologías digitales.

Los docentes serán uno de los pilares fundamentales en la formación de los estudiantes, estarán en todo su proceso de aprendizaje y serán las personas que reten constantemente a los estudiantes, con el fin de potenciar las habilidades y las capacidades de cada uno. Habrá docentes que serán tutores académicos, que realizarán el seguimiento académico de cada grupo asignado, con el fin de brindar soporte en las materias en que el estudiante tenga dificultades. Otro grupo de docentes serán los asesores, quienes tendrán la misión de asesorar a los estudiantes en los proyectos integradores, en sus proyectos de las pasantías y en sus proyectos de tesis, teniendo así tres estadios importantes de asesoría. Y un tercer grupo de docentes, quienes serán los que ayuden a fortalecer las competencias transversales, tales como la innovación, la comunicación, el liderazgo, el trabajo en equipo y la digitalización, y esto será mediante sus materias asignadas.

\section{Globalización.}

La necesidad actual de un mundo más interconectado hace que las personas nos movilicemos más y, con ello, se propone el intercambio estudiantil de los estudiantes, ya sea con otros institutos dentro del país, así en el extranjero, sin dejar de lado a universidades que tienen el mismo o similar modelo del instituto. Estos intercambios se pueden dar para que estudien un semestre académico en el otro instituto o puedan realizar una pasantía o realización de un proyecto. Del mismo modo, la movilización de los docentes también es fundamental con el fin de generar nuevas o mejores prácticas pedagógicas.

Esta globalización implica que el área de internacionalización genere más convenios con institutos que tengan similitud en sus mallas curriculares para que mayor cantidad de estudiantes 
tengan esta experiencia internacional e intercambio en el campus o sede. Este componente obliga a que los estudiantes tengan, como mínimo, el manejo de otro idioma extranjero (como base, el inglés) u otro idioma que el estudiante considere que se habla en el país donde realizará el intercambio.

Las competencias laborales que se estarían desarrollando desde el primer ciclo a través de estrategias didácticas, así como actividades extracurriculares son las siguientes:

\section{Competencias \\ Laborales}

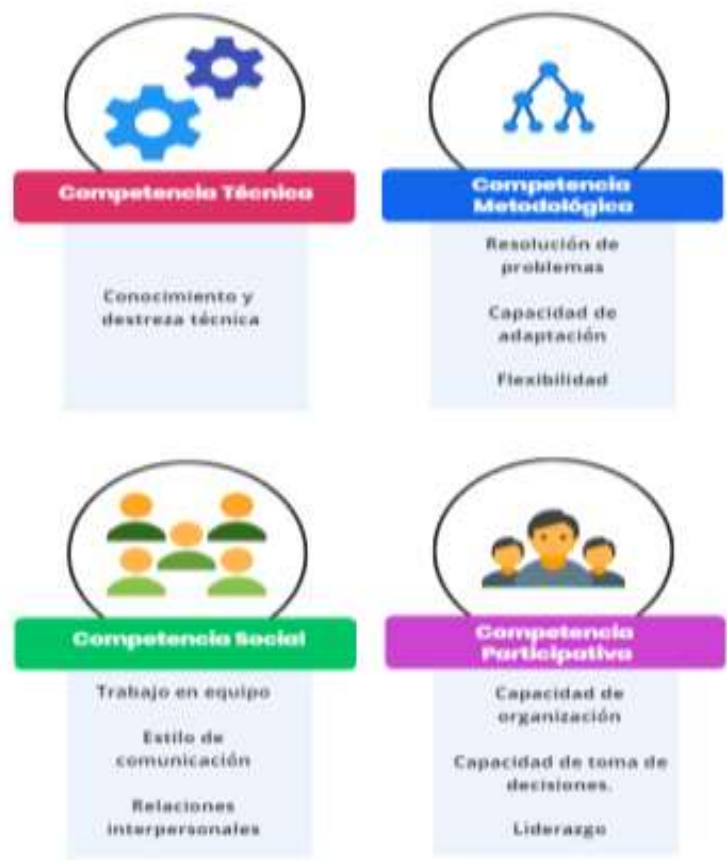

Figura 15. Componentes laborales transversales de la propuesta Fuente: Elaboración propia (2019)

Son cuatro las competencias laborales que se estarían desarrollando: competencia técnica, competencia metodológica, competencia social y competencia participativa. De estas cuatro competencias se despliegan otras más que van a ayudar en la obtención de dicha competencia, las cuales se denominan subcompetencias. 


\section{Dimensión filosófica}

La educación que imparte el instituto bajo investigación tiene en la comunidad técnica una buena reputación no solo por la inserción laboral que tienen sus recién egresados, sino por la calidad de sus conocimientos técnicos y el sentido humano.

Para enfrentar los cambios de estas nuevas generaciones, así como económicos y sociales, es importante que el instituto complemente la formación de estudiantes con responsabilidad social. Además, el instituto genera actividades que contribuyen en la formación multicultural, así como estrategias de campaña de valores y de reconocimientos de hechos históricos.

En esta dimensión estamos contemplando el objetivo de la institución, tal como su misión, su visión y sus principios éticos.

\section{Historia del instituto tecnológico de Lima.}

El instituto fue creado el 14 de agosto de 1984 por Luis Hochschild Plaut como una asociación privada sin fines de lucro gracias al apoyo del ingeniero Rodolfo Beeck, quien era su cuñado, además de un grupo de empresarios peruanos, quienes, preocupados por el desarrollo técnico, decidieron aportar en este gran reto. Inicialmente, tuvieron la propuesta de una oferta educativa que pueda cubrir la brecha que había en aquel entonces entre el ingeniero y los técnicos. El término que ellos usaron fue el de 'tecnólogo', vocablo empleado en Europa (Alemania, específicamente, de donde provenía Luis Hochschild). El tecnólogo era el técnico capaz de gestionar y coordinar entre el ingeniero de campo y el técnico con el fin de obtener resultados óptimos.

Su primer campus inició en 1984 en Santa Anita, Lima. A modo de inicio, arrancaron con tres carreras; luego, al cabo de unos años, se crearon tres carreras académicas más, con lo cual se tuvo un total de seis. Como la demanda era grande, se fundó el segundo campus en 1993 y esta vez se dio en Arequipa, con el fin de brindar soporte a la minería del sur del país. Después de estar 
ya posicionados en dos ciudades importantes del país, decidieron tener la tercera sede y en esta oportunidad se creó el campus en Trujillo en 2008; en este campus las carreras están orientadas al rubro de la zona, es decir, agrícola y de minería.

Actualmente, el instituto oferta dieciocho carreras académicas de tres y dos años a nivel técnico y profesional técnico, y sigue brindando educación a jóvenes de todo el país, con modalidad presencial y virtual. Para efectos de esta investigación, este modelo será propuesto para la sede de Lima (página web del instituto).

Visión.

Generar un efecto desproporcionado de bienestar en la sociedad a través de la educación.

Misión.

Formar profesionales globalmente competitivos, éticos e innovadores que cuenten con un profundo conocimiento tecnológico; asimismo, apoyar a las empresas a incrementar su productividad y valor.

Principios.

El instituto contempla los siguientes principios como parte de su cultura organizacional, los cuales han sido extraídos de su portal web.

\section{Innovación.}

Crear y desarrollar, en la comunidad de innovadores, soluciones de gran impacto en la sociedad, a través de nuevos productos o servicios con valor agregado.

\section{Impacto social.}

Formar personas íntegras que, a través de la educación, tienen el poder de transformar el presente y crear el futuro de nuestra sociedad. 


\section{Calidad.}

Brindar atención genuina a las necesidades de nuestros clientes de manera ágil y constante, con el fin de satisfacerlos más allá de sus expectativas.

\section{Ética.}

Actuar siempre con integridad, honestidad y respeto a la diversidad, siendo un referente para nuestro entorno.

\section{Trabajo colaborativo.}

Promover la comunicación y el liderazgo participativo en toda la organización, con el propósito de superarnos constantemente.

Como pueden ver, teniendo en cuenta esta información, el modelo educativo que se estaría siguiendo debe tener como pilar su visión y su misión, para así saber en qué se estaría formando a los estudiantes de manera integral.

\section{Dimensión académica}

Esta dimensión contribuye a la formación de competencias profesionales de los estudiantes (técnicas y laborales). Dimensión que contemplan los procesos de enseñanza-aprendizaje, las mallas curriculares, las estrategias didácticas, así como la formación en empresas para todas las carreras académicas técnicas profesionales, técnicas, como cursos o programas cortos o a la medida. También se tendría en cuenta la empleabilidad y las experiencias formativas en situación real de trabajo.

La propuesta académica del instituto debe ser a dos niveles: el primero es el estudio del grado de técnico profesional o bachiller técnico, y luego apoyar al egresado a obtener su título técnico; el segundo es la especialización técnica el cual brinda mayor conocimiento especializado en sus disciplinas. 
El área académica, bajo dirección académica, debe liderar los procesos de esta área. Incluye las políticas y las normas que deben seguir las tres sedes para brindar una educación de calidad y cumplir con las exigencias del mercado laboral actual.

El organigrama del área académica es el siguiente:

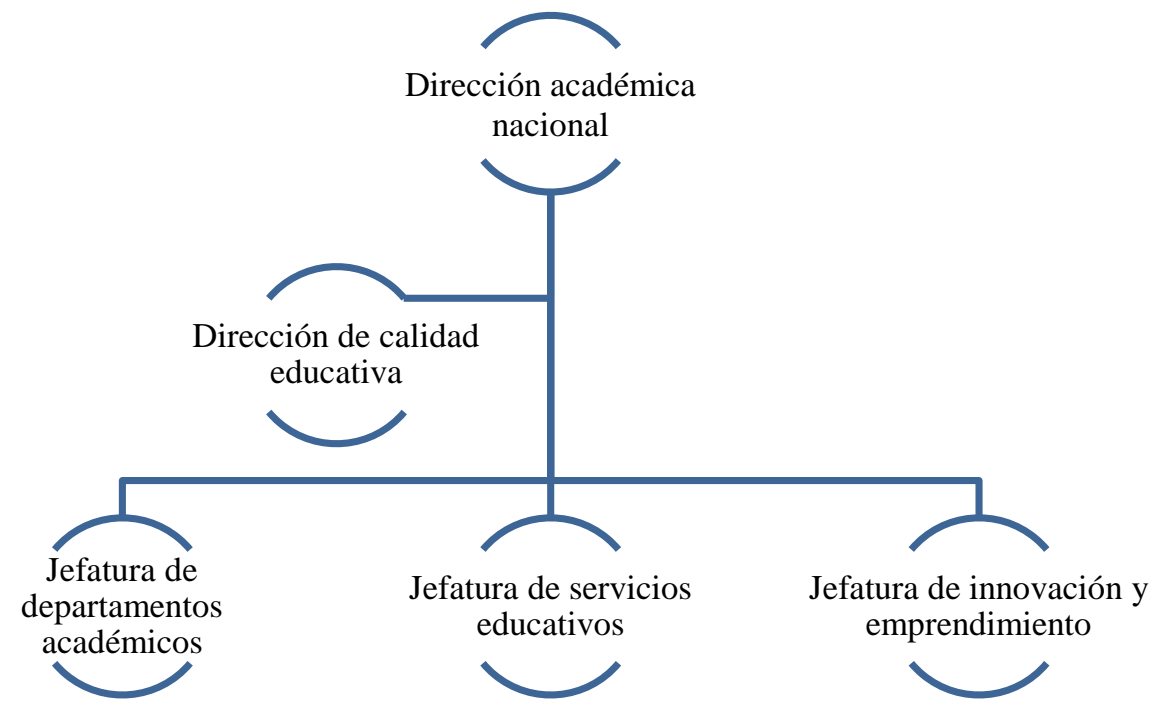

Figura 16. Propuesta del organigrama del área académica Fuente: Elaboración propia (2019).

El instituto cuenta con 15 carreras académicas del programa de formación regular de tres años, organizadas en 6 departamentos académicos:

i. Departamento de minería y procesos químicos-metalúrgicos

ii. Departamento de mecánica y aviónica

iii. Departamento de electricidad y electrónica

iv. Departamento de tecnología digital

v. Departamento de diseño y producción industrial

vi. Departamento de estudios generales 
El instituto ofrece programas académicos para estudiantes escolares, jóvenes y adultos, bajo modalidades de presencial, semipresencial y virtual; y bajo estas modalidades, deben adecuarse en sus procesos de enseñanza y aprendizaje.

\section{Área psicopedagógica.}

Con el fin de consolidar el modelo educativo del instituto de Lima, es necesario conceptualizar los procesos académicos que implican sus competencias genéricas y específicas. Las competencias genéricas son las competencias comunes en todas las carreras, como innovación, investigación, comunicación, pensamiento abstracto y crítico, así como las habilidades interpersonales. Las competencias específicas son las competencias técnicas y propias de cada carrera, tales como comprender manuales eléctricos, procesos mineros, gestión de mantenimiento, aplicativas de software, entre otras. Si bien es cierto que el rubro del instituto son las carreras tecnológicas industriales, dentro de las mismas hay diferencias, las cuales son propias de saber hacer dentro de su campo específico laboral.

En esta área se contendrán los procesos de enseñanza-aprendizaje, así como las estructuras psicológicas de los estudiantes para identificarlas y ayudarlas a lograr el objetivo de sus competencias. Por otro lado, también se trabajaría con los docentes en metodologías didácticas activas, metodologías ágiles como medio de enseñanza.

Mediante estrategias y con el trabajo articulado de los departamentos académicos, así como servicios educativos, se deben generar actividades extracurriculares que ayuden al desarrollo de las cuatro competencias laborales propuestas.

\section{Proceso de aprendizaje.}

Se entiende como aprendizaje el proceso cíclico que tiene una persona para adquirir, entender, procesar y aplicar información, habilidades, conocimientos y experiencias. El aprendizaje es 
resultado de la interacción de varios procesos cognitivos básicos o superiores, tales como la atención, la percepción, la memoria, el lenguaje, el pensamiento y la inteligencia.

El estudiante, siendo el protagonista de este proceso cognitivo, es quien debe lograr la competencia metacognitiva, en la cual pueda aplicar todos sus conocimientos y sus experiencias en diversas situaciones dependiendo el contexto. Este proceso lo debe realizar mediante un docente inspirador y estrategias didácticas que estén acorde a la necesidad de él y de lo que suceda a su alrededor. En síntesis, el estudiante debe aprender a hacer.

\section{Contenidos educativos.}

Las carreras académicas que se imparten en el IEST son especialidades que están ligadas al avance tecnológico y a la evolución que se está llevando actualmente, es por ello la importancia de la relación cercana entre el instituto y las industrias nacional e internacional.

Los contenidos de los programas académicos deben contemplar los conceptos teóricos (saber conocer), la práctica o componente procedimental (saber hacer), así como un sentido ético (saber ser y saber convivir), con el fin de formar profesionales íntegros.

Para esto, es necesario que constantemente se revisen y actualicen los contenidos vertidos en las mallas curriculares, así como el material didáctico que se brinda a la comunidad estudiantil, esto con el fin de proporcionar conocimientos relevantes y necesarios para cuando salgan al mercado laboral y que su inserción sea efectiva.

Es importante contemplar que cada malla curricular debe estar dividida por módulos (según la Ley de Institutos, n. ${ }^{\circ}$ 30512), en las carreras que trata esta investigación son tres módulos, y que cada uno debe alcanzar las competencias necesarias para la vida técnica profesional y de la pertinencia de contenidos. 


\section{Estrategias didácticas.}

El proceso educativo se da entre el estudiante y el docente; ambos sujetos generan una interacción que debe ser recíproca y de formación que contribuya recíprocamente. A este tipo de intercambio se le denomina relación didáctica.

Cada docente, ya habiendo entendido y comprendido a su comunidad estudiantil, debe aplicar estrategias que generen y faciliten el aprendizaje en sus estudiantes. Es necesario e importante que el docente entienda un factor que está tomando mucha fuerza y es cambio generacional, que está generando que los docentes modifiquen o adapten sus estrategias según sea su comunidad estudiantil.

Una propuesta son las estrategias de metodologías ágiles, la cual, a través de proyectos de casuísticas reales, genera y fomenta el logro de la competencia de cada materia. Esta estrategia ayuda en el desarrollo de la creatividad, del pensamiento disruptivo, a la flexibilidad del aprendizaje, así como a la esquematización del problema.

Otra estrategia que se propone es el aula invertida, en donde los estudiantes ya vienen con el concepto o tarea previamente generada y en el aula es donde se debate, según la información que cada estudiante puede aportar. En esta estrategia no solo se aprende los conceptos, sino a debatir, así como generar análisis de este. En esta estrategia el docente es el modelador y el guía; no es que el docente no vaya a hacer la sesión de clases, sino que va a contribuir en el desarrollo de la competencia de la sesión o tema, así como en la consolidación de un objetivo educacional.

Aparte de las estrategias que cada docente considere necesarias, según sea el perfil de sus estudiantes, también debe cumplir en los planes de clases, así como sus rúbricas de clases y el desarrollo de las competencias laborales propuestas. El instituto tiene rúbricas que ya ayudan a desarrollar algunas competencias laborales. 


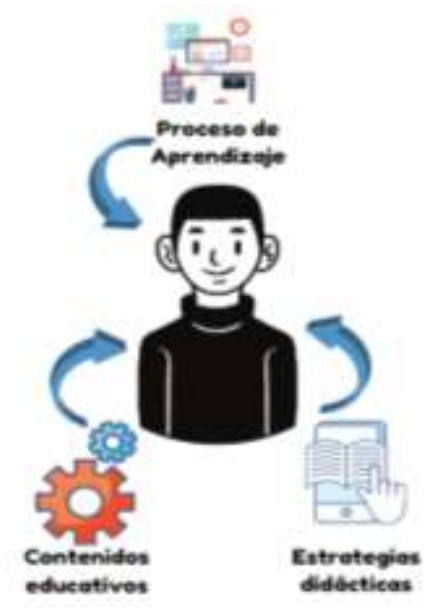

Figura 17. El estudiante, como eje primordial del proceso de aprendizaje, contenidos educativos y estrategias didácticas

Fuente: Elaboración propia (2019)

\section{Área curricular.}

Esta área involucra los planes curriculares y los programas de estudios que estén acordes a las necesidades de la industria y la propia carrera; asimismo, bebe estar regulada por la Ley de Institutos de 2016 (ley n. ${ }^{\circ}$ 30512) publicada en el diario oficial El Peruano. Con el fin de lograr los objetivos educacionales, según el perfil de técnicos profesionales, los componentes curriculares son: competencias técnicas o específicas, competencias para la empleabilidad y experiencias formativas en situación real de trabajo.

Los planes y los programas académicos deben cumplir con las pertinencias curriculares con relación a lo que el mercado laboral esté necesitando y requiriendo en sector técnico. El diseño curricular debe ser flexible y con una perspectiva holística, además de propiciar el trabajo multidisciplinario, técnico y humanista. 


\section{Área relación con las empresas.}

Área que se encargará de las relaciones con empresas, bajo las diversas oficinas o departamentos. La relación con empresas debe estar sujeta a través de convenios o alianzas para que los estudiantes puedan realizar sus experiencias formativas en situación real de trabajo bajo cualquier modalidad con el objetivo de afianzar y comprobar las competencias adquiridas en sus años de estudios; asimismo, que los docentes puedan generar proyectos tecnológicos en industrias como asesorías consultivas, a miras de obtener una oportunidad de ventas corporativas.

Este espacio debe contribuir a un espacio de diálogo directo con las empresas con el fin de encontrar una oportunidad de mejora en todos nuestros procesos.

Dentro de esta área se encuentran las experiencias formativas en situación real de trabajo, así como las modalidades formativas, según la ley n. ${ }^{\circ} 28518$ de 2005, publicada en el diario oficial El Peruano. Los proyectos integradores, en el último año, deben responder a la necesidad industrial frente a una propuesta real y, de ese modo, generar alianzas o convenios para que, a través de estos proyectos, se contribuya a la industria actual y en la formación de los estudiantes.

Las oficinas y los componentes que deben contribuir a esta área serían los siguientes:

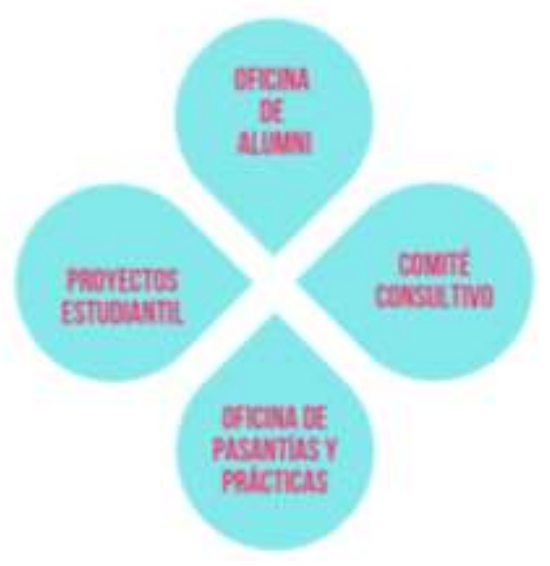

Figura 18. Propuesta de las áreas involucradas al contacto con las empresas

Fuente: Elaboración propia (2019) 


\section{Dimensión organización}

La dimensión organización vincula a las dos dimensiones anteriores, con el fin de que estén articulados bajo un soporte de procesos y gestión.

Esta dimensión vincula tanto la dimensión filosófica como la dimensión académica, ya que estaría generando la base de sus procesos, pero con la filosofía del instituto.

\section{Gestión y procesos educativos.}

Se deben generar procesos que busquen la mejora continua y faciliten el logro de metas institucionales. Se deben contemplar los siguientes procesos:

i. Proceso académico: admisión, servicios educativos, departamentos académicos, área comercial y estudios generales.

ii. Proceso administrativo: crédito educativo, tesorería, área comercial (posventa), admisión y gestión del talento.

iii. Proceso de calidad: área comercial, área académica y área administrativa. Desde la oficina de calidad educativa se debe asegurar este proceso, sin bajar los estándares ya establecidos por el instituto en las tres sedes.

iv. Proceso de integración de sistema: sistemas internos de tecnología informática, procesos transversales en las tres sedes e inteligencia de negocios.

v. Proceso de internacionalización: tanto a estudiantes como a docentes bajo la modalidad de intercambios, pasantías o convenios interinstitucionales. Este proceso debe ser liderado por el área de calidad educativa o generar una oficina de internacionalización, a fines de generar mayores convenios de cooperación interinstitucional. 


\section{Área de calidad educativa.}

Esta área debe estar en todos los procesos tanto educativos como administrativos. Aquí se deben tener en cuenta los resultados educacionales, los resultados de desempeño, así como la calidad de docentes, estudiantes, ingresantes y egresados.

Es necesario precisar que esta área debe ser transversal, tanto el área comercial, la administrativa como la académica, con el fin de lograr las metas institucionales.

El área de calidad educativa debe tener sub áreas que ayuden o acompañen a todos los procesos, hablamos de calidad educativa como calidad organizacional. Todos los procesos deben tener el mínimo estándar de calidad.

El área de calidad debe generar y asegurar que sus docentes cumplan con el perfil que buscan: innovador, tecnológico, con vocación de servicios y experiencia en la industria. Dependiendo del curso a dictar, debe tener niveles a lograr, así como grados o especializaciones. Asimismo, debe propiciar constantes capacitaciones y actualizaciones dependiendo de las nuevas necesidades ya sean tecnológicas o pedagógicas, ya que muchos docentes son profesionales en otras materias, mas no pedagogos de profesión y eso genera retraso en el proceso de enseñanza y aprendizaje.

\section{Área administrativa.}

Área que contempla las gestiones administrativas, desde la gestión del talento, así como los sistemas tecnológicos de gestión. Es importante definir aquí los procesos administrativos para la sostenibilidad económica de la institución. También se contemplaría el marco legal actual de educación y el contexto social del país.

Dentro de esta área se encontrará el área de gestión del talento, la cual va a contribuir en la gestión de las potencialidades y las competencias, ya sea de los administrativos o de los docentes; 
por ende, debe estar en constante comunicación y relación con el área de calidad docente para así generar programas de crecimiento de los colaboradores que trabajan en el instituto.

Generar manuales, flujogramas y organigramas a través de los cuales informar a todos de la comunidad educativa es una de las funciones que debe contemplar esta área.

Fases, etapas y actividades de las propuestas

Tabla 13.

Cronograma de la propuesta

\begin{tabular}{|c|c|c|c|c|}
\hline Fase & Propósito & Actividades & Detalle & Tiempo \\
\hline \multirow{2}{*}{$\begin{array}{c}\text { Fase I } \\
\text { Presentación } \\
\text { de la } \\
\text { propuesta }\end{array}$} & \multirow{2}{*}{$\begin{array}{l}\text { Informar a los } \\
\text { directivos sobre la } \\
\text { propuesta de la } \\
\text { modelación. }\end{array}$} & $\begin{array}{l}\text { 1.1 Presentación de } \\
\text { propuesta a } \\
\text { implementar. }\end{array}$ & $\begin{array}{l}\text { Reunión con las direcciones } \\
\text { académicas, administrativas, } \\
\text { comerciales y de calidad educativa, } \\
\text { se mostrará la propuesta del modelo } \\
\text { educativo para desarrollar las } \\
\text { competencias laborales. }\end{array}$ & 7 días \\
\hline & & $\begin{array}{l}\text { 1.2. Reunión con la } \\
\text { dirección de calidad } \\
\text { educativa }\end{array}$ & $\begin{array}{l}\text { Se presentará y detallará las acciones } \\
\text { para el área académica, tanto a jefes } \\
\text { académicos como a docentes y } \\
\text { estudiantes. }\end{array}$ & 7 días \\
\hline $\begin{array}{c}\text { Fase II: } \\
\text { Desarrollo }\end{array}$ & $\begin{array}{l}\text { Implementar la } \\
\text { propuesta a toda la } \\
\text { comunidad } \\
\text { educativa }\end{array}$ & $\begin{array}{l}\text { 2.1. Sensibilizar a toda } \\
\text { la comunidad } \\
\text { educativa del IES con } \\
\text { una campaña } \\
\text { comunicacional en } \\
\text { etapas. }\end{array}$ & $\begin{array}{l}\text { Primera } \\
\text { Gestionar webinars y comunicados } \\
\text { oficiales a los docentes sobre el } \\
\text { enfoque del modelo educativo } \\
\text { propuesto. } \\
\text { Se capacitará a los docentes en las } \\
\text { competencias laborales que se } \\
\text { desarrollará en los estudiantes. Estas } \\
\text { capacitaciones serán en } 3 \text { grupos: } \\
\text { Docentes especialistas, docentes } \\
\text { completos y docentes parciales. } \\
\text { Segunda etapa: } \\
\text { Coordinación con servicios } \\
\text { educativos sobre los comunicados y } \\
\text { videos que se enviarán a los } \\
\text { estudiantes sobre el enfoque del } \\
\text { modelo educativo propuesto. } \\
\text { Se utilizará la herramienta digital de } \\
\text { correos, site del estudiante, así como } \\
\text { el app y la plataforma digital para } \\
\text { comunicar a los estudiantes. }\end{array}$ & 15 días \\
\hline
\end{tabular}




\subsection{Actualizar los contenidos curriculares}

Informar el plan de trabajo que detallará la ejecución de la propuesta.

Se revisará los planes curriculares, así como el plan de mejora continua con cada objetivo educacional de cada unidad didáctica. Los coordinadores académicos actualizarán esta información para cada unidad didáctica, con el fin de cumplir los objetivos educacionales. En las rúbricas de cada evaluación, se contemplará las competencias comunicativas y participativas, además de las competencias técnicas de cada unidad didáctica, a medida que se avance de ciclo, la complejidad de las competencias a evaluar, serán de 1 a 3 puntos.

Con el área de procesos y mejora contínua, se revisarán y actualizarán los procesos administrativos $\mathrm{y}$ educativos.

Generación de reuniones y mesa de trabajo con cada área (Académico, comercial, administrativo y $\mathrm{TI}$ ) para revisar cada proceso que tienen a su cargo. Se generará un manual de

2.2.Fortalecer los procesos educativos organizacionales procesos institucionales.

Reunión con el área de tecnología de la información para revisar la actualización de los sistemas tecnológicos internos y que estén 20 días interconectados entre sí.

Con el área de gestion de talentos se actualizará en manual de puestos y de funciones, así como el perfil del docente que debe tener la institución educativa.

Reuniones y planes de trabajo con el área de servicios educativos para generar los cronogramas de charlas y talleres de desarrollo profesional así

2.3. Generar actividades extracurriculares para desarrollar las competencias laborales. como de inducción al mundo laboral.

Las charlas y talleres serán dadas de manera progresiva, donde el primer año de estudios se tratará temas como el autoconcepto, autoestima y autoconomiento. En el segundo año se trabajará competencias sociales y participativas $y$, en el tercer año, competencias participativas. 


\begin{tabular}{|c|c|c|c|c|}
\hline & & $\begin{array}{l}\text { 2.4. Gestionar } \\
\text { convenios } \\
\text { internacionales para } \\
\text { intercambios }\end{array}$ & $\begin{array}{l}\text { Las oficina de pasantías y prácticas y } \\
\text { de alumni, con el apoyo de la } \\
\text { dirección de calidad educativa, } \\
\text { revisará el listado de universidades e } \\
\text { institutos en el extranjero para } \\
\text { realizar los diferentes convenios } \\
\text { académicas y de movilidad } \\
\text { estudiantil, esto con el fin de } \\
\text { proporcionar el componente de } \\
\text { globalización. }\end{array}$ & 15 días \\
\hline & & académicos & $\begin{array}{l}\text { El centro de idiomas "Conversa", } \\
\text { potenciará sus ofertas de estudios en } \\
\text { idiomas (Portugués, francés, alemán } \\
\text { y chino) que ayudarán a la } \\
\text { globalización de los estudiantes; del } \\
\text { mismo modo. Contratación de } \\
\text { docentes }\end{array}$ & 30 días \\
\hline \multirow{7}{*}{$\begin{array}{c}\text { Fase III: } \\
\text { evaluación }\end{array}$} & \multirow{7}{*}{$\begin{array}{l}\text { Evaluar el resultado } \\
\text { mediante } \\
\text { herramientas de } \\
\text { desempeño a } \\
\text { docentes, } \\
\text { estudiantes y } \\
\text { administrativos. }\end{array}$} & \multirow{4}{*}{$\begin{array}{c}\text { 3.1. Generar un } \\
\text { sistema de evaluación } \\
\text { para las áreas } \\
\text { académicas y } \\
\text { administrativas. }\end{array}$} & $\begin{array}{l}\text { Reunión con Gestión del talento para } \\
\text { diseñar y difundir e sistema de } \\
\text { evaluación de desempeño que } \\
\text { cumpla con el objetivo de la } \\
\text { modelación. }\end{array}$ & 2 días \\
\hline & & & $\begin{array}{l}\text { Revisión con cada líder la propuesta } \\
\text { de la evaluación. }\end{array}$ & 7 días \\
\hline & & & $\begin{array}{lll}\text { Generar un cronograma } & \text { de } \\
\text { comunicación y ejecución } & \text { de } \\
\text { evaluación de desempeño } & \\
\end{array}$ & 2 días \\
\hline & & & Revisión y análisis de resultados. & 5 días \\
\hline & & \multirow{3}{*}{$\begin{array}{l}\text { 3.2. Evaluar el } \\
\text { desempeño de los } \\
\text { estudiantes en sus } \\
\text { experiencias } \\
\text { formativas en } \\
\text { situación real de } \\
\text { trabajo }\end{array}$} & $\begin{array}{l}\text { Reuniones con las empresas para que } \\
\text { nos brinden información acerca de } \\
\text { las competencias laborales de } \\
\text { estudiantes y egresados. }\end{array}$ & 15 días \\
\hline & & & $\begin{array}{l}\text { Revisión de las fichas de evaluación } \\
\text { por estudiante y programa } \\
\text { académico. }\end{array}$ & 15 días \\
\hline & & & $\begin{array}{l}\text { Análisis de los resultados. } \\
\text { Oportunidad de mejora. }\end{array}$ & 5 días \\
\hline
\end{tabular}

Fuente: Elaboración propia (2019) 


\section{Validación de la propuesta por juicio de especialista}

A fines de validar la propuesta del modelo educativo para desarrollar competencias laborales en los estudiantes en un instituto de Lima, se aplicó la técnica de juico de expertos, la cual constataba de valoración interna como externa. Los expertos consultados fueron tres, quienes, con su conocimiento en la materia académica y sus años de experiencia en el campo educativo, pudieron brindar su validación.

Tabla 14.

Expertos seleccionados para validar los instrumentos

\begin{tabular}{ccccc}
\hline $\begin{array}{c}\text { Nombres y } \\
\text { apellidos }\end{array}$ & $\begin{array}{c}\text { Grado } \\
\text { académico }\end{array}$ & $\begin{array}{c}\text { Especialidad } \\
\text { profesional }\end{array}$ & Ocupación & $\begin{array}{c}\text { Años de } \\
\text { experiencia }\end{array}$ \\
\hline $\begin{array}{c}\text { Ronal Garnelo } \\
\text { Escobar }\end{array}$ & Doctor & $\begin{array}{c}\text { Educación en } \\
\text { Políticas Públicas }\end{array}$ & $\begin{array}{c}\text { Docente } \\
\text { investigador }\end{array}$ & 20 años \\
\hline $\begin{array}{c}\text { Miriam Velázquez } \\
\text { Tejeda }\end{array}$ & Doctora & Educación & $\begin{array}{c}\text { Docente } \\
\text { investigador }\end{array}$ & 20 años \\
\hline $\begin{array}{c}\text { Félix Fernando Goñi } \\
\text { Cruz }\end{array}$ & Doctor & $\begin{array}{c}\text { Ciencias de la } \\
\text { Educación }\end{array}$ & $\begin{array}{c}\text { Docente } \\
\text { superior }\end{array}$ & 17 años \\
\hline
\end{tabular}

Fuente: Elaboración propia a partir de la ficha de validación de la propuesta metodológica USIL (2020)

\section{Valoración interna y externa.}

Para la realización de la valoración, se utilizaron dos fichas con criterios e indicadores cuantitativos y cualitativos. Referente a la valoración cuantitativa, se tiene una escala que se distribuye de la siguiente manera: a) deficiente, b) bajo, c) regular, d) bien y e) muy bien. 
Tabla 15.

Tabla de valoración

\begin{tabular}{cc}
\hline Escala & Rango \\
\hline Deficiente & $0-25$ \\
\hline Bajo & $26-50$ \\
\hline Regular & $51-70$ \\
\hline Bien & $71-85$ \\
\hline Muy bien & $86-100$ \\
\hline
\end{tabular}

Fuente: Elaboración propia a partir de la ficha de validación de la propuesta metodológica USIL (2020).

En relación con el análisis de la valoración cuantitativa, los especialistas hicieron una valoración tanto interna como externa según sus respectivos análisis. El primer especialista nos dio como resultado una valoración final de $88 \%$, el segundo especialista nos evaluó con un resultado final de $88 \%$ y el último y tercer especialista, con un resultado final de $84 \%$. Como resultados, se obtuvo de puntuación un 84 \% de aceptación; ello encaja en una valoración de muy bien respecto a la propuesta presentada, lo cual resuelve la necesidad de esta investigación.

Tabla 16.

Resultados de valoración interna y externa por expertos

\begin{tabular}{ccccc}
\hline $\begin{array}{c}\text { Nombres y } \\
\text { apellidos }\end{array}$ & $\begin{array}{c}\text { Grado } \\
\text { académico }\end{array}$ & $\begin{array}{c}\text { Valoración } \\
\text { interna }\end{array}$ & $\begin{array}{c}\text { Valoración } \\
\text { externa }\end{array}$ & $\begin{array}{c}\text { Valoración } \\
\text { final }\end{array}$ \\
\hline Ronal Garnelo Escobar & Doctor & 44 & 44 & $88 \%$ \\
\hline Miriam Velázquez Tejeda & Doctora & 46 & 42 & $88 \%$ \\
\hline Félix Fernando Goñi Cruz & Doctor & 42 & 42 & $84 \%$ \\
\hline
\end{tabular}

Fuente: Elaboración propia a partir de la ficha de validación de la propuesta metodológica USIL (2019) 
Tabla 17.

Tabla de valoración general

\begin{tabular}{cc}
\hline Escala & Rango \\
\hline Deficiente & $20 \%-35 \%$ \\
\hline Bajo & $36 \%-51 \%$ \\
\hline Regular & $52 \%-67 \%$ \\
\hline Bien & $68 \%-83 \%$ \\
\hline Muy bien & $84 \%-100 \%$ \\
\hline
\end{tabular}

Fuente: Elaboración propia a partir de la ficha de validación de la propuesta metodológica USIL (2020) 


\section{Conclusiones}

Al terminar el proceso de investigación, con el desarrollo de la propuesta del modelo educativo para desarrollar las competencias laborales, se describen las conclusiones:

\section{Primera}

El proceso investigativo permitió que cumpla con el objetivo general de diseñar una propuesta de modelo educativo para desarrollar competencias laborales en los estudiantes de un instituto de educación superior de Lima, cumpliendo con dar respuesta a la pregunta científica principal de la investigación.

\section{Segunda}

Se realizó el diagnóstico del estado actual de las competencias laborales de los estudiantes de un instituto de educación superior de Lima, mediante el desarrollo del trabajo de campo, en el cual se aplicaron diversas técnicas e instrumentos de recolección de datos, se analizó la información encontrada de las unidades de análisis, lo cual permitió encontrar deficiencias de este, así como fortalezas. De tal forma, se cumplió con la primera tarea científica.

\section{Tercera}

Se sistematizaron los fundamentos teóricos y científicos acerca de los modelos educativos y competencias laborales en la actualidad, así como las evoluciones que ambas categorías y subcategorías propias de la investigación han tenido a lo largo del tiempo. Esta sistematización permitió encontrar un pobre sustento de investigación acerca de las competencias laborales en los estudiantes de un instituto tecnológico de Lima. Dicho de otro modo, se alcanzó la segunda tarea científica. 


\section{Cuarta}

Para desarrollar la propuesta de un modelo educativo, se considera información teórica y actualizada durante el proceso de investigación. Los resultados obtenidos en el trabajo de campo, así como las categorías emergentes ayudaron a la propuesta para desarrollar las competencias laborales. El modelo contempla la generación de competencias laborales en los estudiantes. Se logró la tercera tarea científica.

\section{Quinta}

Se validó de manera positiva la propuesta de un modelo educativo para el desarrollo de las competencias laborales de los estudiantes, propuesta que implica un modelo integral e innovador que comprende a toda la comunidad educativa del instituto con el objetivo de mejorar la inserción al mercado laboral de los estudiantes. De esta manera, se cumplió con la cuarta tarea científica. 


\section{Recomendaciones}

\section{Primera}

Aplicar la propuesta de un modelo educativo para desarrollar competencias laborales en los estudiantes del instituto que es parte de esta investigación, con el fin de generar una mejor y rápida inserción al mercado laboral de sus estudiantes y sus egresados.

\section{Segunda}

Brindar el valor sustancial a las competencias laborales, así como a las competencias técnicas, ya que, a partir de ello, en muchos casos, las empresas solo evalúan estas competencias, puesto que se consideran las habilidades o destrezas propias del estudiante.

\section{Tercera}

Proponer talleres de habilidades socioemocionales o de competencias laborales desde el primer ciclo, mediante el curso de desarrollo personal, y generar una estructura sistematizada hasta el último ciclo, esto con el fin de identificar y potenciar las competencias que tiene cada estudiante.

\section{Cuarta}

Generar capacitaciones o talleres con los docentes para brindarles información actualizada acerca del impacto y la importancia de poseer adecuadas competencias laborales para un mejor desempeño profesional. 


\section{Referencias}

Aguirre, R. (2015). Análisis de la educación superior no universitaria en el Perú y su relación con el desarrollo económico nacional: la experiencia del instituto superior tecnológico privado peruano de sistemas "Sise" en Lima Metropolitana y los retos de la educación superior no universitaria. (Tesis de maestría inédita). Universidad Nacional Mayor de San Marcos, Lima. Recuperada de http://cybertesis.unmsm.edu.pe/handle/cybertesis/4492.

Alfaro, S. (2011). Competencias profesionales de los recursos humanos de las bibliotecas universitarias del Perú. (Tesis de licenciatura). Universidad Nacional Mayor de San Marcos, Lima. Recuperada de https://cybertesis.unmsm.edu.pe.

Alles, M. (2002a). Desempeño por competencias: evaluación 360. Buenos Aires: Granica.

Alles, M. (2002b). Dirección estratégica de recursos humanos: el diccionario. Buenos Aires: Granica.

Alles, M. (2005). Desarrollo del talento humano: basado en competencias. Buenos Aires: Granica.

Alles, M. (2009). Diccionario de competencias: la trilogía. Buenos Aires: Granica.

Alonzo, D., Valencia, M del C., Vargas, J. \& Bolívar, N. (2017). Estrategias para el desarrollo de competencias en el aula, con enfoque socioformativo. Boletín Redipe. Recuperado de https://revista.redipe.org/index.php/1/article/view/341.

Arnal, J. (1992). Investigación educativa. Fundamentos y metodología. Barcelona: Labor.

Bandura, A. (1962). Aprendizaje social a través de la imitación. Lincoln: Prensa de la Universidad de Nebraska.

Barreda, M (2009). Evaluación de competencias genéricas en Medicina Veterinaria desde la perspectiva del empleador: importancia y nivel alcanzado por los egresados en la ciudad 
de Lima. (Tesis de maestría). Universidad Nacional Mayor de San Marcos, Lima. Recuperado de http://cybertesis.unmsm.edu.pe/handle/cybertesis/745.

Bastante, J. \& Pacheco, A. (2018). Modelo educativo. Lima: Área de Calidad del Instituto Tecnológico de Lima.

Bernal, C. (2010). Metodología de la investigación (3. a ed). Colombia: Pearson Educación.

Byham. (2003). The meaning Asociated with the Competency (II, Vol. 6). Prentice Hall European.

Brunner, J. (2000). Educación: escenarios del futuro. Nuevas tecnologías y sociedad de la información. Santiago de Chile. Preal.

Bunk, G. (1994). La transmisión de las competencias en la formación y el perfeccionamiento profesionales de la RFA. Revista Europea de Formación Profesional, 1, 8-14.

Castellanos, A., Verduzco, A., Moreno, M., Padilla, R. \& Pérez, S. (2007). Modelo educativo siglo 21. Rectoría general 2001-2007. Guadalajara: Universidad de Guadalajara.

Chiavenato, I. (2005). Introducción a la teoría general de la administración. Ciudad de México: McGraw-Hill.

Cortez, L. (2018). Componentes del modelo educativo correlacionados con la calidad de la formación profesional de los estudiantes de Periodismo de las universidades de Guayaquil. (Tesis de doctorado). Universidad Nacional Mayor de San Marcos. Lima. Recuperado de http://cybertesis.unmsm.edu.pe/handle/cybertesis/7553.

Congreso de la República del Perú (2015). Constitución Política. Lima. Recuperado de http://www.constitucionpoliticadelperu.com.

Consejo Nacional de Educación (2007). Proyecto Educativo Nacional. Lima: Consejo Nacional de Educación.

De Ansorena, A. (1996). 15 pasos para la selección de personal con éxito. Barcelona: Paidós. 
Delors, J. (1996). Informe Delors. La educación encierra un tesoro. Madrid: Santillana.

De la Cruz, C. (1 de octubre de 2015). Generación Y: ¿cómo retener a la generación que siempre se quiere ir? Recuperado de https://chinndelacruz.com/millennials-en-el-peru-unageneracion-con-grandes-oportunidades-laborales.

Díaz Barriga, F. (2011). Metodología de diseño curricular para educación superior. Ciudad de México: Trillas.

Doménech, F. (1999). El proceso de enseñanza/aprendizaje universitario. Oviedo: Universidad de Oviedo.

Estrada, A. (2005). De la percepción a la realidad: análisis comparativo entre las competencias profesionales de los estudiantes de Ingeniería Industrial de la universidad del Bío-Bío, Chile, y la Universidad Nacional de Misiones, Argentina. (Tesis de licenciatura). Recuperada de http://repobib.ubiobio.cl.

Flores, J. et al. (2017). Estrategias didácticas para el aprendizaje significativo en contextos universitarios. Santiago de Chile: Trama Impresores.

Forjas, J. (2003). Modelo para la formación profesional en la educación técnica y profesional sobre la base de competencias profesionales en la rama mecánica. (Tesis doctoral). Recuperada de https://uvadoc.uva.es.

ICE de la Universidad de Zaragoza (2008). Competencias genéricas y transversales de los titulados universitarios. Zaragoza: Universidad de Zaragoza.

García, J. (2011). Modelo educativo basado en competencias: importancia y necesidad. Revista electrónica actualidades investigativas en educación, 11(3), 1-24. 
Granados, M. (2013) Desarrollo competencias laborales y formación de los profesionales en Turismo, en la Universidad Nacional Mayor de San Marcos. (Tesis doctoral). Recuperada de https://cybertesis.unmsm.edu.pe.

Godoy, M (2014). Las competencias laborales de los mandos medios y altos de una industria papelera. (Tesis inédita). Universidad Rafael Landívar, Guatemala.

Herrera, A. (2015). Competencias laborales en los colaboradores del departamento de ventas de Bimbo Centroamérica, agencia Huehuetenango. (Tesis de licenciatura inédita). Recuperado de http://recursosbiblio.url.edu.gt.

Hernández, R., Fernández, C. \& Baptista, P. (2010). Metodología de la investigación. Ciudad de México: McGraw-Hill Interamericana.

Hernández, P. (2011). Modelo para la implantación del programa basado en competencias en la división de administración de la Universidad Tecnológica de Nezahualcóyotl. Ciudad de México: Univeridad Tecnológica de Nezahualcóyotl.

Hurtado, J. (2000). Metodológica de la investigación holística. Caracas: Fundación Sypal.

ITESM. (2006). Capacitación en estrategias y técnicas didácticas. Monterrey: Instituto Tecnológico y de Estudios Superiores de Monterrey. Recuperado de http//www.sistema.itesm.mx/va/dide/inf-doc/estrategias.

Latorre, M. (2013). Diseño curricular por capacidades y competencias en educación superior. Lima: Fondo Editorial de la Universidad Marcelino Champagnat.

Lanuez, M., Martínez, M. \& Pérez, V. (2008). El maestro y la investigación educativa en el siglo XXI. La Habana: Pueblo y Educación.

Ley n. 28044. Ley General de Educación. (2013). En diario oficial El Peruano. 594334. Perú. 
Ley n. ${ }^{\circ}$ 30512. Ley de Institutos y Escuelas de Educación Superior y de la Carrera Pública de sus Docentes. (2016). En diario oficial El Peruano. Recuperado de https://busquedas.elperuano.pe/normaslegales/ley-de-institutos-y-escuelas-de-educacionsuperior-y-de-la-c-ley-n-30512-1448564-1.

Málaga, R., Oré, T. \& Tavera, J. (2014). Jóvenes que no trabajan ni estudian: el caso peruano. Lima: Pontifica Universidad Católica del Péru.

Miranda, M. (2010). Metodología de la investigación cuantitativa y cualitativa. Asunción: Universidad Nacional de Asunción.

McClelland, D. (1993). Introduction. En Spencer, L. \& Spencer, S. (eds) Competence at work. Nueva York: Jhon Wiley and Sons.

Mejía, E. (2005). Técnicas e instrumentos de investigación. Lima: Centro de producción editorial e imprenta de la Universidad Nacional Mayor de San Marcos.

Mertens, L. (1996). Competencia laboral: sistemas, surguimiento y modelos. Montevideo, Uruguay: Cinterfor/OIT.

Mertens, L. (2000). La gestión por competencia laboral en la empresa y la formación profesional. Madrid, España: Ediciones OEI

Minedu (2015). Diseño Curricular Básico Nacional de la Educación Superior Tecnológica. Lima: Ministerio de Educación.

MTPE (2016). Estrategia de competencias de la OCDE. Reporte diagnóstico. Lima: Ministerio de Trabajo y Promoción del Empleo.

OIT. Competencias laborales. Recuperado de https://www.oitcinterfor.org/banco-competenciaslaborales/inicio. Ginebra: Oficina Internacional del Trabajo. 
OIT (2014). Mejorar la empleabilidad de los jóvenes: la importancia de las competencias clave. Ginebra: Oficina Internacional del Trabajo.

OIT (2015). Tendencias mundiales del empleo juvenil 2015: promover la inversión en empleos decentes para los jóvenes. Ginebra: Oficina Internacional del Trabajo.

Ortoll, E. (2003). Competencias profesionales y uso de la información en el lugar de trabajo. Barcelona: Sección Científica de Ciencias de la Documentación de la Universidad Pompeu Fabra.

Proyecto Tuning de América Latina (2008). Reflexiones y perspectivas de la educación superior en América $\quad$ Latina. $\quad$ Recuperado de http://tuning.unideusto.org/tuningal/index.php?option=com_docman\&Itemid=191\&task= view_category\&catid=22\&order=dmdate_published\&ascdesc $=$ DESC.

RAE (2014). Diccionario de la lengua española (23. ${ }^{a}$ ed.) Bogotá: Espasa.

Repreza, E. (2009). Las competencias a lo largo de la historia. El Salvador: Universidad Católica de El Salvador.

Saenz, B. (2010). Modelo educativo para la formación de competencias genéricas en estudiantes de la carrera profesional técnica de Administración Bancaria y su interrelación con las competencias genéricas laborales exigidas por el mercado laboral bancario de Lima Metropolitana en el año 2009 a marzo 2010. (Tesis de maestría). Recuperado de http://cybertesis.edu.pe.

The Secretary's Commission on Achieving Necessary Skills (SCANS) (1991). The SCANS skills and competencies: an overview. Washington D. C.: U.S. Department of Labor.

Spencer, L. \& Spencer S. (1993). Competence al work. Nueva York: Jhon Wiley and Sons. 
Tacca, D. (2011). El «nuevo» enfoque pedagógico: las competencias. Lima: Universidad Nacional Mayor de San Marcos.

Tobón, S. (2005). Formación basada en competencias. Bogotá: Eco Ediciones.

Tobón, S. (2008). La formación basada en competencias en la educación superior. Guadalajara: Universidad Autónoma de Guadalajara.

Tunnermann, C. (2008). Modelos educativos y académicos. Nicaragua: La Prensa.

Vielma, E. \& Salas, M. (2000). Aportes de las teorías de Vygotsky, Piaget, Bandura y Bruner. Paralelismo en sus posiciones en relación con el desarrollo. Mérida: Escuela de Educación de la Universidad de Los Andes.

Vygostky, L. (1978). El desarrollo de los procesos psicológicos superiores. Barcelona: Crítica Ediciones.

Woodruffe, C. (1993). What is meant by a competency? Leadership and Organization Development Journal, 14(1), 29-36. 


\section{Anexos}

Anexo 1: Matriz metodológica.

Anexo 2: Instrumentos de recojo de información.

Anexo 3: Validación por juicio de expertos de las fichas de validación interna y externa. 


\section{Anexo 1: Matriz de categorización}

\begin{tabular}{|c|c|c|c|c|c|c|c|c|c|}
\hline \multicolumn{10}{|c|}{ MATRIZ DE CATEGORIZACION } \\
\hline \multirow{2}{*}{\multicolumn{10}{|c|}{$\begin{array}{l}\text { MODELO EDUCATIVO PARA DESARROLLAR COMPETENCIAS LABORALES EN ESTUDIANTES EN UN INSTITUTO DE E } \\
\text { AUTOR: Katherine Paola Ramirez Arias }\end{array}$}} \\
\hline & & & & & & & & & \\
\hline $\begin{array}{l}\text { Problema de } \\
\text { investigación o } \\
\text { pregunta cientifica }\end{array}$ & Preguntas especificaS & Objetivo principal & Objetivos especificos & Categorías principales & $\begin{array}{l}\text { Subcategorías apriorísticas } \\
\text { por categoria principal }\end{array}$ & Indicadores por subcategorías & $\begin{array}{l}\text { Paradigma, método y } \\
\text { diseño (Tipo de } \\
\text { investigación) }\end{array}$ & $\begin{array}{l}\text { Población, } \\
\text { muestray } \\
\text { muestreo }\end{array}$ & $\begin{array}{c}\text { Técnicas e } \\
\text { instrumentos }\end{array}$ \\
\hline \multirow{20}{*}{$\begin{array}{l}\text { ¿Cómo contribuir en } \\
\text { la formación de } \\
\text { competencias } \\
\text { laborales en los } \\
\text { estudiantes en un } \\
\text { instituto de } \\
\text { educación superior } \\
\text { de Lima? }\end{array}$} & \multirow{3}{*}{\begin{tabular}{|c|} 
¿En qué estado se \\
encuentra actualmente el \\
desarrollo de las \\
competencias laborales en \\
los estudiantes en un \\
instituto de educación \\
superior de Lima? \\
\end{tabular}} & \multirow{6}{*}{$\mid$} & \multirow{3}{*}{$\begin{array}{c}\text { Identificar el estado } \\
\text { actual de las } \\
\text { competencias laborales } \\
\text { en los estudiantes en un } \\
\text { instituto de educación } \\
\text { superior de Lima. }\end{array}$} & \multirow{10}{*}{$\begin{array}{l}\text { Competencias } \\
\text { Laborales }\end{array}$} & Competencia Técnica & $\begin{array}{c}\text { Conocimiento y destreza } \\
\text { técnica }\end{array}$ & \begin{tabular}{|l|} 
Tipo de \\
Investigación
\end{tabular} & $\begin{array}{l}\text { Muestreo No } \\
\text { probabilística }\end{array}$ & Observación \\
\hline & & & & & \multirow{3}{*}{$\begin{array}{l}\text { Competencia } \\
\text { Metodológica }\end{array}$} & Resolución de problemas & Aplicada & & \\
\hline & & & & & & Capacidad de adaptación & Paradigma naturalista & Docentes: 5 & Entrevista \\
\hline & \multirow{3}{*}{$\begin{array}{c}\text { ¿Cuáles son los } \\
\text { fundamentos teóricos del } \\
\text { modelo educativo para el } \\
\quad \text { desarrollo de } \\
\text { competencias laborales? }\end{array}$} & & Explorar la información & & & Flexibilidad & DISEÑO & & \\
\hline & & & $\begin{array}{c}\text { existente acerca de } \\
\text { modelos educativos para }\end{array}$ & & \multirow{3}{*}{ Competencia social } & Trabajo en equipo & $\begin{array}{c}\text { Investigación } \\
\text { cualitativa }\end{array}$ & Estudiantes: 25 & Encuesta \\
\hline & & & competencias laborales. & & & Estilo de comunicación & & & \\
\hline & \multirow{9}{*}{$\begin{array}{c}\text { ¿Cómo diseñar la } \\
\text { modelación de la } \\
\text { propuesta de un modelo } \\
\text { educativo para el } \\
\text { desarrollo de las } \\
\text { competencias laborales en } \\
\text { los estudiantes en un } \\
\text { instituto de educación } \\
\text { superior de Lima? }\end{array}$} & \multirow{14}{*}{\begin{tabular}{|c} 
Diseñar un modelo \\
educativo para el \\
desarrollo de \\
competencias \\
laborales en los \\
estudiantes en un \\
instituto de \\
educación superior \\
de Lima.
\end{tabular}} & \multirow{9}{*}{$\begin{array}{c}\text { Diseñar la modelación de } \\
\text { una propuesta de un } \\
\text { modelo educativo para el } \\
\text { desarrollo de las } \\
\text { competencias laborales } \\
\text { en los estudiantes en un } \\
\text { instituto de educación } \\
\text { superior de Lima. }\end{array}$} & & & Relaciones interpersonales & METODO & Empresas: 5 & \\
\hline & & & & & \multirow{3}{*}{$\begin{array}{l}\text { Competencia } \\
\text { Participativa }\end{array}$} & Capacidad de organización & Descriptiva & & \\
\hline & & & & & & Capacidad de decisiones. & Analítico-sintético & & \\
\hline & & & & & & Liderazgo & Inductivo-deductivo & & \\
\hline & & & & \multirow{10}{*}{ Modelo Educativo } & \multirow{3}{*}{ Perfil de las carreras } & Misión, visión y valores & Sistémico-estructural & & \\
\hline & & & & & & Objetivos educacionales & Histórico-lógico & & \\
\hline & & & & & & Plan curricular & Modelación & & \\
\hline & & & & & & $\begin{array}{c}\text { Elaboración del material } \\
\text { didáctico }\end{array}$ & & & \\
\hline & & & & & Proceso de enseñanza & Estrategia de enseñanza. & & & \\
\hline & ¿Cómo medir el impacto & & Validar el impacto de la & & & Perfil del docente & & & \\
\hline & $\begin{array}{c}\text { de la aplicación del } \\
\text { modelo educativo para el }\end{array}$ & & $\begin{array}{l}\text { aplicación del modelo } \\
\text { educativo para el }\end{array}$ & & & Estrategia de evaluación & & & \\
\hline & $\begin{array}{c}\text { desarrollo de las } \\
\text { competencias laborales en }\end{array}$ & & $\begin{array}{l}\text { desarrollo de las } \\
\text { competencias laborales }\end{array}$ & & & $\begin{array}{c}\text { Acompañamiento del } \\
\text { estudiante. }\end{array}$ & & & \\
\hline & los estudiantes en un & & en los estudiantes en un & & Calidad educativa & Resultados académicos & & & \\
\hline & superior de Lima? & & superior de Lima. & & & $\begin{array}{c}\text { Empleabilidad de los } \\
\text { egresados. }\end{array}$ & & & \\
\hline
\end{tabular}


Anexo 2: Instrumentos de recojo de información.

\section{Guía de entrevista a los docentes}

Objetivo: Identificar las condiciones pedagógicas para el desarrollo de competencias laborales en los estudiantes del instituto tecnológico superior de Lima.

Instrucciones: A continuación, se presenta una serie de preguntas a los docentes:

\begin{tabular}{|c|c|}
\hline $\mathbf{N}^{\circ}$ & ITEMS \\
\hline \multicolumn{2}{|c|}{ PERFIL DE LAS CARRERAS } \\
\hline 1 & $\begin{array}{l}\text { ¿Los objetivos educacionales están acordes de lo que pide el mercado laboral } \\
\text { actual? }\end{array}$ \\
\hline 2 & ¿Usted considera que su labor como docente está acorde a la visión del Instituto? \\
\hline 3 & ¿El plan de temas cumple con el objetivo del curso que enseña? \\
\hline \multicolumn{2}{|c|}{ PLANEACIÓN DIDÁCTICA } \\
\hline 4 & ¿Le es sencillo explicar los temas a desarrollar en sus clases? \\
\hline 5 & $\begin{array}{l}\text { ¿Considera que sus materiales de clases están acordes del aprendizaje de sus } \\
\text { estudiantes? }\end{array}$ \\
\hline 6 & ¿Genera actividades que ayuden al pensamiento disruptivo en el estudiante? \\
\hline 7 & $\begin{array}{l}\text { ¿Refuerza la idea de la importancia de ambas competencias (Técnicas y } \\
\text { laborales)? }\end{array}$ \\
\hline 8 & $\begin{array}{l}\text { ¿Propone actividades que permiten contribuir el aprendizaje a través de } \\
\text { metodologías innovadoras? }\end{array}$ \\
\hline \multicolumn{2}{|c|}{ CALIDAD EDUCATIVA } \\
\hline 9 & $\begin{array}{l}\text { ¿Promueve proyectos que impliquen la innovación y la creatividad con otras } \\
\text { carreras académicas? }\end{array}$ \\
\hline 10 & ¿Considera que nuestros egresados están bien posicionados profesionalmente? \\
\hline 11 & $\begin{array}{l}\text { ¿Considera que en el instituto tecnológico superior se genera convenios con } \\
\text { empresas industriales que ayudaran al desarrollo profesional de sus estudiantes y } \\
\text { egresados? }\end{array}$ \\
\hline \multicolumn{2}{|c|}{ COMPETENCIAS TÉCNICAS } \\
\hline 12 & $\begin{array}{l}\text { ¿Consideras que el instituto tecnológico superior brindó a los estudiantes y } \\
\text { egresado las herramientas necesarias para insertarte con facilidad al mercado } \\
\text { laboral? }\end{array}$ \\
\hline 13 & $\begin{array}{l}\text { ¿Usted considera que los estudiantes por egresar cumplen con el perfil del } \\
\text { egresado del instituto tecnológico superior? }\end{array}$ \\
\hline
\end{tabular}




\begin{tabular}{|c|l|}
\hline \multicolumn{2}{|l|}{ COMPETENCIAS METODOLÓGICAS } \\
\hline 14 & $\begin{array}{l}\text { ¿Consideran que los estudiantes o recién egresados tienen la capacidad de resolver } \\
\text { problemas sin supervisión? }\end{array}$ \\
\hline 15 & $\begin{array}{l}\text { ¿Consideras que los estudiantes o egresados se adaptan con facilidad en los } \\
\text { diferentes escenarios físicos que le proponga la empresa? }\end{array}$ \\
\hline 16 & $\begin{array}{l}\text { ¿Consideras que los estudiantes o egresados se adaptan con facilidad al entorno } \\
\text { laboral ya sea en tus prácticas, pasantías o trabajo? }\end{array}$ \\
\hline COMPETENCIAS SOCIALES \\
\hline 17 & $\begin{array}{l}\text { ¿Consideras que los estudiantes tienen un nivel de comunicación adecuada para el } \\
\text { mercado laboral actual? }\end{array}$ \\
\hline 18 & $\begin{array}{l}\text { ¿Considera que los estudiantes se pueden relacionar con personas de diferentes } \\
\text { cargos? }\end{array}$ \\
\hline 19 & ¿Los estudiantes o egresados trabajan efectivamente en equipo? \\
\hline COMPETENCIAS PARTICIPATIVAS \\
\hline 20 & ¿Los estudiantes y egresados son capaces de liderar un equipo? \\
\hline 21 & $\begin{array}{l}\text { ¿Consideras que los estudiantes y egresados toman decisiones laborales } \\
\text { adecuadamente? }\end{array}$ \\
\hline 22 & $\begin{array}{l}\text { ¿Crees que los estudiantes o egresados cumplen con las responsabilidades } \\
\text { encomendadas en el tiempo dado? }\end{array}$ \\
\hline
\end{tabular}

¡Gracias por su colaboración! 


\section{Encuesta para empleadores sobre competencias laborales de los estudiantes/egresados}

Objetivo: Recopilar información con respecto a su conocimiento sobre las competencias laborales que observa en nuestros estudiantes y egresados.

Instrucciones: Por favor, lea detenidamente las preguntas y responda con toda honestidad.

\begin{tabular}{|l|l|}
\hline Empresa & \\
\hline Área & \\
\hline Cargo & \\
\hline Fecha & \\
\hline
\end{tabular}

Marque con un aspa el casillero correspondiente al nivel que más se ajuste a su respuesta:

$$
\begin{gathered}
\text { Nunca }=1 \\
\text { Casi Nunca }=2 \\
\text { A veces }=3 \\
\text { Casi siempre }=4 \\
\text { Siempre }=5
\end{gathered}
$$

\begin{tabular}{|c|c|c|c|c|c|c|}
\hline $\mathbf{N}^{\circ}$ & ITEMS & Siempre & $\begin{array}{c}\text { Casi } \\
\text { siempre }\end{array}$ & A veces & $\begin{array}{c}\text { Casi } \\
\text { nunca }\end{array}$ & Nunca \\
\hline \multicolumn{2}{|c|}{ COMPETENCIAS TÉCNICAS } & 5 & 4 & 3 & 2 & 1 \\
\hline 1 & Realizan sus tareas con eficiencia y eficacia & & & & & \\
\hline 2 & $\begin{array}{l}\text { Aplican sus conocimiento técnicos en sus funciones } \\
\text { diarias }\end{array}$ & & & & & \\
\hline 3 & $\begin{array}{l}\text { Sus conocimiento técnicos están acorde a la necesidad de } \\
\text { la empresa }\end{array}$ & & & & & \\
\hline 4 & Tiene aspiraciones de crecimiento profesional y personal & & & & & \\
\hline 5 & $\begin{array}{l}\text { Son capaces de reconocer sus capacidades y limitaciones } \\
\text { profesionales }\end{array}$ & & & & & \\
\hline \multicolumn{7}{|c|}{ COMPETENCIAS METODOLÓGICAS } \\
\hline 6 & $\begin{array}{l}\text { Sigue ordenes de sus superiores sin demostrar } \\
\text { complicaciones }\end{array}$ & & & & & \\
\hline 7 & $\begin{array}{l}\text { Se les hace muy difícil identificar los elementos más } \\
\text { importantes de un problema o asunto complejo }\end{array}$ & & & & & \\
\hline 8 & $\begin{array}{l}\text { Tiene facilidad para definir un objetivo y empezar a } \\
\text { trabajar en él }\end{array}$ & & & & & \\
\hline
\end{tabular}

\section{Consideras que los estudiantes o egresados...}




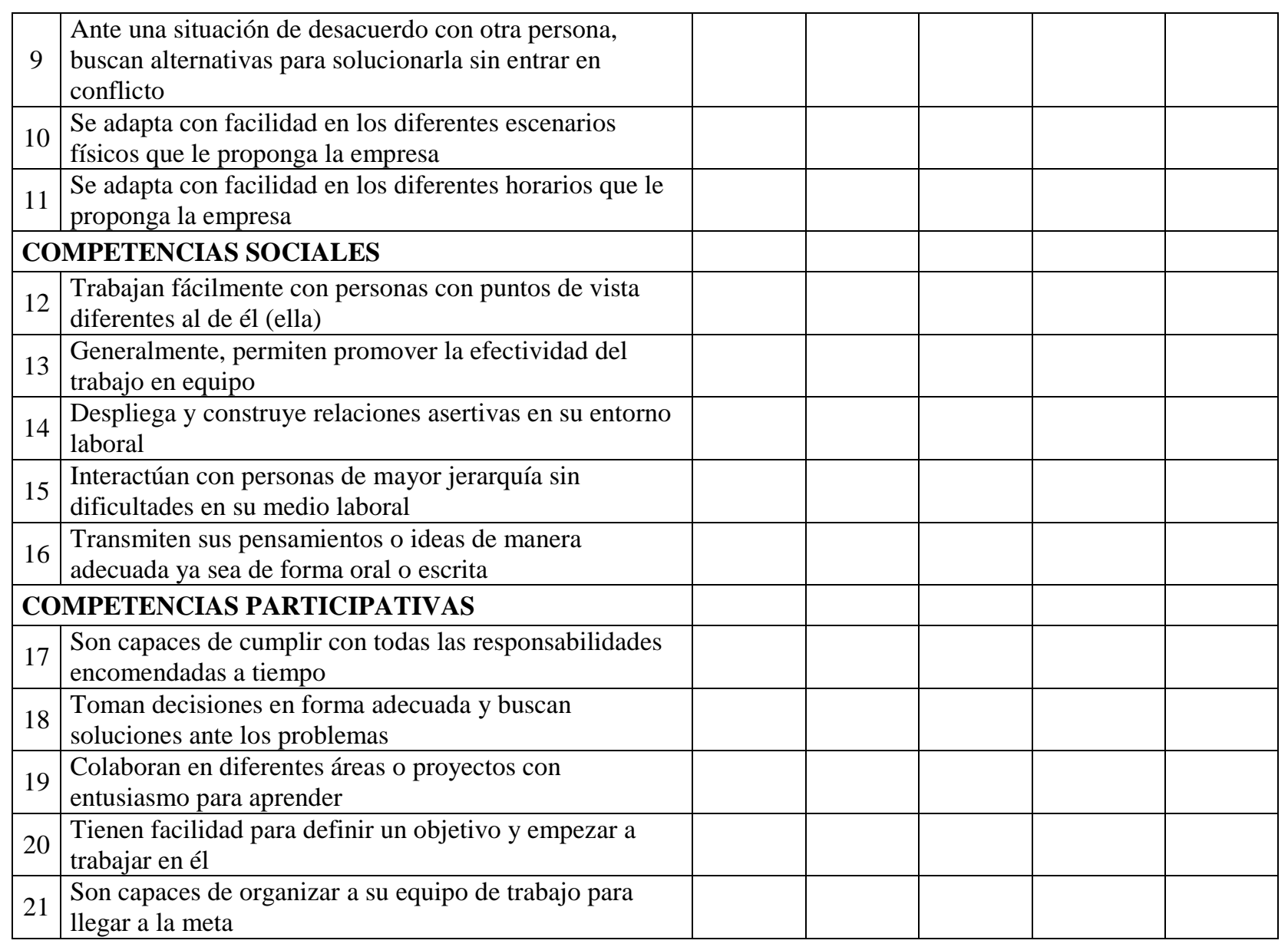

\section{¡Gracias por su colaboración!}




\section{Encuesta para estudiantes sobre sus competencias laborales}

Objetivo: Identificar la percepción del nivel de competencias que tienen los estudiantes en las empresas cuando realizan sus pasantías y prácticas.

Instrucciones: Por favor, lea detenidamente las preguntas y responda a toda con honestidad.

Carrera académica:

Sexo:

Situación Actual: Egresado ( ) Estudiante ( )

Marque con un aspa el casillero correspondiente al nivel que más se ajuste a su respuesta:

$$
\begin{gathered}
\text { Nunca }=1 \\
\text { Casi Nunca=2 } \\
\text { A veces }=3 \\
\text { Casi siempre }=4 \\
\text { Siempre }=5
\end{gathered}
$$

\begin{tabular}{|c|c|c|c|c|c|c|}
\hline $\mathbf{N}^{\circ}$ & ITEMS & Siempre & $\begin{array}{c}\text { Casi } \\
\text { Siempre } \\
\end{array}$ & $\begin{array}{c}\text { A } \\
\text { Veces } \\
\end{array}$ & $\begin{array}{c}\text { Casi } \\
\text { Nunca } \\
\end{array}$ & Nunca \\
\hline \multicolumn{2}{|c|}{ COMPETENCIAS TÉCNICAS } & 5 & 4 & 3 & 2 & 1 \\
\hline 1 & $\begin{array}{l}\text { ¿Consideras que el instituto tecnológico donde estudias o } \\
\text { estudiaste te brindó las herramientas necesarias para } \\
\text { insertarte con facilidad al mercado laboral? }\end{array}$ & & & & & \\
\hline 2 & $\begin{array}{l}\text { ¿Los cursos aprendidos son necesarios para la aplicación } \\
\text { de tu carrera en el mercado laboral actual? }\end{array}$ & & & & & \\
\hline \multicolumn{7}{|c|}{ COMPETENCIAS METODOLÓGICAS } \\
\hline 3 & $\begin{array}{l}\text { ¿Tus competencias adquiridas en tu formación en Tecsup } \\
\text { te permitieron que tomes decisiones adecuadas en tus } \\
\text { pasantías o prácticas? }\end{array}$ & & & & & \\
\hline 4 & $\begin{array}{l}\text { ¿Consideras que el trabajo en equipo ayuda a resolver } \\
\text { conflictos? }\end{array}$ & & & & & \\
\hline 5 & $\begin{array}{l}\text { ¿Consideras que te adaptas con facilidad al entorno laboral } \\
\text { ya sea en tus prácticas, pasantías o trabajo? }\end{array}$ & & & & & \\
\hline \multicolumn{7}{|c|}{ COMPETENCIAS SOCIALES } \\
\hline 6 & $\begin{array}{l}\text { ¿Mantienes relaciones empáticas con personas de puntos } \\
\text { de vista diferentes a los tuyos? }\end{array}$ & & & & & \\
\hline 7 & ¿Te comunicas de manera fluida con tus pares? & & & & & \\
\hline 8 & $\begin{array}{l}\text { ¿Consideras que promueves la efectividad de trabajo en tu } \\
\text { equipo? }\end{array}$ & & & & & \\
\hline 9 & ¿Te comunicas de manera fluida con tus superiores? & & & & & \\
\hline \multicolumn{7}{|c|}{ COMPETENCIAS PARTICIPATIVAS } \\
\hline 10 & $\begin{array}{l}\text { ¿Consideras que respondes con responsabilidad ante las } \\
\text { tareas encomendadas en tus pasantías o prácticas? }\end{array}$ & & & & & \\
\hline 11 & $\begin{array}{l}\text { ¿Colaboras con otras áreas en tus pasantías o prácticas por } \\
\text { iniciativa personal? }\end{array}$ & & & & & \\
\hline 12 & ¿Posees la cualidad de líder? & & & & & \\
\hline
\end{tabular}




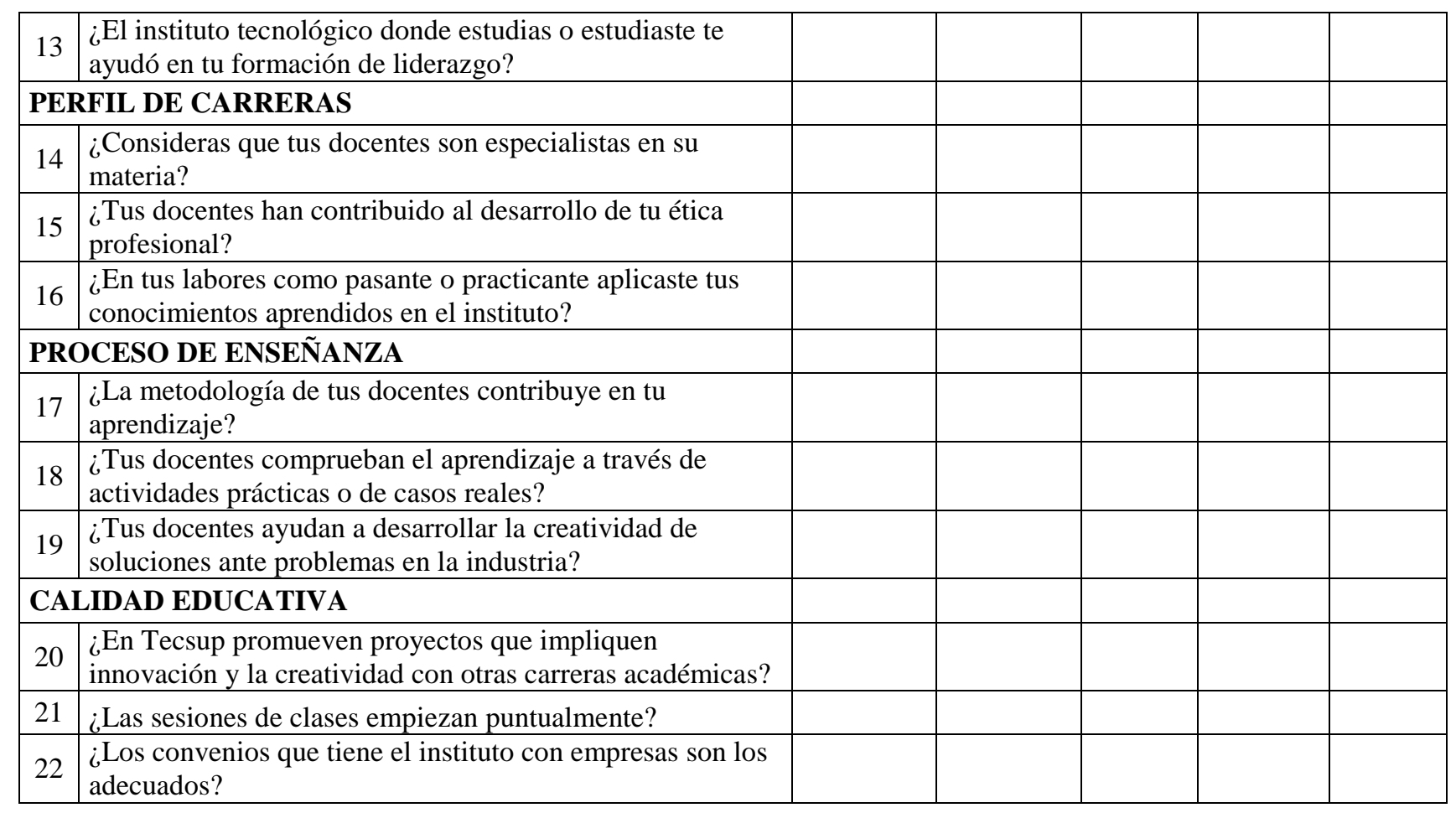

¡Gracias por su colaboración! 
Anexo 3: Validación por juicio de expertos de las fichas de validación interna y externa.

Ficha de validación de la propuesta metodológica

\section{Datos generales.}

Apellidos y nombres de especialista: Garnelo Fscobar, Ronal

Grado de estudios alcanzado: Doctor

Resultado cientifico en valoración: Modelo educativo para desarrollar las competencias laborales en los estudiantes en un instituto de educación superior de Lima.

Autor del resultado cientifico: Bachiller Ramirez Arias, Katherine Paola

\section{Aspectos a observar}

\section{Validación interna}

\begin{tabular}{|c|c|c|c|c|c|c|c|}
\hline \multirow[t]{3}{*}{ indicadores } & \multirow{2}{*}{\multicolumn{4}{|c|}{$\begin{array}{l}\text { Escala de } \\
\text { valoración }\end{array}$}} & \multicolumn{3}{|l|}{ Aspectos } \\
\hline & & & & & \multirow[t]{2}{*}{ Positivos } & \multirow[t]{2}{*}{ Negativos } & \multirow[t]{2}{*}{ Sugerencias } \\
\hline & 1 & $2 / 3$ & 4 & 5 & & & \\
\hline Factibilidad de aplicación del resultado que se presenta. & & & & $x$ & & & \\
\hline Claridad de la propuesta para ser aplicado por otros & & & $x$ & & & & \\
\hline $\begin{array}{l}\text { Posibilidad de la propuesta do extensión a otros } \\
\text { contextos semejantes }\end{array}$ & & & & X & & & \\
\hline $\begin{array}{l}\text { Correspondencia con las necesidades sociales e } \\
\text { individuales actuaies }\end{array}$ & & & & $x$ & & & \\
\hline $\begin{array}{l}\text { Congruencia entre el resultado propuesto y el objetivo } \\
\text { fijado. }\end{array}$ & & & & $X$ & & & \\
\hline $\begin{array}{l}\text { Novedad en el uso de conceptos y procedimientos de ta } \\
\text { propuesta. }\end{array}$ & & & $x$ & & & & \\
\hline $\begin{array}{l}\text { La modelación contiene propósitos basados en los } \\
\text { fundamentos educativos, curriculares y pedagogicos. } \\
\text { detallado, preciso y efectivo }\end{array}$ & & & $y$ & & & & \\
\hline $\begin{array}{l}\text { La propuesta está contextualizada a la realidad en } \\
\text { estudio. }\end{array}$ & & & $x$ & & & & \\
\hline $\begin{array}{l}\text { Presenta objetivos claros, coherentes y posibles de } \\
\text { alcanzar. }\end{array}$ & & & $x$ & & & & \\
\hline Contiene un plan de acción de io general a lo particular. & & & 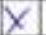 & & & & \\
\hline
\end{tabular}


Ficha de validación externa (forma)

\begin{tabular}{|c|c|c|c|c|c|c|c|c|}
\hline \multicolumn{2}{|l|}{ Indicadoren } & \multirow{2}{*}{\multicolumn{4}{|c|}{$\begin{array}{l}\text { Escala do } \\
\text { valoracion }\end{array}$}} & \multicolumn{3}{|l|}{ Aapectos } \\
\hline & & & & & & \multirow{3}{*}{ Positivos } & \multirow{3}{*}{ Negativas } & \multirow{3}{*}{ Sugerencias } \\
\hline & & 1 & \begin{tabular}{l|l}
2 & 3 \\
\end{tabular} & 4 & 5 & & & \\
\hline Ciaridad & $\begin{array}{l}\text { Es formulado con lenguaja } \\
\text { apropiado }\end{array}$ & & & $y$ & & & & \\
\hline Objetivided & $\begin{array}{l}\text { Esta expresado en conductas } \\
\text { observabies }\end{array}$ & & & & $y$ & & & 5 \\
\hline Actualided & $\begin{array}{l}\text { Adecuado al avance de la } \\
\text { ciencia pedagogica }\end{array}$ & & & $y$ & & & & \\
\hline Organización & Existe una organezación lógica & & & Y & & & & \\
\hline Suficiencia & $\begin{array}{l}\text { Comprende los aspectios de } \\
\text { cantidad y calided }\end{array}$ & & & 4 & & & & \\
\hline Intencionalidad & $\begin{array}{l}\text { Adecuado para vatorar los } \\
\text { aspectos de las categorias }\end{array}$ & & & $x$ & & & & \\
\hline Consistencia & $\begin{array}{l}\text { Basado en aspectos tedricos } \\
\text { cienuificos de is educación }\end{array}$ & & & $y$ & & & ${ }^{2}$ & \\
\hline Coherencia & $\begin{array}{l}\text { Entre el propobias, diseno y la } \\
\text { implementacion de ta propuesta }\end{array}$ & & & & $x$ & & & \\
\hline Metodologia & $\begin{array}{l}\text { La estrategia responde at } \\
\text { proposita de la imvestigacion }\end{array}$ & & & & $\lambda$ & & & \\
\hline Partinencia & $\begin{array}{l}\text { Es stif y adecuado para to } \\
\text { investigación }\end{array}$ & & & & $x$ & & & \\
\hline
\end{tabular}

Aportes o suzerencias nara el perfeccionamiento del resultado cientifico:

\section{Opinión de aplicabilidad.}

\section{Resultados}

Promedio de valoración = Valorectón internatvaloveción externa

Resultado de valoración: 44 
Escala de valoración

\begin{tabular}{lcc}
\hline Escala & Rango frecuencia & Rango porcentaje \\
\hline Deficiente & {$[10-17]$} & {$[20 \%-35 \%]$} \\
Bajo & {$[18-25]$} & {$[36 \%-51 \%]$} \\
Regular & {$[26-33]$} & {$[52 \%-67 \%]$} \\
Bien & {$[34-41]$} & {$[68 \%-83 \%]$} \\
Muy bien & {$[42-50]$} & {$[84 \%-100 \%]$} \\
\hline
\end{tabular}

Opinión de aplicabilidad:

a) Deficiente ( ) b) Bajo ( ) c) Regular ( ) d) Bien ( ) Muy bien )

\begin{tabular}{|c|c|c|c|}
\hline Nombres y Apellidos & RONDL GDRNGZOE & $\mathrm{DNIN}^{*}$ & 0656457 \\
\hline Dirección domiciliaria & & Teléfono / Celular & \\
\hline $\begin{array}{l}\text { Titulo profesional / } \\
\text { Especialidad }\end{array}$ & 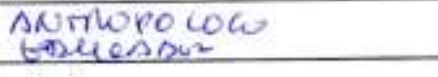 & & \\
\hline Grado Académico & DA. & & \\
\hline $\begin{array}{l}\text { Ocupación y año de } \\
\text { experiencia }\end{array}$ & 20 & & \\
\hline Metodólogontemático & OISTODOLOCN-2 & & \\
\hline
\end{tabular}

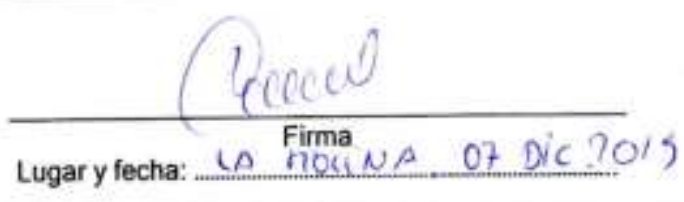


Ficha de validación de la propuesta metodológica

\section{Datos generales.}

A pellidos y nombres de especialista: Velázquez Tejeda, Miriam

Grado de estudios alcanzado: Doctora

Resultado científico en valoración: Modelo educativo para desarrollar las competencias laborales en los estudiantes en un instituto de educación superior de Lima.

Autor del resultado cientifico: Bachiller Ramirez Arias, Katherine Paola

\section{Aspectos a observar}

Validación interna

\begin{tabular}{|c|c|c|c|c|c|c|}
\hline \multirow[t]{3}{*}{ indicadores } & \multicolumn{3}{|c|}{$\begin{array}{l}\text { Escala de } \\
\text { valoración }\end{array}$} & \multicolumn{3}{|l|}{ Aspectos } \\
\hline & & & & \multirow[t]{2}{*}{ Positivos } & \multirow[t]{2}{*}{ Negativos } & \multirow[t]{2}{*}{ Sugerencias } \\
\hline & 12 & 3 & $4: 5$ & & & \\
\hline Factibilidad de aplicación del resultado que se presenta. & & & Q & & & \\
\hline Claridad de la propuesta para ser aplicado por otros & & & $x$ & & & \\
\hline $\begin{array}{l}\text { Posibilidad de la propuesta de extensión a otros } \\
\text { contextos semejantes }\end{array}$ & & & $y$ & & & \\
\hline $\begin{array}{l}\text { Correspondencia con las necesidades sociales e } \\
\text { individuales actuales }\end{array}$ & & & y & & & \\
\hline $\begin{array}{l}\text { Congruencia entre el resultado propuesto y el objetivo } \\
\text { fijado. }\end{array}$ & & & $y$ & & & \\
\hline $\begin{array}{l}\text { Novedad en el uso de conceptos y procedimientos de la } \\
\text { propuesta. }\end{array}$ & & & $x$ & & & \\
\hline $\begin{array}{l}\text { La modelación contiene propósitos basados en los } \\
\text { fundamentos educativos, curriculares y pedagógicos. } \\
\text { detallado, preciso y efectivo }\end{array}$ & & & & $k$ & & \\
\hline $\begin{array}{l}\text { La propuesta está contextualizada a la realidad en } \\
\text { estudio. }\end{array}$ & & & > & & & \\
\hline $\begin{array}{l}\text { Presenta objetivos claros, coherentes y posibles de } \\
\text { alcanzar. }\end{array}$ & & & $x$ & & & \\
\hline Contiene un plan de acción de lo general a lo particular. & & & $x$ & & & \\
\hline
\end{tabular}


Ficha de validación externa (forma)

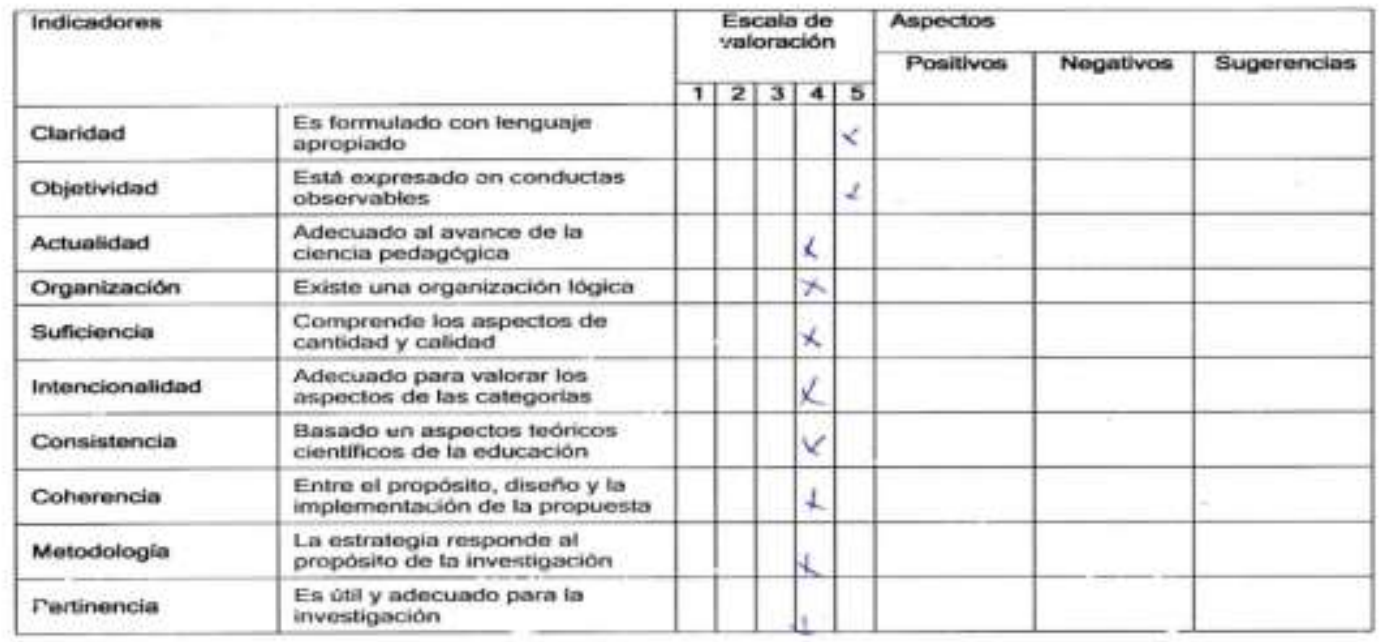

Aportes o suzerencias para el perfescionamiento del resuliadu cientifico:

Opinión de aplicabilidad.

\section{Resultados}

Promedio de valoración $=\frac{\text { Valoración interaatvalonación exrerna }}{2}$

Resultado de valoración: $4 / 4$ 


\section{Escala de valoración}

\begin{tabular}{lcc}
\hline Escala & Rango frecuencia & Rango porcentaje \\
\hline Deficiente & {$[10-17]$} & {$[20 \%-35 \%]$} \\
Bajo & {$[18-25]$} & {$[36 \%-51 \%]$} \\
Regular & {$[26-33]$} & {$[52 \%-67 \%]$} \\
Bien & {$[34-41]$} & {$[68 \%-83 \%]$} \\
Muy bien & {$[42-50]$} & {$[84 \%-100 \%]$} \\
\hline
\end{tabular}

\section{Opinión de aplicabilidad:}

a) Deficiente ( ) b) Bajo ( ) c) Regular ( ) d) Bien ( ) Muy bien ( )

\begin{tabular}{|c|c|c|c|}
\hline Nombres y Apellidos & 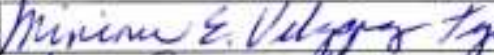 & $\mathrm{DNIN}^{*}$ & \\
\hline Dirección domiciliaria & & Teléfono / Celular & 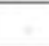 \\
\hline $\begin{array}{l}\text { Titulo profesional / } \\
\text { Especialidad }\end{array}$ & $\varepsilon$ & 7 & \\
\hline Grado Académico & 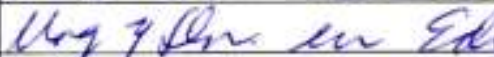 & ieces & \\
\hline $\begin{array}{l}\text { Ocupación y año de } \\
\text { experiencia }\end{array}$ & & $E$ & \\
\hline Matodólogo/temático & & & \\
\hline
\end{tabular}

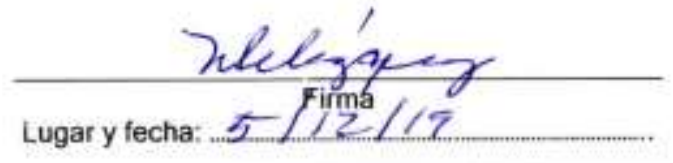


Ficha de validación de la propuesta metodológica

\section{Datos generales.}

Apellidos y nombres de especialista: Goñi Cruz, Félix Fernando

Grado de estudios alcanzado: Doctor

Resultado científico en valoración: Modelo educativo para desarrollar las competencias laborales en los estudiantes en un instituto de educación superior de Lima.

Autor del resultado cientifico: Bachiller Ramirez Arias, Katherine Paola

\section{Aspectos a observar}

\section{Validación interna}

\begin{tabular}{|c|c|c|c|c|c|c|c|}
\hline \multirow[t]{3}{*}{ indicadores } & \multicolumn{4}{|c|}{$\begin{array}{l}\text { Escala de } \\
\text { valoración }\end{array}$} & \multicolumn{3}{|l|}{ Aspectos } \\
\hline & & & & & \multirow{2}{*}{ Positivos } & \multirow[t]{2}{*}{ Negativos } & \multirow{2}{*}{ Sugerencias } \\
\hline & 1 & 2 & 3 & $4:$ & & & \\
\hline \multicolumn{8}{|l|}{ Factibilidad de aplicación del resultado que se presenta. } \\
\hline \multicolumn{8}{|l|}{ Claridad de la propuesta para ser aplicado por otros } \\
\hline \multicolumn{8}{|l|}{$\begin{array}{l}\text { Posibilidad de la propuesta de extensión a otros } \\
\text { contextos semejantes }\end{array}$} \\
\hline \multicolumn{8}{|l|}{$\begin{array}{l}\text { Correspondencia con las necesidades sociales e } \\
\text { individuales actuales }\end{array}$} \\
\hline \multicolumn{8}{|l|}{$\begin{array}{l}\text { Congruencia entre el resultado propuesto y el objetivo } \\
\text { fijado. }\end{array}$} \\
\hline \multicolumn{8}{|l|}{$\begin{array}{l}\text { Novedad en el uso de conceptos y procedimientos de la } \\
\text { propuesta. }\end{array}$} \\
\hline \multicolumn{8}{|l|}{$\begin{array}{l}\text { La modelación contiene propositos basados en los } \\
\text { fundamentos educativos, cumiculares y pedagdgicos, } \\
\text { detallado, preciso y efectivo }\end{array}$} \\
\hline \multicolumn{8}{|l|}{$\begin{array}{l}\text { La propuesta está contextualizada a la realidad en } \\
\text { estudio. }\end{array}$} \\
\hline \multicolumn{8}{|l|}{$\begin{array}{l}\text { Presenta objetivos claros, coherentes y posibles de } \\
\text { aicanzar. }\end{array}$} \\
\hline Contiene un plan de acción de lo general a lo particular. & & & & $x$ & & & \\
\hline
\end{tabular}


Ficha de validación externa (forma)

\begin{tabular}{|c|c|c|c|c|c|c|c|c|}
\hline \multicolumn{2}{|l|}{ Indicadores } & \multicolumn{4}{|c|}{$\begin{array}{l}\text { Escala de } \\
\text { valoración }\end{array}$} & \multicolumn{3}{|l|}{ Aspectos } \\
\hline & & & & & & \multirow[t]{3}{*}{ Positivos } & \multirow{3}{*}{ Negativos } & \multirow{3}{*}{ Sugerencias } \\
\hline & & 1 & \begin{tabular}{l|l}
2 & 3 \\
\end{tabular} & 4 & 5 & & & \\
\hline Claridad & $\begin{array}{l}\text { Es formulado con lenguaje } \\
\text { apropiado }\end{array}$ & & & y & & & & \\
\hline Objetividad & $\begin{array}{l}\text { Esta expresado en conductas } \\
\text { observables }\end{array}$ & & & $x$ & & & & 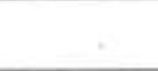 \\
\hline Actualidad & $\begin{array}{l}\text { Adecuado al avance de la } \\
\text { ciencia pedagogica }\end{array}$ & & & $x$ & & & & \\
\hline Organización & Existe una organización lógica & & & & $x$ & . & & \\
\hline Suficiencia & $\begin{array}{l}\text { Comprende los aspectos de } \\
\text { cantidad y calidad }\end{array}$ & & & $\infty$ & & & & \\
\hline Intencionalidad & $\begin{array}{l}\text { Adecuado para valorar los } \\
\text { aspectos de las categorlas }\end{array}$ & & & $\infty$ & & & & \\
\hline Consistencia & $\begin{array}{l}\text { Basado en aspectos teóricos } \\
\text { cientificos de la educación }\end{array}$ & & & $\infty$ & & & s. & \\
\hline Coherencia & $\begin{array}{l}\text { Entre el propósito, diseño y la } \\
\text { implementación de la propuesta }\end{array}$ & & & $\infty$ & & & & \\
\hline Metodologla & $\begin{array}{l}\text { La estrategia responde at } \\
\text { propósitho de la investigación }\end{array}$ & & & C) & & & & \\
\hline Pertinencia & $\begin{array}{l}\text { Es útil y adecuado para la } \\
\text { investigación }\end{array}$ & & & & 0 & & & \\
\hline
\end{tabular}

Aportes o sugerencias para el perfeccionamiento del resultado científico:

\section{Opinión de aplicabilidad.}

\section{Resultados}

Promedio de valoración $=\frac{\text { Valoración interna }+ \text { valoración externe }}{2}$

Resultado de valoración: 42 